\title{
ESSAYS ON DEEP TRADE AGREEMENTS
}

\author{
by \\ Sara Rohany-Tabatabai \\ Master of Arts-Economics, University of Waterloo, Canada, 2011 \\ Bachelor of Arts-Economics, Shahid Beheshti University, Iran, 2008
}

A dissertation
presented to Ryerson University

in partial fulfillment of the

requirements for the degree of

Doctor of Philosophy

in the program of

Economics

Toronto, Ontario, Canada, 2020

(C) Sara Rohany-Tabatabai, 2020 


\section{AUTHOR'S DECLARATION}

I hereby declare that I am the sole author of this dissertation. This is a true copy of the dissertation, including any required final revisions, as accepted by my examiners.

I authorize Ryerson University to lend this dissertation to other institutions or individuals for the purpose of scholarly research.

I further authorize Ryerson University to reproduce this dissertation by photocopying or by other means, in total or in part, at the request of other institutions or individuals for the purpose of scholarly research.

I understand that my dissertation may be made electronically available to the public. 
Essays on Deep Trade Agreements

\author{
Sara Rohany-Tabatabai \\ Doctor of Philosophy, 2020 \\ Department of Economics \\ Ryerson University
}

\begin{abstract}
The number of preferential trade agreements (PTAs) has increased tremendously since 1990. The natural question to ask is why. PTAs are not only about lowering down tariffs further than the most favoured nation (MFN) tariff levels. There are many economic and non-economic policies other than border policies that are addressed in PTAs. Trade agreements dealing with border policies (tariffs) are referred to as "shallow"; and those that are dealing with a broader set of policies are referred to as "deep". Therefore, PTAs are about something deeper. Parallel to the increase in the PTAs, trade in intermediate inputs has grown exponentially over past decades. Therefore, the first question that arises is whether trade in intermediate inputs generates the need for deep integration. In this dissertation, we show that the nature of trade in intermediate goods requires deep integration. The second question to be addressed is whether the deep trade agreements need to be preferential. With a three-country model, we show that the deep bilateral agreements are rarely chosen over the shallow agreements. Finally, by introducing the deep integration in the multilateral trading system, we conclude that although trade in intermediate inputs calls for deep integration, they do not call for deep PTAs. However, deep integration is better implied under multilateral agreements. Therefore, the deep integration in economic policies does not contribute to the increase in the number of PTAs.
\end{abstract}




\section{Co-Authorship Statement}

The materials in chapters 2 and 3 of this thesis are based on papers co-authored with Richard Chisik. Together we worked on the conception of the theoretical model and its resolution. 


\section{Acknowledgements}

I would like to express my gratitude to my supervisor, Professor Richard Chisik for his unwavering support in my Ph.D. studies. Richard's words of wisdom, insightful approach towards modeling, and words of encouragement will continue to resonate with me through the coming years.

I am grateful to my committee members, Professor Germán Pupato and Professor Halis Yildiz, for their guidance, suggestions, and support during my graduate studies. Their constructive comments and questions have been invaluable in improving both the content and presentation of this thesis and I am very fortunate to have them in my committee.

I would like to thank my external examiners, Professor Eugene Charles Beaulieu from the Department of Economics at University of Calgary and Professor Sui Sui from the Ted Rogers School of Management at Ryerson University for being external-external and internal-external in my Ph.D. thesis defense.

I would like to express my gratitude to the faculty and staff in the Department of Economics at Ryerson University for providing a wonderful environment for research and study.

Finally, I would like to thank my parents, Matin Fotohi and Hasan Rohany-Tabatabai, who have always supported and encouraged me to pursue my goals. My son, Hirbod, brought a smile on my face during my last year of studying. Last but not least, I would like to thank my husband, Amir, for his love and encouragement. 


\section{Dedication}

I dedicate this dissertation to my parents. 


\section{Table of Contents}

Author's Declaration $\quad$ ii

$\begin{array}{lll}\text { Abstract } & \text { iii }\end{array}$

Co-Authorship Statement iv

$\begin{array}{ll}\text { Acknowledgements } & \text { v }\end{array}$

Dedication $\quad$ vi

List of Tables $\quad$ xi

List of Figures $\quad$ xii

1 Introduction $\quad 1$

2 Shallow, Narrow and Deep Trade Agreements 5

2.1 Introduction . . . . . . . . . . . . . . . . . 5 
2.2 Basic Model . . . . . . . . . . . . . . . . . . . . . . . . . . . . . . . . 12

2.2 .1 Consumer preferences . . . . . . . . . . . . . . . . . . . . . . . 12

2.2 .2 Production . . . . . . . . . . . . . . . . . . 13

2.2 .3 Government . . . . . . . . . . . . . . . . . . . . . . 14

2.2 .4 Equilibrium . . . . . . . . . . . . . . . . . . 15

2.3 Timing . . . . . . . . . . . . . . . . . . . . . . . . . . . . . . . . . 19

2.4 Equilibrium Concepts of Trade agreements . . . . . . . . . . . . . . 20

2.5 Deep Multilateral Trade Agreement . . . . . . . . . . . . . . . . . . . . 21

2.6 Non-cooperative Nash equilibrium . . . . . . . . . . . . . . . . . . . . . 22

2.7 Shallow integration . . . . . . . . . . . . . . . . . . . . . . . . . . 24

2.8 Narrow deep integration . . . . . . . . . . . . . . . . . . . . . . 30

2.9 Conclusion . . . . . . . . . . . . . . . . . . . . . . 37

3 Shallow, Narrow and Deep Trade Agreements with a Potential Hold-up $\begin{array}{ll}\text { Problem } & 38\end{array}$

3.1 Introduction . . . . . . . . . . . . . . . . . . . . . . . 38

3.2 Timing . . . . . . . . . . . . . . . . . . . . . 44

3.3 Deep Multilateral Trade Agreement . . . . . . . . . . . . . . . . . . . . . 45

3.4 Non-cooperative Nash equilibrium . . . . . . . . . . . . . . . . . . 46

3.5 Shallow Integration $\ldots \ldots \ldots \ldots$

3.6 Narrow deep integration $\ldots \ldots \ldots \ldots$

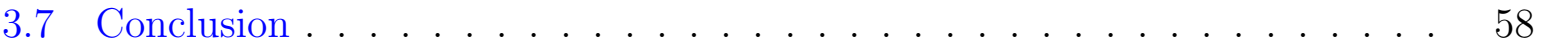


4 Trade Agreements and the Endogenous Structure of Multinational Firms 60

4.1 Introduction . . . . . . . . . . . . . . . . . . . 60

4.2 Basic Structure . . . . . . . . . . . . . . . . . . . . 66

4.3 Deep Trade Agreement . . . . . . . . . . . . . . . . . . . . 67

4.3 .1 Deep Free Trade . . . . . . . . . . . . . . . . . 67

4.3.2 Deep Integration . . . . . . . . . . . . . . . . . . 72

4.4 The shallow Trade Agreement . . . . . . . . . . . . . . . . . . . 77

4.4.1 Shallow Free Trade . . . . . . . . . . . . . . . . . . . . 77

4.4 .2 Shallow Integration . . . . . . . . . . . . . . . 80

4.5 Non-cooperative Nash Policies . . . . . . . . . . . . . . . . . . . 82

4.6 Conclusion . . . . . . . . . . . . . . . . . . . . 88

$\begin{array}{lr}\text { References } & 90\end{array}$

$\begin{array}{lc}\text { APPENDICES } & 93\end{array}$

A Proof of Lemmas in Chapter 2 94

A.1 Welfare Derivations and Analysis . . . . . . . . . . . . . . . 94

A.2 Proof of lemma 2.6.1 . . . . . . . . . . . . . . . . 95

A.3 Proof of lemma 2.7.1 . . . . . . . . . . . . . . . . . 96

A.4 Proof of lemma $2.7 .2 \ldots \ldots \ldots$. . . . . . . . . . . . . . . 97

A.5 Proof of lemma 2.7.3 . . . . . . . . . . . . . . . . . 98 
A.6 Proof of lemma 2.8.1 f . . . . . . . . . . . . . . . . . . . . . 98

A.7 Proof of lemma 2.8.2 . . . . . . . . . . . . . . . . . . 99

A.8 Proof of proposition $2.8 .1 \ldots \ldots \ldots$. . . . . . . . . . . . . 100

B Proof of Lemmas in Chapter $3 \quad 101$

B.1 Proof of lemma 3.4.1 . . . . . . . . . . . . . . . . . 101

B.2 Proof of lemma 3.5.1 . . . . . . . . . . . . . . . 102

B.3 Proof of lemma 3.5.2 . . . . . . . . . . . . . . . . 103

B.4 Proof of proposition $3.5 .1 \ldots \ldots \ldots$. . . . . . . . . . . . 104

B.5 Proof of lemma 3.6.1 . . . . . . . . . . . . . . . . 104

B.6 Proof of proposition $3.6 .1 \ldots \ldots \ldots$. . . . . . . . . . . . 106

B.7 Proof of proposition $3.6 .2 \ldots \ldots \ldots \ldots$. . . . . . . . . . . 107

$\begin{array}{ll}\text { C Proof of Lemmas in Chapter } 4 & 108\end{array}$

C.1 Proof of proposition $4.3 .1 \ldots \ldots \ldots$. . . . . . . . . . . 108

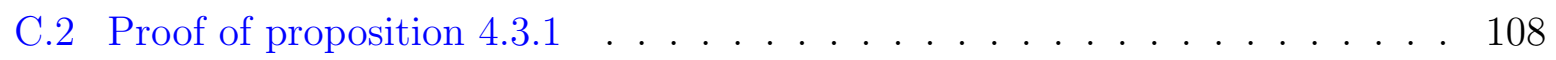

C.3 Proof of proposition $4.3 .2 \ldots \ldots \ldots$. . . . . . . . . . . . 109

C.4 Proof of proposition $4.3 .2 \ldots \ldots \ldots$. . . . . . . . . . . . . 109

C.5 Proof of proposition $4.3 .5 \ldots \ldots \ldots \ldots$. . . . . . . . . . . 109

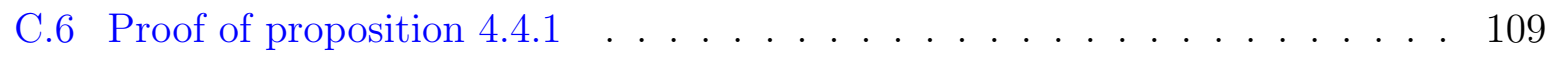

C.7 Proof of lemma $4.4 .2 \ldots \ldots \ldots \ldots$. . . . . . . . . . . . . 110

C.8 Proof of proposition $4.5 .1 \ldots \ldots \ldots \ldots$. . . . . . . . . . . . 110 


\section{List of Tables}

A.1 Summary of welfare and intermediate input levels under free trade and Nash

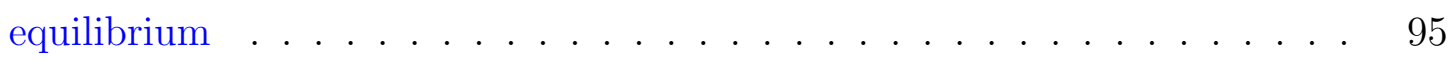

A.2 Summary of welfare and intermediate input levels under shallow integration 96

A.3 Summary of the input production and welfare when country $i$ deviates . . 97

A.4 Summary of the input production and welfare when countries $i$ and $j$ deviate 98

A.5 Summary of the input production and welfare levels under Narrow deep

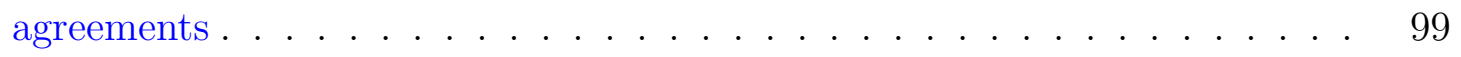

B.1 Summary of welfare and intermediate input levels under free trade and Nash

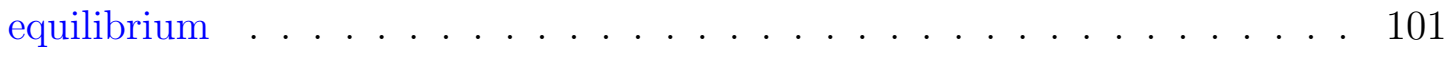

B.2 Summary of welfare and input levels under shallow integration . . . . . . . 102

B.3 Summary of welfare and input levels when country i deviates . . . . . . . . 103

B.4 Joint deviation . . . . . . . . . . . . . . . . . . . 104

B.5 Summary of welfare and input levels under narrow deep integration . . . . 105 


\section{List of Figures}

4.1 Best response function of trade policies under outsourcing. . . . . . . . . . 84

4.2 Best response function of trade policies under FDI. . . . . . . . . . . . 86 


\section{Chapter 1}

\section{Introduction}

The number of preferential trade agreements has increased rapidly over the past couple of decades. But why do we have so many PTAs? Article XXIV of the General Agreements on Tariff and Trade (GATT) and its successor, the World Trade Organization (WTO) grant an exception of the two key principles, reciprocity, and non-discrimination, to the countries that form a preferential trade agreement. However, recent studies argue that the PTAs are not only about lowering tariffs among the member countries ${ }^{1}$. Therefore, the PTAs should be about something deeper.

When trade agreements are dealing with negotiations over the border policies, they are referred to as shallow integration. This type of agreement is what we see in the current GATT/WTO agreements. However, if the trade agreements include a broader set of policies, specifically domestic (behind-the-border) policies, they are referred to as deep integration. Currently, PTAs are deeper in the sense that they cover substantially more

\footnotetext{
${ }^{1}$ See, for example, Saggi, Wong, and Yildiz [2019], Bagwell, Bown, and Staiger [2016], Secretariat [2011], and Carpenter and Lendle [2010]
} 
provisions than the shallow ones, which focus mostly on tariff liberalization. Therefore, the first question to ask is whether the need for deep integration is the reason for the tremendous rise in PTAs.

Not all the deep PTAs are narrowly economic. Some of the non-narrowly economic policies that have been addressed in the PTAs are harmonization of law, government procurement contract, and the right to sue the government. However, these types of provisions are hard to consider in an economic framework. Therefore, in this thesis, we refer deep to an agreement which includes broader sets of narrowly economic provisions such as domestic tax/subsidies.

The second question to ask is when there a need for deep integration? Parallel to the rise in the number of PTAs, trade in intermediate inputs has been increasing in recent years. Some studies suggest that the nature of trade in intermediate inputs calls for deeper policy negotiations. Therefore, we continue the literature on trade in intermediate inputs and ask if there is a need for deep integration when the trade is intermediate inputs? And does the deep agreement need to be preferential? Finally, we ask if the deep agreements operate better under multilateral agreements?

In the first chapter after the introduction, we answer the above questions with a threecountry model where the trade is in intermediate inputs. In this chapter, a bilateral trade agreement is referred to as a PTA, while a multilateral agreement is when all three countries are trading. We consider that all the countries are WTO members and ask if there is any incentive for two of the countries to form a deep bilateral agreement? We show that the deep bilateral agreement is rarely chosen over the shallow integration. The non-member country's choice of behind-the-border policy has an impact on the member countries' PTA formation. Further, we examine the welfare effect of deep agreements under the multilateral trading system for each country. We show that deep agreements are essential, but it should 
be multilateral.

In the second chapter, after the introduction, we address the above questions when there is a potential hold-up problem. More specifically, we assume that the hold-up problem might arise from the fact that the input production in the exporting countries may require a sunk investment before the trade. For example, we can assume that the production of intermediate inputs may require installation of capacity for a feasible production, and this capacity installation is irreversible. By examining the welfare effect of shallow, deep bilateral, and deep multilateral agreements, we show that although deep bilateral agreements can be chosen over the shallow agreements, countries have the incentive to move to deep multilateral agreements.

In the last chapter, we consider a more general case of a hold-up problem in which the contract between buyers and sellers of intermediate inputs (trading parties) is imperfect and compare the result with the one where the contract is perfect. In particular, we consider two alternative options for the import of intermediate inputs: outsourcing versus foreign direct investment (FDI). The former occurs when a firm imports its required intermediate inputs from an independent supplier and the latter happens when the firm obtains its intermediate inputs from a wholly-owned subsidiary. Furthermore, we assumed that the contracts between trading parties could be better enforced under FDI. Therefore, the price of the traded inputs under outsourcing is not determined through market-clearing condition and the trading parties bargain over the price. We show that the hold-up problem does not play a key role in the need for deep trade agreements and the nature of trade in intermediate inputs calls for the deep agreements. Also, we show that deep trade agreements have an impact on the structural form of the firms; that is deep trade agreements motivate firms to choose to outsource over FDI. However, in this chapter, with a two-county model, we are not able to answer whether the need for deep integration motivates countries to join 
PTAs. 


\section{Chapter 2}

\section{Shallow, Narrow and Deep Trade}

\section{Agreements}

\section{$2.1 \quad$ Introduction}

Preferential trade agreements (PTAs) have become very popular, and their numbers have increased to over 400 since 1990. As of June 2016, all members of the World Trade Organization (WTO) are participating in at least one type of PTA. But why are there so many preferential trade agreements? The majority of PTAs are "deep" in the sense that

they cover substantially more policy areas than the "shallow" agreements that focus mostly on tariff liberalization. Therefore, the natural question to ask is whether the increase in the number of PTAs is attributable to the importance of deep integration.

In this chapter, we study whether a need for deep integration justifies the increase in the PTAs. More specifically, we first study the reasons behind the need for deep integration. Then, in a setting that requires deep integration, we show that deep integration should 
not necessarily be preferential, and they could operate better under a multilateral trading system. Therefore, deep agreements cannot be considered as the sole reason for the increase in PTAs.

Article XXIV of the General Agreements on Tariffs and Trade (GATT) and its successor, the World Trade Organization (WTO), grants an exception on the two fundamental principles, reciprocity and non-discrimination, to the countries that form a preferential trade agreement. Therefore, the question is whether the tariff reduction further than negotiated most favored nation (MFN) is the reason for increase in the PTAs? This article allows a group of countries to form PTAs and discriminate between the member and nonmember countries by eliminating tariffs on "substantially all trade" between them. The purpose of the PTA formations based on Article XXIV's reasoning is the welfare and trade improvements that are caused by tariff elimination.

However, PTA members are not always committed to this rule. Recent studies have noted that the increase in the share of the world trade between PTA members and intraPTAs is not entirely due to the preferential tariff arrangements. Saggi, Wong, and Yildiz [2019] examine the possible incentives of the PTA members for a positive internal tariff rate and conclude that the member countries benefit from not eliminating their internal tariff on each other when they are engaged in a free trade agreement (FTA). Carpenter and Lendle [2010] study the import flow based on the tariff levels for the 20 largest importers, which covers $90 \%$ of the world trade, and conclude that only $16.3 \%$ of the global trade has a positive preferential margin. Also, they note that the share of preferential imports with high margins (above 10\%) is small for most countries other than intra-EU trade and imports of Mexico. Furthermore, $52 \%$ of world trade is taking place under zero MFN tariff. Thus, no preferences can be granted. Another study shows that in 2007, around two-thirds of the tariffs with MFN rates above $15 \%$ have not been reduced through PTAs 
for 85 countries that cover about $90 \%$ of the world trade (Secretariat [2011]). Moreover, in the real world, the PTAs do not always lead to zero tariffs, and the tariff concession can only be limited to a specific amount of import from the partner country. For example, a preferential agreement between the US and Australia led to a zero tariff imported butter from Australia only for the 3,000 tonnes per year, and the excess amount of the butter imports is subject to the MFN tariff rate (Damuri [2012]). Therefore, PTAs are about something deeper.

Besides the increase in the number of PTAs, the scope of policy coverage has gone beyond the traditional border levels. The majority of the PTAs signed after 2003 are referred to as deep PTAs, which include at least ten legally enforceable provisions (see Mulabdic, Osnago, and Ruta [2017] for more details). Mulabdic et al. [2017] noted that European countries are involved in PTAs with the highest depth, which is mostly due to the strong integration inside the EU. As of 2015, the EU members are engaged in 36 agreements, and each member deals on average with more than 25 provisions with its PTA partner. The next highest depths of PTAs belong to the agreements signed by Japan and the Republic of Korea with an average of 21 and 20 provisions, respectively. Other countries such as the United States, Australia, Taiwan, China, and most Latin American countries established a relatively deep relationship with their partners, although shallower compared to European countries. Finally, South East Asian countries have the lowest depth of agreements and mostly focused on shallow agreements.

Therefore, our main questions in this chapter are as follow: First, does the increase in the number of PTAs attribute to the importance of deep integration? Second, why is there a need for deep integration? Finally, does the deep integration need to be under a preferential trading system or it can be under a multilateral one?

To answer the first questions, we need to know the scope of deep integration under 
PTAs. Deep integration under the PTAs is categorized into two groups: non-narrowly economic and narrowly economic provisions. The former refers to policies such as harmonization of law, government procurement contracts, the right to sue the government. ${ }^{1}$ The latter refers to domestic (behind-the-border) policies such as domestic taxes/subsidies. Since the non-narrowly economic policies are hard to be addressed in a theoretical framework, in this chapter, we focus on the narrowly economic policies as the behind-the-border policies.

Furthermore, trade is no more only about the final-goods. Using OECD input-output table, Miroudot and Lanz [2011] concluded that trade in intermediate inputs has been growing at an average of $6.2 \%$ for goods and 7\% for services between 1995 and 2006 . Similarly, Ramanarayanan [2007] concluded that in the late 1990s, intermediate goods comprised about $60 \%$ of total international merchandise trade for many of the industrial economies. The changes in the nature of trade, from final-good to intermediate good, have an impact on the scope of policy coverage of trade agreements, which WTO rules have not considered. Therefore, to answer the second question, we examine if trade in the intermediate goods calls for deep integration.

The results presented in this chapter are using a three-country model in which we examine the impact of shallow multilateral, deep bilateral, and deep multilateral agreements on the welfare of all countries. We consider three symmetric countries, $A, B$, and $C$, where each country produces a non-numeraire final-good, two intermediate inputs, and a numeraire good. For producing the final-good, each country needs to import the required inputs from the other two countries. The final-goods are consumed domestically, and the intermediate inputs are either consumed domestically or exported to be used as

\footnotetext{
${ }^{1}$ For more details on the harmonization of law and government procurement contracts see Jackson [1995] and Anderson, Müller, and Pelletier [2015].
} 
an input for the final-good production of the other two countries. The government in each country can impose import tariff/subsidies on the imports of intermediate inputs, and impose behind-the-border policies on the domestic consumption in the form of consumption tax/subsidy.

Starting from the Nash equilibrium, we show that the Nash equilibrium border and behind-the-border policies are inefficiently high. As a result of that, the input trade levels are inefficiently low. We further show that welfare improves for all countries when countries start negotiating over the border policies. However, since the behind-the-border policies are not negotiated under the shallow integration, we examine whether there is an incentive for the countries to deviate from the Nash level behind-the-border policies and conclude that shallow agreement is equilibrium.

Moreover, we introduce the possibility that two of the countries sign a deep bilateral agreement, and we define it as "narrow deep" bilateral agreement. The member countries of the narrow deep agreement enjoy the improvement in their welfare levels. However, there is no binding contract between the member and non-member countries regarding the non-member country's behind-the-border policy, which gives an incentive to the nonmember country to deviate from its shallow level behind-the-border policies and increase its welfare. In addition to that, the non-member deviation leads to lower welfare for the member countries. Thus, the narrow deep agreement is not always an equilibrium.

Finally, we introduce the deep multilateral trade agreement, when all of the countries reduce their border and behind-the-border policies to zero and conclude that the welfare and input production levels for all of them improve under this type of agreement. This result leads us to conclude that the rise in trade of intermediate inputs calls for deep negotiations. However, deep integration is not necessarily preferential. The deep agreements are better implied under the multilateral trading system where all countries benefit from the 
trade agreement. Therefore, the inclusion of narrowly economic policies in PTAs cannot justify the rise in these types of arrangements.

This chapter contributes to trade agreements literature in two ways: First, by considering the international trade between final-good producers and input suppliers, we show that the policy choices of the government can affect the volume of trade and welfare in each country. Antràs and Staiger [2012] and Ornelas and Turner [2008] considered the impact of trade liberalization on the volume of the trade when trade is in intermediate inputs. The authors studied a relationship-specific investment between the buyers and suppliers of the intermediate inputs that led to a hold-up problem and showed that trade agreements could alleviate the under-investment in the level of inputs that occurs in the presence of the hold-up problem. Ornelas and Turner [2008] examined the impact of international trade agreements when the policies under trade agreements are exogenous. Antràs and Staiger [2012] considered the effect of different types of trade agreements and the resulting optimal policies on the volume of trade. In this chapter, we abstract from the incompleteness of the contracts; thus, we ignore the possibility of the hold-up problem between the input buyers and sellers. We show that the nature of trade in intermediate goods in itself is sufficient to motivate countries to join trade agreements.

Our second contribution to the literature is through introducing the deep integration and emphasizing that there need to be more profound trade agreements under such conditions. Lawrence [2000] was the first to address the need for a deeper form of integration. The author noted that an increase in international production networks requires agreements that smooth the difficulties related to the national policies. Later on, Antràs and Staiger [2012] showed that the rise of offshoring, which is accomplished with the possibility of the hold-up problem, generates the need for deep trade agreements. Therefore, we also contribute to the literature on the role of WTO on liberalization. Antràs and Staiger [2012] 
used a two-country model and suggested that the WTO-member countries that experience an increase in the offshoring might seek preferential trade agreements as a way to achieve deep integration. More specifically, they concluded that the rise in offshoring and its implication for international price determination challenges the effectiveness of the current WTO approach toward liberalization. Therefore, countries that seek trade liberalization prefer to join the preferential trade agreement. However, to examine whether deep integration is achieved under the preferential trade agreement, we need to have a third country to see how a preferential trade agreement is affecting the member and non-member countries. In this chapter, we introduce such a three-country model and show that the need for deep integration cannot always be fulfilled through PTAs. That is, the deep integration through the multilateral trading system can benefit countries more.

The remainder of this chapter is organized as follows: in sections 2.2 to 2.3 , we outline our basic model and the specific timing constraints considered in it. In section 2.4 we introduce our equilibrium concept in the model. In section 2.5, we introduce the deep multilateral agreement and show that all the countries can improve their welfare when the border and behind-the-border policies are negotiated. In section 2.6, we consider the noncooperative Nash equilibrium policies when countries unilaterally maximize their welfare. In section 2.7, we introduce the shallow integration and show the improvement in the welfare of all countries when they negotiate over the border policies, given the Nash level behind the border policies. In section 2.8, we examine the possibility that two of the countries might engage in a narrow deep bilateral and examine if this type of agreement is viable. Section 2.9 concludes this chapter. 


\subsection{Basic Model}

In this section, we construct a perfectly competitive equilibrium model of trade between three countries: $H \in\{A, B, C\}$. Each country produces four goods: a non-numeraire finalgood $X_{H}$, two intermediate inputs, $x_{i}^{H}$, and $x_{j}^{H}$, and a numeraire good $z$. To produce the final-good $X_{H}$, each country needs to import the required inputs from the other two countries. That is, the domestically produced intermediate inputs are consumed domestically or are exported to the other two countries as an input for final-good production. We could easily assume that there exists a rest-of-the-world as a secondary market for the inputs that are produced in the country $H$. However, to avoid the complexity of the model, we assume that each country either consume its intermediate inputs domestically or export it as an input for the other two countries.

The government in each country has access to border and behind-the-border policies to affect trade in intermediate inputs between the final-good producers and intermediate input producers.

The details on the model are described as follow:

\subsubsection{Consumer preferences}

The preferences of the representative consumer in country $H$ over the consumption of four goods can be represented by a quasi-linear utility function as:

$$
U^{H}=D_{z}+u\left(D_{X_{H}}\right)+u\left(D_{x_{i}^{H}}\right)+u\left(D_{x_{j}^{H}}\right)
$$

where $D_{z}$ is the consumption of numeraire good, $D_{X_{H}}=D\left(p_{X_{H}}\right)$ is the consumption of

the final-good $H$, and $D_{x_{i}^{H}}=D^{H}\left(p_{x_{i}^{H}}\right)$ and $D_{x_{j}^{H}}=D^{H}\left(p_{x_{j}^{H}}\right)$ are the demand for the 
domestically produced inputs $x_{i}^{H}$ and $x_{j}^{H}$ in country $H$. The sub-utility functions are quadratic in consumption of final-good and intermediate inputs and are represented as:

$$
\begin{gathered}
u\left(D_{X_{H}}\right)=\alpha D_{X_{H}}+\frac{D_{X_{H}}{ }^{2}}{2}, \\
u\left(D_{x_{\nu}^{H}}\right)=\phi D_{x_{\nu}^{H}}+\frac{D_{x_{\nu}^{H}}^{2}}{2}, \nu \in i, j .
\end{gathered}
$$

\subsubsection{Production}

The technology for the production of the intermediate inputs in each country is represented as a quadratic cost function with the marginal cost defined by:

$$
C_{\nu}^{H}=c+x_{\nu}^{H}
$$

where $c>\alpha>\phi>0$. Therefore, each country has a comparative advantage in the production of inputs $x_{i}^{H}$ and $x_{j}^{H}$. That is, the technology in each country for the production of intermediate inputs is not the same, and only country $H$ can profitably produce the intermediate inputs $x_{\nu}^{H}, \nu \in\{i, j\}$.

Once the final-good producers in country $H$ obtain the required inputs, they produce the final-good following a Leontief production function:

$$
X_{H}=\min \left\{x_{i}^{I}, x_{j}^{J}\right\} \quad \text { where } \quad H, I, J \in\{A, B, C\}
$$

The above production function justifies that the inputs needed for the final-good are perfect complements, and both are necessary for the production. That is, the final-good producers in country $H$ have to use inputs from country $I, x_{i}^{I}$, and $J, x_{j}^{J}$. Therefore, trade over intermediate inputs involves all the three countries. Also, the intermediate input 
exporters are not competing over the export level to the final-good producing country directly; however, they can manipulate the final-good producers' demand for the inputs and indirectly impact the export levels.

We assume that the production cost of the final-good is zero, and the only cost associated with the final-good production is the cost that each firm has to pay in order to obtain the necessary inputs from abroad. That is:

$$
T C_{X_{H}}=p_{x_{i}^{I}}^{H} \cdot D^{H}\left(p_{x_{i}^{I}}\right)+p_{x_{j}^{J}}^{H} \cdot D^{H}\left(p_{x_{j}^{J}}\right)
$$

where $p_{x_{i}^{I}}^{H}, p_{x_{j}^{J}}^{H}, D^{H}\left(p_{x_{i}^{I}}\right)$, and $D^{H}\left(p_{x_{j}^{J}}\right)$ are the prices and demand of inputs $x_{i}^{I}$ and $x_{j}^{J}$ in country $H$.

The numeraire good $z$ in each country is produced by a constant returns to scale technology. The supply of labor in each country is sufficiently large to have a positive numeraire good production in all the three countries. Therefore, the equilibrium wage (the price of numeraire good) is normalized to one for each country.

\subsubsection{Government}

The government in each country can choose to impose border and behind-the-border policies in order to maximize their welfare. That is, the government in each country imposes import tariff (or subsidy) on its import of intermediate inputs, $\tau_{\nu}, \nu \in\{i, j\}$, referred to as border policies. Also, the government in each country imposes domestic policies (consumption subsidy/tax) on the consumption of domestically produced inputs, $\sigma_{\nu}$, referred to as behind-the-border policies. 


\subsubsection{Equilibrium}

Given the equilibrium level of government policies, the consumer's objective is to maximize their preferences. Using, the utility function 2.1, and the sub-utility function, the market demand for the final-good, and the domestic inputs in country $H$ are given by:

$$
D\left(p_{X_{H}}\right)=\alpha-p_{X_{H}}, \quad D^{H}\left(p_{x_{\nu}^{H}}\right)=\phi-p_{x_{\nu}^{H}}
$$

where $\nu \in\{i, j\}$. To justify the positive demand of intermediate good abroad, we have assumed that $\alpha>\phi$.

The final-good and intermediate input producers in each country maximize their profit, respectively, as follow:

$$
\begin{gathered}
\max \left\{p_{X_{H}} X_{H}-\left(p_{x_{i}^{I}}^{H}+p_{x_{j}^{J}}^{H}\right) X_{H}\right\} \\
\max \left\{p_{x_{\nu}}^{H} x_{\nu}^{H}-c x_{\nu}^{H}-\frac{1}{2}\left(x_{\nu}^{H}\right)^{2}\right\}
\end{gathered}
$$

where $p_{x_{\nu}}^{H}, \nu \in\{i, j\}$ is the producer's price of intermediate goods in country $H$. Following the profit maximization in the perfectly competitive equilibrium model, the price of the final-good $X_{H}$ in country $H$ can be written as:

$$
p_{X_{H}}=\left(p_{x_{i}}^{I}+\tau_{i}\right)+\left(p_{x_{j}}^{J}+\tau_{j}\right)
$$

where $p_{x_{i}}^{I}=c+x_{i}-\sigma_{i}, p_{x_{j}}^{J}=c+x_{j}-\sigma_{j}, \tau_{i}$, and $\tau_{j}$ are the producer's price of intermediate inputs, and the trade tax (import tariff/subsidy) that $H$ imposes on the imports from countries $I$ and $J$, respectively.

The pattern of trade between all the three countries can be shown as follow: 


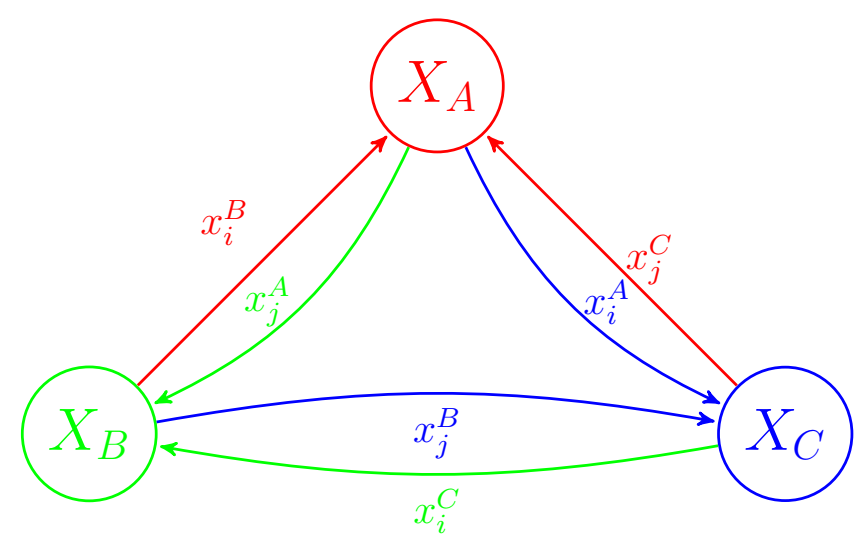

It is clear from the above graph that to produce final-goods each country is required to import inputs from the other two countries while it exports its inputs as an input for the production of final-goods in other countries. However, since all the countries are symmetric, we can take a snapshot of the above graph and focus on trade of intermediate inputs between the buyer and seller of intermediate inputs for a specific final-good. Therefore, from this point onward, we can assume that each country is once a home country $(h)$ for the production of final-good $X$ that imports intermediate goods $x_{i}$ and $x_{j}$ from countries $i$ and $j$, respectively. The pattern of trade can be simplified as follow:

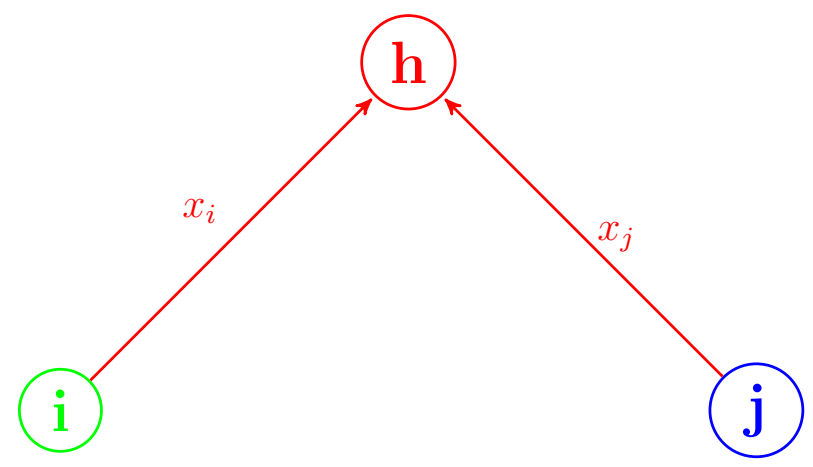

Therefore, the government in country $h$ chooses a specific trade taxes $\tau_{i}$ and $\tau_{j}$ (border policies) on its import from country $i$ and $j$, which is a wedge between the local price and international prices:

$$
p_{X}=\left(p_{i}+\tau_{i}\right)+\left(p_{j}+\tau_{j}\right)
$$


Where $p_{X}, p_{i}$, and $p_{j}$ are the consumer price of final good $X$, and producer price of input $i$, and input $j$ in country $h, i$, and $j$, respectively. In addition to the border policies, the governments in country $i$ and $j$ choose a behind-the-border policy (tax or subsidy), $\sigma_{i}$ and $\sigma_{j}$, respectively. The governments redistribute the revenue from these policies in a lump-sum fashion equally to all agents.

Therefore, equations (2.3)-(2.8) combined with the market clearing condition for each good implies the following equilibrium prices for the final-good and intermediate inputs:

$$
\begin{aligned}
& p_{X}=\frac{2(\phi+\alpha)-x_{i}-x_{j}+\sigma_{i}+\sigma_{j}+\tau_{i}+\tau_{j}}{3} \\
& p_{i}=\frac{\phi+\alpha-2 x_{i}+x_{j}+2 \sigma_{i}-\sigma_{j}-\tau_{i}-\tau_{j}}{3} \\
& p_{j}=\frac{\phi+\alpha-2 x_{j}+x_{i}+2 \sigma_{j}-\sigma_{i}-\tau_{i}-\tau_{j}}{3}
\end{aligned}
$$

Given the perfect competitive assumption, by equating the input producers' prices to the marginal cost, the world supply of inputs $x_{i}$ and $x_{j}$ are determined as:

$$
\begin{aligned}
& x_{i}=\frac{2(\phi+\alpha-3 c)+3 \sigma_{i}-\sigma_{j}-2 \tau_{i}-2 \tau_{j}}{8}, \\
& x_{j}=\frac{2(\phi+\alpha-3 c)+3 \sigma_{j}-\sigma_{i}-2 \tau_{i}-2 \tau_{j}}{8}
\end{aligned}
$$

Finally, by substituting the equilibrium prices in equation (2.9) into equation (2.5), the equilibrium demand functions can be derived as:

$$
\begin{aligned}
& D\left(p_{X}\right)=\frac{(\alpha-2 \phi)+x_{i}+x_{j}-\sigma_{i}-\sigma_{j}-\tau_{i}-\tau_{j}}{3} \\
& D\left(p_{i}^{i}\right)=\frac{(2 \phi-\alpha)+2 x_{i}-x_{j}+\sigma_{i}+\sigma_{j}+\tau_{i}+\tau_{j}}{3} \\
& D\left(p_{j}^{j}\right)=\frac{(2 \phi-\alpha)+2 x_{j}-x_{i}+\sigma_{i}+\sigma_{j}+\tau_{i}+\tau_{j}}{3}
\end{aligned}
$$


where $D\left(p_{X}\right), D\left(p_{i}^{i}\right), D\left(p_{j}^{j}\right), p_{i}^{i}$, and $p_{j}^{j}$ are the demand of final-good $X$, demand of inputs $x_{i}$ and $x_{j}$ in country $h, i$ and $j$, and the consumer prices of inputs in country $i$ and $j$, respectively. It is clear from the above equations, the import tariffs imposed by country $h$ increase the price of the final-good, leading to lower demand for the final-good and the imported intermediate good in the home country. The reduction of the final-good producers' demand for the intermediate inputs decreases the level of input productions. Also, since the demand for the export in country $i(j)$ has reduced, the domestic consumption will increase. The consumption subsidy in country $i(j)$ increases the demand for domestic consumption, which increases the production of the inputs in the country $i(j)$. However, an increase in consumption subsidy increases the price of the final-good $X$ and the demand for the final-good decreases.

Given the quasi-linear preferences, a country's welfare is defined as the sum of the consumer surplus, producer surplus, and the tariff revenue (or the subsidy loss). The country $i(j)$ is the exporter of the intermediate inputs, and the only policy in its disposal is the behind-the-border policy (subsidy), which is represented as a loss to the welfare. Moreover, the producers surplus in country $h$ is equal to zero, and the welfare is just the sum of the consumer surplus from the final-good consumption and the tariff revenue from the imported inputs $x_{i}$ and $x_{j}$. The welfare for each country is defined by:

$$
\begin{aligned}
W_{i}\left(\sigma_{i}, p_{i}\left(\sigma_{i}, \sigma_{j} \tau_{i}, \tau_{j}\right)\right) & =\int_{p_{i}^{i}}^{\phi} D(p) d p+\int_{c}^{p_{i}} x(p) d p-\sigma_{i} D\left(p_{i}^{i}\right) \\
W_{j}\left(\sigma_{j}, p_{j}\left(\sigma_{i}, \sigma_{j}, \tau_{i}, \tau_{j}\right)\right) & =\int_{p_{j}^{j}}^{\phi} D(p) d p+\int_{c}^{p_{j}} x(p) d p-\sigma_{j} D\left(p_{j}^{j}\right) \\
W_{h}\left(\tau_{i}, \tau_{j}, p_{X}\left(\sigma_{i}, \sigma_{j}, \tau_{i}, \tau_{j}\right)\right) & =\int_{p_{X}}^{\alpha} D(p) d p+\tau_{i} D\left(p_{X}\right)+\tau_{j} D\left(p_{X}\right)
\end{aligned}
$$




\section{$2.3 \quad$ Timing}

The structure of the relationship between the importers and exporters of the intermediate inputs is as follows: First, the government in each country sets its policy simultaneously. The home country $h$ imposes border policies on its import $x_{i}, x_{j}$, and country $i$ and $j$ set the behind-the-border policies on their domestic consumption. Second, the input producers in country $i(j)$ decides on the level of input production. Finally, the final-good producers import the required inputs from countries $i$ and $j$ and produce the final-good $X$. Being able to set the policies before any production or trade take place allows each government to impact the welfare level of the other two countries, and also allows the input producers to produce accordingly and avoid any hold-up problem.

We start with deep multilateral trade, where the border and behind-the-border policies are both negotiated to zero and then move to the non-cooperative Nash equilibrium, shallow, where the negotiation is only on the border policies, and narrow deep integration, where the negotiation is over the border policies and behind-the-border policies only for the member countries. The timing would be the same; however, the procedure for setting the policies are different. More specifically:

- Under the non-cooperative Nash equilibrium, each country sets its policies unilaterally given the policy of the other two countries.

- Under the shallow trade agreements, countries cooperate only over the border policies, and behind-the-border policies are chosen non-cooperatively.

- Finally, under the narrow deep agreements, countries continue with the shallow level border policies, while, two of the countries, $h$ and $i$, sign narrow deep bilateral trade 
agreement and negotiate over the behind-the-border policy. Also, the country $j$, the non-member country, determines its behind-the-border policy non-cooperatively.

\subsection{Equilibrium Concepts of Trade agreements}

In this section, we define two possible scenarios for the shallow and narrow deep trade agreements:

(i) Myopic scenario: The government in countries $i$ and $j$ under shallow agreements and the government in country $j$ under the narrow deep agreements can choose a myopic policy instead of setting the behind-the-border policy optimally. Under the shallow trade agreement, a myopic outcome occurs when the behind-the-border policies of both countries $i$ and $j$ remain fix at the original Nash levels; and under the narrow deep the myopic outcome occurs when the behind-the-border policy of the non-member country remains fix at the one under shallow integration. The myopic outcome results in a viable equilibrium when there is no incentive to deviate for country $i(j)$ from the fixed Nash or shallow level behind-the-border policies.

(ii) Strategic scenario: Given the type of the agreement, shallow or narrow deep, the behind-the-border policies in member non-member countries is determined optimally. Therefore, the strategic response to the negotiated policies leads to a viable trade agreement equilibrium.

Although the myopic outcomes are not equilibrium, to see how the results change when countries decide to keep their behind-the-border policies at the Nash levels, we consider the myopic outcomes as well as the strategic outcomes. 


\subsection{Deep Multilateral Trade Agreement}

Suppose that all the governments agreed to free trade in both the border and behind-theborder policies so that they set their policies as $\tau_{i}=\tau_{j}=0$ and $\sigma_{i}=\sigma_{j}=0$. It can be easily seen from the equations (2.10) and (2.11) that by implying free trade level policies the input production and demand for final-good and intermediate inputs become:

$$
\begin{aligned}
x & =\frac{\phi+\alpha-3 c}{4} \\
D\left(p_{\nu}^{\nu}\right) & =\frac{3 \phi-\alpha-c}{4} \\
D\left(p_{X}\right) & =\frac{\alpha-\phi-c}{2}
\end{aligned}
$$

From this point onward, for simplicity, we assume that the size of the final-good producing country is twice as big as the size of the input exporting countries (in terms of the finalgood H), i.e $\alpha=2 \phi$. Therefore, the input levels and demand function can be rewritten as:

$$
x=\frac{3 \theta}{4}, \quad D\left(p_{X}\right)=\frac{\theta}{2}, \quad D\left(p_{\nu}^{\nu}\right)=\frac{\theta}{4} \quad \text { where } \quad \theta=\phi-c
$$

Finally, by substituting the equilibrium supply and demand for the intermediate inputs and final-good in equation (2.12), the free trade level of welfare for countries $i, j$ and $h$ are derived as $W^{i}=W^{j}=5 \theta^{2} / 16$ and $W^{h}=\theta^{2} / 8$, respectively.

The symmetry implies that each country acts as a final-good producer, who earns $W^{h}$ and at the same time acts as input producer for two different types of inputs $i$ and $j$ that earn $W^{i}$ and $W^{j}$ from producing and consuming those inputs. Therefore, the welfare of each country for all the good that it produces and consumes will be equal to the sum of the welfare from the final-good and intermediate good sectors

$$
W^{T}=W^{h}+W^{i}+W^{j}=3 \theta^{2} / 4
$$




\subsection{Non-cooperative Nash equilibrium}

In the absence of trade agreements, each country simultaneously chooses its border or behind-the-border policies to maximize its domestic welfare; the home country chooses $\tau_{i}$ and $\tau_{j}$ to maximize $W^{h}$, and country $i$ and $j$ choose $\sigma_{i}$ and $\sigma_{j}$ to maximize $W^{i}$ and $W^{j}$, respectively. Given the timing of the model, the policies (border and behind-the-border) have a direct and indirect effect on the prices. The direct effect can be clearly seen from the equation (2.9). However, the indirect effect passes through the impact of policies on the supply of intermediate inputs, which can be seen in equation (2.10). The optimal policy for each country is derived as:

$$
\begin{aligned}
\frac{\partial W_{h}}{\partial \tau_{i}} & =\frac{\partial W_{h}}{\partial \tau_{i}}+\frac{\partial W_{i}}{\partial p_{X}}\left(1+\frac{\partial p_{X}}{\partial x_{i}} \frac{\partial x_{i}}{\partial \tau_{i}}+\frac{\partial p_{X}}{\partial x_{j}} \frac{\partial x_{j}}{\partial \tau_{i}}\right)=0 \\
\frac{\partial W_{i}}{\partial \sigma_{i}} & =\frac{\partial W_{i}}{\partial \sigma_{i}}+\frac{\partial W_{i}}{\partial p_{i}}\left(1+\frac{\partial p_{i}}{\partial x_{i}} \frac{\partial x_{i}}{\partial \sigma_{i}}+\frac{\partial p_{i}}{\partial x_{j}} \frac{\partial x_{j}}{\partial \sigma_{i}}\right)=0
\end{aligned}
$$

The best response functions are derived as:

$$
\begin{aligned}
\tau_{i}^{R} & =\frac{(\alpha-2 \phi)+x_{i}+x_{j}-\sigma_{i}-\sigma_{j}-4 \tau_{j}}{4} \\
\sigma_{i}^{R} & =\frac{(\alpha-2 \phi)+x_{i}+x_{j}-\sigma_{j}-\tau_{i}-\tau_{j}}{6}
\end{aligned}
$$

Since countries are symmetric, we can impose symmetry on policies. That is $\tau_{i}=\tau_{j}=\tau$ and $\sigma_{i}=\sigma_{j}=\sigma$. Therefore, we can rewrite the above best response function as:

$$
\tau^{R}=\frac{x_{i}+x_{j}-\sigma_{i}-\sigma_{j}}{8}=\frac{x_{i}+x_{j}-2\left(\sigma^{N}\right)^{R}}{8}
$$




$$
\sigma^{R}=\frac{x_{i}+x_{j}-\tau_{i}-\tau_{j}}{7}=\frac{x_{i}+x_{j}-2\left(\tau^{N}\right)^{R}}{7}
$$

By substituting $x_{i}$ and $x_{j}$ from equation (2.10), the best response functions can be derived as:

$$
\tau^{R}(\sigma)=\frac{\theta-\sigma^{N}}{6}, \quad \sigma^{R}(\sigma)=\frac{3 \theta-6 \tau^{N}}{13}
$$

Finally, the equilibrium level of Nash policies are derived as:

$$
\tau^{N}=\frac{5 \theta}{36}, \quad \sigma^{N}=\frac{\theta}{6}
$$

It is easily seen that $\frac{\partial^{2} W}{\partial \tau^{2}}<0$ and $\frac{\partial^{2} W}{\partial \sigma^{2}}<0$ holds and that the non-cooperative Nash policies are maximizing welfare for each country.

It is clear from the best response function that $\frac{d \tau}{d \sigma}<0$. That is, if the home country reduces its import tariff, the response of country $i(j)$ is to raise its behind-the-border policy and an increase in the domestic demand to compensate for the welfare loss regarding their export. Similarly, if country $i(j)$ increase their consumption subsidy, the home demand for inputs ( and the final-good) will decrease, leading to the home country increasing its import tariffs. Therefore, the border and behind-the-border policies are strategically substituted.

Following the optimal non-cooperative Nash policies, import tariff, and consumption subsidy, we can find the equilibrium level of welfare, supply, and demand for the intermediate and final-good.

Lemma 2.6.1. The welfare effect of Nash equilibrium on each sector and country compared to deep multilateral trade agreements (free trade) is as follows:

(i) $W_{h}^{N}<W_{h}^{F T}, W_{i}^{N}<W_{i}^{F T}, W_{j}^{N}<W_{j}^{F T}$

(ii) $\omega^{N} \equiv W_{T}^{N}-W_{T}^{F T}<0$ 
(iii) $x^{N}-x^{F T}<0$

Proof. See the appendix A.2.

The inefficiently high level of the border and behind-the-border policies in the absence of trade lead to lower total welfare for each country; therefore, the intermediate input suppliers produce at a level lower than the efficient level.

\subsection{Shallow integration}

Under shallow integration, all countries negotiate over the border policies. We have considered three types of negotiation for the border policies:

- first, the border policies are chosen optimally by maximizing the joint welfare $W^{W}=$ $W_{h}+W_{i}+W_{j}, \tau_{\nu}^{s h} \equiv \arg \max _{\tau} W^{W}$, where $\nu \in i, j ;$

- second, the border policies are negotiated toward zero;

- third, the border policies are negotiated to a level lower than the non-cooperative Nash import tariffs, $t<\bar{\tau}^{N}$.

The WTO approach towards the behind-the-border policies is justified under the terms of trade theory literature. Staiger and Sykes [2011] and Staiger [2012] have pointed that under non-cooperative Nash equilibrium the behind-the-border policies are set at efficient levels. Also, Staiger [2012] has shown that efficiency under free trade is achieved if and only if the domestic policies are fixed at their non-cooperative Nash levels.

Although we are not looking for the efficient level of behind-the-border policies in this section, we use the literature justification on the shallow level behind-the-border policies 
and consider two scenarios for the behind-the-border policies. The behind-the-border policies are either fixed at the original non-cooperative Nash levels $\bar{\sigma}^{N}$ or individually determined by countries $i$ and $j$. That is, given the shallow level border policies, the government in country $i$ and $j$ re-optimize their behind-the-border policies using equation (2.16):

$$
\sigma^{R}(\tau)=\frac{x_{i}+x_{j}-2 \tau}{7}
$$

It is clear from the above equation that $\frac{d \sigma}{d \tau}<0$. Therefore, a decrease in the level of border policy $\tau$ leads to an increase in the behind-the-border policies. The intuition for this result is that the border policies are determined by negotiation of all the three countries, that is, the home country takes into account the potential impacts of its tariff on the welfare of countries $i$ and $j$. However, countries $i$ and $j$ determined their behind-the-border policies unilaterally, and they only take into account their domestic welfare. Therefore, the government in the countries $i$ and $j$ manipulate their behind-the-border (consumption subsidy) to extract welfare from the home country in addition to the welfare-improving benefits that shallow integration brings for them.

Depending on the approach toward behind-the-border policies, we can define two sets of shallow integration strategies as follow:

(i) Myopic shallow strategies: under this scenario, the behind-the-border policies are fixed at the non-cooperative Nash levels, $\bar{\sigma}^{N}$. However, the border policies can be negotiated optimally $\tau=\tau^{s h}$, negotiated to zero $\tau=0$ or negotiated to a positive tariff level $\tau=t<\bar{\tau}^{N}$. Therefore, the myopic outcomes are shown as:

$$
\begin{aligned}
& \text { - } \Gamma_{m}^{s h}\left(\tau=\tau^{R}(\sigma), \sigma=\bar{\sigma}^{N}\right) \\
& \text { - } \Gamma_{m}^{F}\left(\tau=0, \sigma=\bar{\sigma}^{N}\right)
\end{aligned}
$$


- $\Gamma_{m}\left(\tau=t, \sigma=\bar{\sigma}^{N}\right)$

(ii) Strategic shallow strategies: under this scenario, the behind-the-border policies are re-optimized in response to the negotiated border policies. Similarly, border policies are negotiated in three ways. Therefore, the strategic scenarios can be shown as:

- $\Gamma_{s}^{s h}\left(\tau=\tau^{R}(\sigma), \sigma=\sigma^{R}\left(\tau=\tau^{s h}\right)\right)$

- $\Gamma_{s}^{F}\left(\tau=0, \sigma=\sigma^{R}(\tau=0)\right)$

- $\Gamma_{s}\left(\tau=t, \sigma=\sigma^{R}(\tau=t)\right)$

where $\Gamma_{m}^{s h}, \Gamma_{m}^{F}, \Gamma_{m}$ and $\Gamma_{s}^{s h}, \Gamma_{m}^{F}, \Gamma_{s}$ are the myopic and strategic shallow integration strategies when the border policies are determined optimally, negotiated to zero, or negotiated to a positive level less than non-cooperative Nash import tariffs, respectively. Starting from the first type of negotiation, the optimal border policies $\tau_{i}\left(\tau_{j}\right)$ satisfies the following first-order condition:

$$
\begin{aligned}
\frac{\partial W_{W}}{\partial \tau_{i}}= & \frac{\partial W_{h}}{\partial \tau_{i}}+\frac{\partial W_{h}}{\partial p_{X}}\left(1+\frac{\partial p_{X}}{\partial x_{i}} \frac{\partial x_{i}}{\partial \tau_{i}}+\frac{\partial p_{X}}{\partial x_{j}} \frac{\partial x_{j}}{\partial \tau_{i}}\right)+\frac{\partial W_{i}}{\partial p_{i}}\left(1+\frac{\partial p_{i}}{\partial x_{i}} \frac{\partial x_{i}}{\partial \tau_{i}}+\frac{\partial p_{i}}{\partial x_{j}} \frac{\partial x_{j}}{\partial \tau_{i}}\right) \\
& +\frac{\partial W_{j}}{\partial p_{j}}\left(1+\frac{\partial p_{j}}{\partial x_{i}} \frac{\partial x_{i}}{\partial \tau_{i}}+\frac{\partial p_{j}}{\partial x_{j}} \frac{\partial x_{j}}{\partial \tau_{i}}\right)=0
\end{aligned}
$$

The best response function can be derived as:

$$
\tau_{i}^{R}=-\frac{1}{2}\left(\sigma_{i}+\sigma_{j}\right)-\tau_{j}
$$

The symmetry among countries implies that $\tau_{i}=\tau_{j}=\tau$ and $\sigma_{i}=\sigma_{j}=\sigma$, thus, the best response function can be rewritten as

$$
\tau^{s h}=-\frac{1}{2} \sigma^{s h}
$$


Therefore, it is clear from the above best response function that the optimal negotiated shallow border policies under both of the scenarios are negative. That is, the home country's optimal border policy is an import subsidy. Since the home country does not produce the inputs $i$ and $j$ which is required for its final-good production, the optimal policy is import subsidy instead of import tariff to boost the final-good production.

Let us define $r \equiv\left(\tau^{N}, \sigma^{N}\right)$ as the policy vector under the non-cooperative Nash equilibrium, then $\Delta \omega \equiv W(\Gamma)-W(r)$ is the changes of welfare for each country moving from non-cooperative equilibrium to the shallow integration. The following lemma summarizes the details on the impact of shallow integration on countries:

Lemma 2.7.1. The impacts of the strategic and myopic shallow outcome on the welfare and volume of trade are summarized as follow:

(i) Welfare improves for each country under shallow integration, $\Delta \omega>0$

(ii) The myopic shallow outcomes improve welfare more than the strategic shallow outcomes

(iii) The volume of trade under the shallow outcome has increased compared to the noncooperative Nash levels, $\Delta x=x(\Gamma)-x(r)>0$

(iv) The inputs are higher under strategic shallow integration

Proof. See appendix A.3.

From the above lemma, it is straightforward to conclude that all the countries overall benefit from signing myopic shallow integration; that is, countries $i$ and $j$ are willing to keep their behind-the-border policy at the original non-cooperative levels. In fact, under 
the strategic shallow integration, the behind-the-border policy is higher than the noncooperative Nash levels. Consequently, the welfare of countries $i$ and $j$ is higher under those types of shallow integration. However, since countries are mirror image of each other, each country is the producer of a final-good and two intermediate inputs that either consume domestically or export to be used as an input abroad, therefore, the total welfare is higher under the myopic shallow due to the higher welfare for the final-good sector in such agreements.

However, countries $i$ and $j$ might have the incentive to deviate from the myopic shallow integration and set their policies optimally given the shallow border policies. Suppose country $i(j)$ deviates from $\sigma_{i}$ under the strategic and myopic shallow integration, given that the negotiated border policies $\tau$ and the behind-the-border policy for country $j(i)$ remain at the shallow outcomes, the best response function of the deviating country is as follows:

$$
\left(\sigma_{i}^{d}\right)^{R}=\frac{x_{i}+x_{j}-\sigma_{j}-2 \tau^{s h}}{6}
$$

The details on the impact of country $i^{\prime}$ s deviation are summarized in the following lemma.

Lemma 2.7.2. Country $i$ has an incentive to deviate from its non-cooperative Nash behindthe-border policies under the following myopic outcome:

(i) $W_{i}^{d}\left(\Gamma_{m^{d}}^{s h}\right)>W_{i}\left(\Gamma_{m}^{s h}\right)$, with $\Gamma_{m}^{s h}\left(\tau=\tau^{s h}, \sigma_{i}=\sigma^{d}, \sigma_{j}=\bar{\sigma}^{N}\right)$

(ii) $W_{i}^{d}\left(\Gamma_{m^{d}}\right)>W_{i}\left(\Gamma_{m}\right)$, with $\Gamma_{m}\left(\tau=t, \sigma_{i}=\sigma^{d}, \sigma_{j}=\bar{\sigma}^{N}\right)$

Proof. See appendix A.4

Therefore, country $i(j)$ has a unilateral incentive to deviate from its non-cooperative Nash level policy. We also examine the joint deviation of country $i$ and $j$ for each myopic 
shallow integration scenario. Following equation (2.16), countries $i$ and $j$ could deviate from their myopic non-cooperative behind-the-border policy given the negotiated border policies:

$$
\sigma^{R}=\frac{x_{i}+x_{j}-2\left(\tau^{N}\right)^{R}}{7}
$$

The impact of the joint deviation on the welfare of countries is summarized in the following lemma:

Lemma 2.7.3. Starting from a myopic shallow integration, there is no incentive for countries $i$ and $j$ to deviate from the shallow integration outcome. Furthermore, when the border policies are negotiated to zero, the myopic outcome improves the welfare of all countries.

Proof. See appendix A.5

Lemma 2.7.1 and 2.7.2 suggest that country $i(j)$ have incentive to deviate only under condition that the shallow border policies are non zero. Therefore, by increasing the behind-the-border policies, they will increase domestic consumption and production and raise their domestic welfare. Since each country is the producer of the final-good and intermediate good, when $i$ deviates, the only change in its total welfare is coming from the changes in the $W_{j}$ given that its welfare with regards to the other input sector and the final-good sector will not change. As a result, the total welfare for the deviating country will increase, which gives the country enough incentive to deviate. Using the results in lemmas 2.7.1 and 2.7.2, we can obtain the following proposition:

Proposition 2.7.1. $\quad$ (i) There are multiple shallow trade agreements:

- The myopic outcome is equilibrium when the border policies are negotiated to zero. 
- The strategic outcomes are equilibrium.

(ii) The equilibrium shallow integration can be ranked as :

$$
W\left(\Gamma_{m}^{F}\right)>W\left(\Gamma_{s}^{s h}\right)>W\left(\Gamma_{s}\right)
$$

Proof. The proof is immediate from lemmas 2.7.1, 2.7.2 and 2.7.3.

The results in the above proposition suggest that the efficiency under free trade is achieved when the behind-the-border policies are fixed at their non-cooperative Nash equilibrium (myopic shallow); however, this is not the only possible equilibrium. The strategic shallow agreements are all the viable equilibrium. The proof is immediate from lemmas 2.7.1, 2.7.2 and 2.7.3.

\subsection{Narrow deep integration}

In this section, we aim to examine whether the negotiation on the behind-the-border policies, narrow deep integration, provides enough incentive to countries to sign preferential trade agreements. Suppose countries $i$ and $h$ start a bilateral narrow deep trade agreement and negotiate over the level of the behind-the-border policy. The optimal negotiated behind-the-border policy $\sigma_{i}^{N D}$ has to satisfy the following first-order condition:

$$
\begin{aligned}
\frac{\partial W_{i h}}{\partial \sigma_{i}}= & -\left(D\left(p_{X}\right)+\tau_{i}+\tau_{j}\right)\left[\frac{\partial p_{X}}{\partial \sigma_{i}}+\frac{\partial p_{X}}{\partial x_{i}} \frac{\partial x_{i}}{\partial \sigma_{i}}+\frac{\partial p_{X}}{\partial x_{j}} \frac{\partial x_{j}}{\partial \sigma_{i}}\right] \\
& +\left(\sigma_{i}-D\left(p_{i}^{i}\right)\right)\left[\frac{\partial p_{i}^{i}}{\partial \sigma_{i}}+\frac{\partial p_{i}^{i}}{\partial x_{i}} \frac{\partial x_{i}}{\partial \sigma_{i}}+\frac{\partial p_{X}}{\partial x_{j}} \frac{\partial x_{j}}{\partial \sigma_{i}}\right] \\
& +x_{i}\left[\frac{\partial p_{i}}{\partial \sigma_{i}}+\frac{\partial p_{i}}{\partial x_{i}} \frac{\partial x_{i}}{\partial \sigma_{i}}+\frac{\partial p_{i}}{\partial x_{j}} \frac{\partial x_{j}}{\partial \sigma_{i}}\right]-D\left(p_{i}^{i}\right)=0
\end{aligned}
$$


Therefore, the best response function can be derived as:

$$
\left(\sigma_{i}^{N D}\right)^{R}=\frac{x_{i}+x_{j}-\sigma_{j}-7 \tau_{i}-7 \tau_{j}}{16}
$$

To focus on the role of the narrow deep negotiations on the formation of the bilateral trade agreements, we keep the border policy levels similar to the shallow agreements and examine the effects of negotiations of the behind-the-border policies on welfare.

Similar to the previous section, we will examine three scenarios:

- first, given the fixed shallow border policies, the behind-the-border policy of the member country is determined optimally as $\sigma_{i}^{N D} \equiv \arg \max _{\sigma} W_{i h}$;

- second, given the border policies, the member countries negotiate the behind the border policy to zero,

- finally, we allow discrimination over the border policies so that member countries negotiate over both border and behind-the-border policies and set them to zero.

Following the equilibrium concepts introduced in the previous section, we take two different approaches towards the behind-the-border policy of the non-member country: the strategic narrow deep where country $j$ sets its behind-the-border policy $\sigma_{j}$ optimally as $\sigma_{j}^{R} \equiv \arg \max _{\sigma} W^{j}$; or the myopic narrow deep where the behind-the-border policy remains fixed at the shallow levels, $\bar{\sigma}^{s h}$.

Throughout this chapter, we have assumed that all three countries are participating in shallow integration, and then two of the countries choose to sign bilateral narrow deep agreements. Therefore, to consider if countries have any incentive to form a bilateral narrow deep agreement, we will start from the viable shallow agreements. We can summarize the strategic narrow deep and myopic narrow deep strategies as follows: 
(i) Starting from the best shallow equilibrium, $\left(\tau=0, \sigma=\bar{\sigma}^{N}\right)$, the following narrow deep outcomes are obtained: Given the border policies fixed at the shallow level policies, the behind-the-border policy for the member country $(i)$ is either optimally determined as, $\sigma_{i}=\sigma_{i}^{N D}$ or negotiated to zero, $\sigma_{i}=0$. However, the behindthe-border policy for the non member country is either individually determined, $\sigma_{j}=\sigma_{j}^{R}\left(\tau, \sigma_{i}\right)$ or myopically set as shallow levels, $\sigma_{j}=\bar{\sigma}^{s h}$. Therefore, the possible outcomes can be summarized as:

- $\Gamma_{m}^{N D}\left(\tau=0, \sigma_{i}=\sigma_{i}^{N D}, \sigma_{j}=\bar{\sigma}^{s h}\right)$

- $\Gamma_{s}^{N D}\left(\tau=0, \sigma_{i}=\sigma_{i}^{N D}, \sigma_{j}=\sigma_{j}^{R}\left(\tau, \sigma_{i}\right)\right)$

- $\Gamma_{m}^{F}\left(\tau=0, \sigma_{i}=0, \sigma_{j}=\bar{\sigma}^{s h}\right)$

- $\Gamma_{s}^{F}\left(\tau=0, \sigma_{i}=0, \sigma_{j}=\sigma_{j}^{R}\left(\tau, \sigma_{i}\right)\right)$

(ii) Starting from shallow agreement $\left(\tau=\tau^{s h}, \sigma=\sigma^{s h}\right)$, the border policies remain the same as the shallow agreements, $\tau=\bar{\tau}^{s h}<0$. The behind-the-border policies among members and the behind-the-border policy for the non-member country are determined through a similar procedure introduced in the previous case.

- $\Gamma_{m}^{N D}\left(\tau=\bar{\tau}^{s h}, \sigma_{i}=\sigma_{i}^{N D}, \sigma_{j}=\bar{\sigma}^{s h}\right)$

- $\Gamma_{s}^{N D}\left(\tau=\bar{\tau}^{s h}, \sigma_{i}=\sigma_{i}^{N D}, \sigma_{j}=\sigma_{j}^{R}(\tau, \sigma)\right)$

- $\Gamma_{m}^{F}\left(\tau=\bar{\tau}^{s h}, \sigma_{i}=0, \sigma_{j}=\bar{\sigma}^{s h}\right)$

- $\Gamma_{s}^{F}\left(\tau=\bar{\tau}^{s h}, \sigma_{i}=0, \sigma_{j}=\sigma^{R}(\tau, \sigma)\right)$

(iii) Starting from the strategic shallow agreement $\left(\tau=t, \sigma=\sigma^{s h}\right)$, the border policies are fixed at the shallow levels, $t<\bar{\tau}^{N}$. The behind-the-border policies follows the similar procedure as previous cases. 
- $\Gamma_{\bar{m}}^{N D}\left(\tau=t, \sigma=\sigma_{i}^{N D}, \sigma_{j}=\bar{\sigma}^{s h}\right)$

- $\Gamma_{\bar{s}}^{N D}\left(\tau=t, \sigma=\sigma_{i}^{N D}, \sigma_{j}=\sigma_{j}^{R}\left(\tau, \sigma_{i}\right)\right)$

- $\Gamma_{\bar{m}}^{F}\left(\tau=t, \sigma_{i}=0, \sigma_{j}=\bar{\sigma}^{s h}\right)$

- $\Gamma_{\bar{s}}^{F}\left(\tau=t, \sigma_{i}=0, \sigma_{j}=\sigma_{j}^{R}\left(\tau, \sigma_{i}\right)\right)$

(iv) Following the strategic shallow agreement $\left(\tau=\tau^{s h}, \sigma=\sigma^{s h}\right)$, the discriminatory narrow deep lead to a zero border and behind-the-border policy for the member countries, i.e. $\tau_{i}=0$ and $\sigma_{i}=0$. The border policies for the non-member countries remain the same as shallow, $\tau_{j}=\bar{\tau}^{s h}$ and the behind-the-border policies are chosen either strategically or myopically.

- $\Gamma_{m}^{D i s}\left(\tau_{i}=0, \sigma_{i}=0, \tau_{j}=\bar{\tau}^{s h}, \sigma_{j}=\bar{\sigma}^{s h}\right)$

- $\Gamma_{s}^{D i s}\left(\tau_{i}=0, \sigma_{i}=0, \tau_{j}=\bar{\tau}^{s h}, \sigma_{j}=\sigma_{j}^{R}\left(\tau_{i}, \tau_{j}, \sigma_{i}\right)\right)$

(v) Following the strategic shallow integration $\left(\tau=t, \sigma=\sigma^{s h}\right)$, the narrow deep outcomes, similar to previous part, can be shown as

- $\Gamma_{\bar{m}}^{D i s}\left(\tau_{i}=0, \sigma_{i}=0, \tau_{j}=\bar{t}, \sigma_{j}=\bar{\sigma}^{s h}\right)$

- $\Gamma_{\bar{s}}^{D i s}\left(\tau_{i}=0, \sigma_{i}=0, \tau_{j}=\bar{t}, \sigma_{j}=\sigma_{j}^{R}\left(\tau_{i}, \tau_{j}, \sigma_{i}\right)\right)$

where the $\tau^{s h}, \sigma^{s h}, \sigma^{N D}$ and $t$ are the shallow level border border, shallow level behind-theborder, optimally determined narrow deep behind-the-border and positive shallow border policy, respectively.

In order to see whether countries $i$ and $h$ have an incentive to join to the narrow deep agreements, it is enough to compare the joint welfare for the member countries under this agreement with the one under shallow integration: that is $\left(W^{i h}\right)^{N D}>\left(W^{h}\right)^{s h}+\left(W^{i}\right)^{s h}$. As we mentioned earlier, countries are a mirror image of each other in the sense that 
each country is once a home country that produces final-good using two intermediate goods inputs which are imported from abroad. Therefore, we only focus on a narrow deep agreement between a specific final-good producer and two intermediate good suppliers. However, the non-member country $j$ is not committed to any agreement regarding its behind-the-border policy and might have the incentive to deviate from the myopic shallow level policies. The details on the level of welfare for each narrow deep scenario is presented in the following lemma:

Lemma 2.8.1. The impact of strategic and myopic narrow deep integration of the welfare of the member countries is summarized as:

(i) Moving from the shallow agreement equilibrium, the myopic narrow deep outcomes improve the joint welfare of the member countries:

- $W_{i h}^{N D}\left(\Gamma_{m}^{N D}\right)>W_{i h}^{s h}\left(\begin{array}{c}s h \\ m\end{array}\right)$

- $W_{i h}\left(\Gamma_{m}^{F}\right)>W_{i h}^{s h}\left(\Gamma_{m}^{F}\right)$

(ii) The only two strategic narrow deep scenario that increases the joint welfare of the member countries occurs when the border policy is negotiated to $t$ : $\Gamma_{\bar{s}}^{N D}\left(\tau=t, \sigma_{i}=\sigma_{i}^{N D}, \sigma_{j}=\sigma_{j}^{R}\left(\tau, \sigma_{i}\right)\right)$ and $\Gamma_{\bar{s}}^{F}\left(\tau=t, \sigma_{i}=0, \sigma_{j}=\sigma_{j}^{R}\left(\tau, \sigma_{i}\right)\right)$

(iii) The myopic discriminatory narrow deep outcome improves the joint welfare of the member countries.

Proof. See the appendix A.6

Since country $j$ has no binding contracts regarding its behind-the-border policy with the other two countries, it has the incentive to deviate from its Nash non-cooperative policy $\sigma_{j}$ 
under the strategic and myopic narrow deep integration. Therefore, country $j$ re-optimize its behind-the-border policy, given the negotiated behind-the-border policy $\sigma_{i}^{N D}$ and the border policies which are remained fix at the shallow levels, as in equation (2.14):

$$
\sigma_{j}^{d}=\frac{x_{i}+x_{j}-\sigma_{i}-2 \tau^{s h}}{6}
$$

The details on the impact of country $j$ 's deviation are summarized in the following lemma.

Lemma 2.8.2. By deviating from the myopic outcome, the non-member country improves its welfare.

Proof. See the appendix A.7

Therefore, following the results on lemmas 2.8.1 and 2.8.2, the only stable narrow deep agreements occur under an agreement with negotiated import tariffs on inputs, $\tau=t$, and behind-the-border policies that are chosen optimally. The negotiation over the behind-theborder policies between member countries, knowing that the non-member country responds optimally, leads to a lower behind-the-border policy for the member countries and a higher one for the non-member country. Consequently, in addition to an increase in the joint welfare of the member countries, the non-member country's welfare will improve. That is, this narrow deep agreement is Pareto improving compared to the shallow agreement. The above results are summarized in the following propositions.

Proposition 2.8.1. A narrow deep agreement is viable if and only if the countries start from the least efficient shallow agreement.

Proof. See the appendix A.8 
Finally, we go back to the deep multilateral agreement. To check if the multilateral agreement improves the welfare of countries, we consider two scenarios: first we check how a deep multilateral trade agreement is going to affect the welfare of all the three countries; second, we check if there is an incentive for countries to move from the narrow deep agreement to the multilateral trade agreement. The results on lemma 2.6.1, 2.7.1 indicate that moving from the shallow agreements to the deep multilateral agreements increases the total welfare for all the countries. Furthermore, adding the results on lemma 2.8.1, 2.8.2 and proposition 2.8.1 indicate an increase in the total joint welfare of the member countries when they move from narrow deep to multilateral deep. Therefore, we can state the final result in the following proposition.

Proposition 2.8.2. Starting at the shallow trade agreement or the only viable narrow deep agreement:

(i) the deep multilateral trade agreement improves the welfare of all countries;

(ii) the deep multilateral agreement is equilibrium.

The above proposition indicates that the deep multilateral trade agreements are improving the welfare of all the three countries. It further suggests that when trade is in intermediate inputs, deep integration is not necessarily improving the welfare of the member countries. Therefore, the rise in preferential trade agreements cannot be only due to the rise in intermediate inputs, where it requires deep integration. In fact, under the setting presented in our model, when trade is in intermediate inputs, the deep integration is not necessarily improving the welfare of the non-member countries. Therefore, the narrow deep integration is not necessarily the best possible deep agreement when trade is intermediate inputs. 


\subsection{Conclusion}

In this chapter, we analyzed the need for deeper trade agreements when trades are in intermediate goods and whether trade in intermediate inputs can explain the reasons behind the proliferation of the PTAs in recent decades.

Our results show that when trade is in intermediate inputs, the inter-dependency between the trading parties requires agreements to be deeper than the conventional ones. Specifically, we showed that in the absence of deep integration, the volume of trade is inefficiently low. However, the deeper agreement not only increases the volume of trade, but it also increases the total welfare for each country.

Furthermore, we have shown that shallow trade agreements are stable. Then given the possible shallow integration, we let the countries join the bilateral narrow deep agreement. To be able to focus on the role of PTAs on a deep integration, we define the preferential trade agreement as an agreement that requires negotiation over behind-the-border policies among the member countries.

We assumed three possible border policy negotiations and kept them fixed through the narrow deep agreements. Under such conditions, the only potential narrow deep agreement we find is the one with the lowest shallow welfare levels. Therefore, we concluded that trade in intermediate inputs which are associated with a need for deeper trade agreements could not be the sole reason for the increase in the number of PTAs. 


\section{Chapter 3}

\section{Shallow, Narrow and Deep Trade Agreements with a Potential Hold-up Problem}

\subsection{Introduction}

As it was noted in the earlier chapter, the number of preferential trade agreements over past decades has significantly increased, and almost all the WTO members are now participating in at least one type of PTA. Although the Article XXIV of the General Agreement on Tariffs and Trade (GATT) has obliged the member countries to eliminate tariffs on "substantially all trade" among the members, the members of PTA do not always apply this restriction in their trade. Therefore, the question remains to answer is: what motivates countries to join these types of agreements? The latter question constitutes the core theme that we investigate in chapter 3 . 
Besides the increase in the number of PTAs, trade in intermediate inputs has increased in recent years as well. However, trade in intermediate inputs often are highly specialized and involves relation-specific investments. ${ }^{1}$. Antràs and Staiger [2012] argue that the rise in the offshoring has changed the way that terms-of-trade are determined. Since contracts between buyers and sellers of intermediate inputs is not fully enforceable, the terms-of-trade (international prices) are determined through bilateral bargaining between the trading parties. Therefore, there is a possibility of a hold-up problem, which leads to an underinvestment on the customized input trading between two countries when contracts are incomplete. Antràs and Staiger [2012] suggested that a deeper trade agreement could alleviate the hold-up problem. The authors used a two-country model where buyers and sellers of intermediate goods trade under imperfect contracts. That is, the trading parties bargain over the price of the input and further conclude that when the trade agreement is deep (covers both border and behind-the-border policies), the under-investment problem can be solved. Ornelas et al. [2018] have shown that when trade is in intermediate goods, and the contracts between the trading parties are incomplete, a deep PTA can solve the under-investment associated with the hold-up problem and potentially improve the welfare for the member countries. However, in both of the above studies, the imperfect contract between the buyer and seller of the intermediate good is only between two countries.

In this chapter, we continue answering the core question that we addressed in chapter 2 ; however, we introduce a hold-up problem to remain consistent with the literature on trade in intermediate inputs. In contrast with the standard conventions in literature, the hold-up problem is not the outcome of the incomplete contracts. Therefore, in this chapter, the international price of inputs is not determined through bargaining between the the buyers and sellers of input, which is the norm under the imperfect contract setting

\footnotetext{
${ }^{1}$ See, for example, Johnson and Noguera [2017], Antràs and Staiger [2012], and Baldwin [2014]
} 
between trading parties. More specifically, we assume that the hold-up problem arises from the fact that the input production in the exporting countries may require a sunk investment before the trade. For example, we can assume that the intermediate input production may require installation of capacity for a feasible production, and this capacity installation is irreversible.

Although the capacity requirement is distinguishable in the presence of renegotiation, to be able to compare the results from this chapter to those presented in chapter 2, we consider a static game. At the time of the policy determination (cooperative or noncooperative), the exporters of intermediate goods have already produced the input for the domestic and international consumption. Consequently, the home country can manipulate the price of imported inputs once the input production decision has been made. Our results indicate that an import tariff increases the production cost of the final-good in the home country, which leads to a decrease in the input demand by final-good producers. However, at this stage, the input producers have already produced their input, and all the production costs are sunk. Therefore, the input producers in input exporting countries consider the potential hold-up problem and under-invest on the level of input production.

Therefore the two main questions in this chapter, similar to the one in chapter 2, are:

- Does trade in intermediate inputs generate the need for deep integration?

- Does the deep integration need to be under preferential trade agreements or could be implied under multilateral trade agreements?

However, in this chapter, these questioned are going to be answered when there is a holdup problem possibility. Similar to the result in chapter 2, the Nash equilibrium border and behind-the-border policies are inefficiently high. We will further show that the welfare 
improved for all the countries when countries start negotiating over the border policies. However, under shallow integration behind-the-border policies are not negotiated, and we examine whether there is an incentive for the countries to deviate from the Nash level behind-the-border policies.

Moreover, we introduce the possibility that two of the countries sign a deep bilateral agreement, and we define it as a "narrow deep" bilateral agreement. The narrow deep agreement improves the joint welfare of the member countries; however, since the nonmember country chooses the behind-the-border policy unilaterally, it has an incentive to deviate from its shallow level behind-the-border policy to increase its welfare. In addition to that, the non-member deviation leads to lower joint welfare for the member countries. In this chapter, we can show that moving from an equilibrium shallow trade agreement, a narrow deep equilibrium is possible. That is, aside from the need for deep trade agreement when trade is in intermediate inputs, the potential hold-up problem gives an incentive to countries engaged in a narrow deep trade agreement.

Finally, we introduce the deep multilateral trade agreement, when all of the countries reduce their border and behind-the-border policies to zero and conclude that the welfare and input production levels for all of them improve under this type of agreement. This result leads us to conclude that the rise in the trade of intermediate input calls for deep negotiations. Although the hold-up problem in this chapter gives rise to the possible narrow deep agreements, deep agreements are still better implied under the multilateral trading system where all countries benefit from the trade agreement. Therefore, the inclusion of narrowly economic policies in PTAs cannot justify the rise in these types of arrangements.

This chapter contributes to trade agreements literature in three ways: First, by considering the international trade between final-good producers and input suppliers, we show that the policy choices of the government can affect the volume of trade and welfare in 
each country. Antràs and Staiger [2012] and Ornelas and Turner [2008] considered the impact of trade liberalization on the volume of trade when trade is in intermediate input. The authors studied a relationship-specific investment between the buyers and suppliers of the intermediate input that led to a hold-up problem and showed that trade agreements could alleviate the under-investment in the level of input that occurs in the presence of the hold-up problem. Ornelas and Turner [2008] examined the impact of international trade agreements when the policies under trade agreements are exogenous. Antràs and Staiger [2012] considered the effect of different types of trade agreements and the resulting optimal policies on the volume of trade. In this chapter, we abstract from the incompleteness of the contracts; thus, we ignore the possibility of the hold-up problem between the input buyers and sellers. We show that the nature of trade in intermediate goods in itself is sufficient to motivate countries to join trade agreements.

Our second contribution to the literature is through introducing the deep integration and emphasizing that there need to be more profound trade agreements under such conditions. Lawrence [2000] was the first to address the need for a deeper form of integration. The author noted that an increase in international production networks requires agreements that smooth the difficulties related to the national policies. Later on, Antràs and Staiger [2012] showed that the rise of offshoring, which is accomplished with the possibility of the hold-up problem, generates the need for deep trade agreements. Therefore, we also contribute to the literature on the role of WTO on liberalization. Antràs and Staiger [2012] used a two-country model and suggested that the WTO-member countries that experience an increase in the offshoring might seek preferential trade agreements as a way to achieve deep integration. More specifically, they concluded that the rise in offshoring and its implication for international price determination challenges the effectiveness of the current WTO approach toward liberalization. Therefore, countries that seek trade liberalization 
prefer to join the preferential trade agreement. However, to examine whether deep integration is achieved under the preferential trade agreement, we need to have a third country to see how a preferential trade agreement is affecting the member and non-member countries. In this chapter, we introduce such a three-country model and show that the need for deep integration cannot always be fulfilled through PTAs. That is, the deep integration through the multilateral trading system can benefit countries more.

Finally, this chapter contributes to the literature on the hold-up problem. There is a large number of studies that examine whether contractual arrangement can solve the hold-up problem and the associated under-investment (See for example Hart and Moore [1988], Chung [1991], and Rogerson [1992]). Some other studies suggest that the holdup problem that arises under international trad between the buyers and sellers of input can be solved with a proper trade agreement (Antràs and Staiger [2012], Ornelas and Turner [2008] and Ornelas et al. [2018]). In the literature, trading parties bargain over the price of traded intermediate goods and abstract from the market-clearing condition prices. However, in this chapter, we introduce a hold-up problem when the prices are determined through market clearing conditions. Therefore, we introduced the hold-up problem when the contracts are perfect between the trading parties.

Following the basic model presented in chapter 2, we have organized the remainder of this chapter as follows: in section 3.2, we outline the timing constraints in our model. Section 3.3 introduces deep multilateral trade agreements. In section 3.4, we consider the non-cooperative Nash equilibrium policies when countries unilaterally maximize their welfare. In section 3.5, we further introduce the shallow integration and show the improvement in the welfare of all countries when they negotiate over the border policies, given the Nash level behind-the-border policies. In section 3.6, we examine the possibility that two of the countries engage in a narrow deep bilateral agreement and examine if whether or not this 
type of agreement is viable. Section 3.7 concludes this chapter.

\subsection{Timing}

Suppose that the producers in input exporting countries, $i$ and $j$, first decide on the level of input with some expectations about the border and behind-the-border policies. Then the government in the home country imports the required level of input to produce the final-good. Therefore, the home country has the power to impact the price strategically and extract infra-marginal profits from country $i$ and $j$ by imposing import tariffs. However, since the inputs are already produced, the governments in countries $i$ and $j$ can only respond to home by imposing some production subsidies (behind-the-border policies). This particular timing generates a potential hold-up problem so that the final-good producers can manipulate the price through the import tariff, and impact the welfare of the exporting countries. In response, the government in countries $i$ and $j$ impose some production subsidies to compensate for the welfare loss.

The timing if the model is as follows:

- First, input levels are determined.

- Second, the border and behind-the-border policies are determined.

- Third, the border and behind-the-border policies are revealed, and the consumption and production of the final-good take place. 


\subsection{Deep Multilateral Trade Agreement}

Suppose that all the governments agreed to the free trade on both border and behind-theborder policies so that they set their policies as $\tau_{i}=\tau_{j}=0$ and $\sigma_{i}=\sigma_{j}=0$. It can be easily seen from the equations (2.10) and (2.11) that by implying free trade level policies the input production and demand for final-good and intermediate inputs become:

$$
\begin{aligned}
x & =\frac{\phi+\alpha-3 c}{4} \\
D\left(p_{\nu}^{\nu}\right) & =\frac{3 \phi-\alpha-c}{4} \\
D\left(p_{X}\right) & =\frac{\alpha-\phi-c}{2}
\end{aligned}
$$

From this point onward, for simplicity, we assume that the size of the final-good producing country is twice as big as the size of the input exporting countries (in terms of the finalgood $\mathrm{K}$ ), i.e $\alpha=2 \phi$. Therefore, the input levels and demand function can be rewritten as:

$$
x=\frac{3 \theta}{4}, \quad D\left(p_{X}\right)=\frac{\theta}{2}, \quad D\left(p_{\nu}^{\nu}\right)=\frac{\theta}{4} \quad \text { where } \quad \theta=\phi-c
$$

Finally, by substituting the equilibrium supply and demand for the intermediate inputs and final-good in equation (2.12), the free trade level of welfare for countries $i, j$, and $h$ are derived as $W^{i}=W^{j}=5 \theta^{2} / 16$ and $W^{h}=\theta^{2} / 8$ respectively.

The symmetry implies that each country acts as a final-good producer, who earns $W^{h}$ and at the same time acts as input producer for two different types of inputs $i$ and $j$ that earn $W^{i}$ and $W^{j}$ from producing and consuming those inputs. Therefore, the welfare of each country for all the good that it produces and consumes will be equal to the sum of 
the welfare from the final-good and intermediate good sectors

$$
W^{T}=W^{h}+W^{i}+W^{j}=3 \theta^{2} / 4
$$

\subsection{Non-cooperative Nash equilibrium}

In the absence of trade agreements, each country simultaneously chooses its border or behind-the-border policies to maximize its domestic welfare; the home country chooses $\tau_{i}$ and $\tau_{j}$ to maximize $W^{h}$, and country $i$ and $j$ choose $\sigma_{i}$ and $\sigma_{j}$ to maximize $W^{i}$ and $W^{j}$, respectively. Given the timing of the model, at the time that governments decide on their border or behind-the-border policies, the input producers in countries $i$ and $j$ have produced the input. Therefore, it is clear to see from equation (2.9) that the policies only have a direct effect on the prices. The optimal policies, $\tau_{i}\left(\tau_{j}\right)$ and $\sigma_{i}\left(\sigma_{i}\right)$ have to satisfy the following first-order conditions:

$$
\begin{gathered}
\frac{\partial W^{h}}{\partial \tau_{i}}=D\left(p_{X}\right)\left(1-\frac{\partial p_{X}}{\partial \tau_{i}}\right)-\left(\tau_{i}+\tau_{j}\right) \frac{\partial p_{X}}{\partial \tau_{i}}=0 \\
\frac{\partial W^{i}}{\partial \sigma^{i}}=-D\left(p_{i}^{i}\right)\left(\frac{\partial p_{i}}{\partial \sigma_{i}}+1\right)+x_{i} \frac{\partial p_{i}}{\partial \sigma_{i}}+\sigma_{i} \frac{\partial p_{i}}{\partial \sigma_{i}}=0
\end{gathered}
$$

The best response functions are as follow:

$$
\begin{aligned}
\tau_{i}^{R} & =\frac{2\left(x_{i}+x_{j}-\sigma_{i}-\sigma_{j}\right)-5 \tau_{j}}{5} \\
\sigma_{i}^{R} & =\frac{2\left(x_{i}+x_{j}-\sigma_{j}-\tau_{i}-\tau_{j}\right)}{5}
\end{aligned}
$$

Since countries are symmetric, we can impose symmetry on the policies. That is $\sigma_{i}=\sigma_{j}=\sigma$ and $\tau_{i}=\tau_{j}=\tau$. Therefore, the above equations can be rewritten as:

$$
\tau^{R}=\frac{x_{i}-x_{j}-2 \sigma}{5}
$$




$$
\sigma^{R}=\frac{2\left(x_{i}+x_{j}-2 \tau_{i}\right)}{7}
$$

By substituting $x_{i}$ and $x_{j}$ from equation (2.10), the best response policies can be derived as:

$$
\tau^{R}=\frac{\theta-\sigma}{4}, \quad \sigma^{R}=\frac{\theta-2 \tau}{2}
$$

Finally the Nash equilibrium level of border and behind-the-border policies are as:

$$
\tau^{N *}=\frac{\theta}{6}, \quad \sigma^{N *}=\frac{\theta}{3}
$$

It can be easily seen that $\frac{\partial^{2} W}{\partial \tau^{2}}<0$ and $\frac{\partial^{2} W}{\partial \sigma^{2}}<0$ holds and that the non-cooperative Nash policies are maximizing welfare for each country.

It is clear to see from the best response functions that $\frac{d \tau}{d \sigma}<0$. That is, if the home country reduces its import tariff, the response of the country $i(j)$ to this decrease is to raise its behind-the-border policy and increase the domestic demand to compensate welfare loss regarding their export. Similarly, if country $j(i)$ increases their consumption subsidy, the home demand for the input (and the final-good) will decrease, leading to the home country increasing its import tariff. Therefore, the border and behind-the-border policies are strategic substitutes.

Following the optimal non-cooperative Nash policies, import tariff, and consumption subsidy, we can find the equilibrium level of welfare, supply, and demand for intermediate and final-good. The following lemma (similar to the results presented in lemma 2.6.1) summarizes the impact of the deep multilateral trade agreement on welfare compared to the non-cooperative Nash equilibrium:

Lemma 3.4.1. The welfare effect of Nash equilibrium on each sector and country compared to deep multilateral trade is as follow: 


$$
\begin{aligned}
& \text { (i) } W_{h}^{N}<W_{h}^{M u l}, W_{i}^{N}<W_{i}^{M u l}, W_{j}^{N}<W_{j}^{M u l} \\
& \text { (ii) } \omega^{N} \equiv W^{N}-W^{M u l}<0 \\
& \text { (iii) } x^{N}=x^{M u l}
\end{aligned}
$$

Proof. See appendix B.1.

Although the level of intermediate input is the same under the deep multilateral agreement and the Nash equilibrium, the high level of the import tariffs and consumption subsidies lead to a lower welfare level for each country.

\subsection{Shallow Integration}

Under the shallow integration, all the countries negotiate over the border policies. Similar to the shallow integration in the previous chapter, we have considered three types of negotiation for the border policies:

- First, the border policies are chosen optimally by maximizing the joint welfare $W^{W}=$ $W_{h}+W_{i}+W_{j}, \tau_{\nu}^{s h} \equiv \arg \max _{\tau} W^{W}$, where $\nu \in\{i, j\}$.

- Second, the border policies are negotiated toward zero.

- Third, the border policies are negotiated to a level lower than non-cooperative Nash import tariffs, $\tau<\bar{\tau}$.

Similar to chapter 2, we assume that the behind-the-border policies are either fixed at their original non-cooperative Nash levels $\bar{\sigma}^{N}$, or individually determined by countries $i$ 
and $j$. That is, given the shallow level border policies, the government in countries $i$ and j re-optimize their behind-the-border policies following equation (3.4):

$$
\sigma^{R}(\tau)=\frac{2\left(x_{i}+x_{j}-2 \tau\right)}{7}
$$

It is clear from the above best response function that $\frac{d \sigma}{d \tau}<0$. Therefore, a decrease in the level of border policy $\tau$ leads to an increase in the behind-the-border policies. The intuition for this result comes from the fact that all three countries negotiate over the border policies; that is, the home country takes into account the potential impacts of its tariff on the welfare of countries $i$ and $j$. However, countries $i$ and $j$ determine their behindthe-border policies individually, and they only take into account their domestic welfare. Therefore, the government in the countries $i$ and $j$ manipulate their behind-the-border (consumption subsidy) to extract welfare from the home country further than the gains that shallow integration brings for them.

Following the equilibrium concept in chapter 2, we can define two sets of shallow integration strategies:

(i) Myopic shallow strategies: Under this scenario, the behind-the-border policies are fixed at the non-cooperative Nash levels, $\bar{\sigma}^{N}$. However, the border policies can be negotiated optimally at $\tau=\tau^{R}(\sigma)$, negotiated to zero $\tau=0$ or negotiated to a positive tariff level $\tau=\bar{t}<\bar{\tau}^{s h}$. Therefore, the Myopic outcomes can be shown as:

- $\Gamma_{m}^{s h}\left(\tau=\tau^{R}(\sigma), \sigma=\bar{\sigma}^{N}\right)$

- $\Gamma_{m}^{F}\left(\tau=0, \sigma=\bar{\sigma}^{N}\right)$

- $\Gamma_{m}\left(\tau=t, \sigma=\bar{\sigma}^{N}\right)$

(ii) Strategic shallow strategies: under this scenario, the behind-the-border policies are 
re-optimized in response to the negotiated border policies. Similarly, border policies are negotiated in three ways. Therefore, the strategic scenarios can be shown as:

- $\Gamma_{s}^{s h}\left(\tau=\tau^{R}(\sigma), \sigma=\sigma^{R}\left(\tau=\tau^{s h}\right)\right.$

- $\Gamma_{s}^{F}\left(\tau=0, \sigma=\sigma^{R}(\tau=0)\right)$

- $\Gamma_{s}\left(\tau=\bar{t}, \sigma=\sigma^{R}(\tau=t)\right)$

where $\Gamma_{m}^{s h}, \Gamma_{m}^{F}, \Gamma_{m}$ and $\Gamma_{s}^{s h}, \Gamma_{m}^{F}, \Gamma_{s}$ are the myopic and strategic shallow integration strategies when the border policies are determined optimally, negotiated to zero, and negotiated to a positive level less than non-cooperative Nash import tariffs, respectively. Starting from the first type of negotiations, the optimal policies $\tau_{i}\left(\tau_{j}\right)$ satisfy the following first-order condition:

$$
\begin{aligned}
\frac{\partial W_{W}}{\partial \tau_{i}}= & \left(p_{X}\right)\left(1-\frac{\partial p_{X}}{\partial \tau_{i}}\right)-D\left(p_{i}^{i}\right) \frac{\partial p_{i}^{i}}{\partial \tau_{i}}-D\left(p_{j}^{j}\right) \frac{\partial p_{j}^{j}}{\partial \tau_{i}}+\frac{\partial p_{i}}{\partial \tau_{i}} x_{i}+\frac{\partial p_{j}}{\partial \tau_{i}} x_{j} \\
& -\left(\tau_{i}+\tau_{j}\right) \frac{\partial p_{X}}{\partial \tau_{i}}+\sigma_{i} \frac{\partial p_{i}^{i}}{\partial \tau_{i}}+\sigma_{j} \frac{\partial p_{j}^{j}}{\partial \tau_{i}}=0
\end{aligned}
$$

The best response function can be derived as:

$$
\tau_{i}^{R}=-\left(\sigma_{i}+\sigma_{j}-\tau_{j}\right)
$$

The symmetry among countries implies that $\tau_{i}=\tau_{j}=\tau$ and $\sigma_{i}=\sigma_{j}=\sigma$, thus, the best response function can be rewritten as:

$$
\tau^{s h}=-\sigma^{s h}
$$

Therefore, it is clear from the above best response function that the optimal negotiated shallow border policy under both scenarios (myopic and strategic) is negative. That is the home country's optimal border policy is the import subsidy. Since the home country does 
not produce the input $i$ and $j$ which is required for its final-good production, the optimal policy is import subsidy instead of import tariff to boost the final-good production.

Let's define $r \equiv\left(\tau^{N}, \sigma^{N}\right)$ as the policy vector under the non-cooperative Nash equilibrium, then $\Delta \omega \equiv W(\Gamma)-W(r)$ is the changes of welfare for each country moving from the non-cooperative equilibrium to the shallow integration. The following lemma summarizes the details on the impact of shallow integration on each country:

Lemma 3.5.1. The impacts of strategic and myopic shallow integration on the welfare and volume of trade are as follow:

(i) The myopic shallow outcomes improve the welfare of each country, $\Delta \omega_{m}>0$.

(ii) The strategic shallow outcomes are not chosen over the non-cooperative Nash equilibrium.

(iii) The volume of trade has increased compared to the non-cooperative Nash levels, $\Delta x_{m}=x(\Gamma)-x(r)>0$.

Proof. See the appendix B.2

From the above lemma, it is straight forward to conclude that myopic outcomes improve the welfare of all countries. In fact, under the strategic shallow integration, the behind-theborder policies are higher compared to the non-cooperative Nash levels. Since countries $i$ and $j$ are individually chosen their behind-the-border policy, they set the behind-theborder inefficiently high and extract the welfare form the home country. However, the higher consumption subsidy increases the domestic demand and decrease the imported input demand of the home country. As a result, the welfare of all countries is adversely affected. However, once the border policies are negotiated, countries $i$ and $j$ might have 
the incentive to deviate from the myopic outcome and re-optimized their policies given the shallow border policies to earn higher welfare. Suppose country $i(j)$ deviates from $\sigma_{i}$ under the myopic integration, given that the negotiated border policies $\tau$ and the behind-theborder policy for country $j(i)$ remain at the shallow outcomes. Following equation (3.2), the best response function of the deviating country is as follow:

$$
\sigma_{i}^{d}=\frac{2\left(x_{i}+x_{j}-\sigma_{j}-2 \tau\right)}{5}
$$

We also examine the joint deviation of countries $i$ and $j$ for each myopic shallow integration scenario. Following equation (2.16), countries $i$ and $j$ could deviate from their myopic noncooperative behind-the-border policy given the negotiated border policies:

$$
\sigma^{N R}=\frac{2\left(x_{i}+x_{j}-2 \tau_{i}\right)}{7}
$$

The following lemma summarizes the impact of the unilateral and the joint deviation on the welfare of countries $i$ and $j$.

Lemma 3.5.2. Starting from a myopic shallow outcome, there is no incentive for unilateral or joint deviation from the non-cooperative Nash behind-the-border policies for countries $i$ and $j$.

Proof. see appendix B.3

It is clear from the above lemma that shallow integration is not possible under the strategic shallow scenario. In particular, strategic shallow, country $i(j)$ individually determines the domestic consumption subsidy without any consideration of its impact on the welfare of the other countries, and as a result, it could increase the welfare beyond the non-cooperative equilibrium. That is, a higher behind-the-border policy combined with the lower negotiated border policy results in higher welfare for country $i(j)$ compared to 
the myopic outcome. However, each country is a final-good producer and the producer of two different types of intermediate inputs. Therefore, the strategic shallow scenario with higher consumption subsidy and lower import tariff worsen off the welfare of the finalgood sector. Thus, the total welfare of each country is lower under the strategic shallow outcomes compared to the myopic shallow scenarios.

Proposition 3.5.1. Negotiated border policies under the shallow trade agreements, induce countries to raise their behind-the-border policy and improve their domestic welfare compared to the non-cooperative Nash levels only for their intermediate good sectors. Therefore, the only shallow equilibrium is obtained from the myopic outcomes.

Proof. See the appendix B.4

\subsection{Narrow deep integration}

In this section, we aim at examining whether the negotiation on the behind-the-border policies, a narrow deep integration, provides enough incentive to countries to sign preferential trade agreements. Suppose countries $i$ and $j$ start a bilateral narrow deep trade agreement and negotiate over the level of behind-the-border policy. The optimal negotiated behind-the-border policy $\sigma_{i}^{N D}$ has to satisfy the following first-order condition:

$$
\frac{\partial W_{i h}}{\partial \sigma_{i}}=-D\left(p_{X}\right) \frac{\partial p_{X}}{\partial \sigma_{i}}-\left(1+D\left(p_{i}^{i}\right)-\sigma_{i}\right) \frac{\partial p_{i}^{i}}{\partial \sigma_{i}}+x_{i} \frac{\partial p_{i}}{\partial \sigma_{i}}=0
$$

Therefore, the best response function can be derived as

$$
\left(\sigma_{i}^{N D}\right)^{R}=\frac{x_{i}+x_{j}-\sigma_{j}-8 \tau}{4}
$$


To focus on the role of the narrow deep negotiations on the formation of the bilateral trade agreements, we keep the border policy levels similar to the shallow agreements and examine the effects of negotiations of the behind-the-border policies on welfare.

Similar to the previous section, we will examine three scenarios:

- first, given the fixed shallow border policies, the behind-the-border policy of the member country is determined optimally as $\sigma_{i}^{N D} \equiv \arg \max _{\sigma} W_{i h}$;

- second, given the border policies, the member countries negotiate the behind-theborder policy to zero,

- finally, we allow discrimination over the border policies so that member countries negotiate over both border and behind-the-border policies and set them to zero.

Following the equilibrium concepts in chapter 2.4 , the non-member country can take two approaches to set its behind-the-border policy. First, the strategic narrow deep where country $j$ sets its behind-the-border policy $\sigma_{j}$ optimally as $\sigma_{j}^{R} \equiv \arg \max _{\sigma} W^{j}$; second, the myopic narrow deep where the behind-the-border policy remains fixed at shallow levels, $\bar{\sigma}^{s h}$. Throughout this chapter, we continue assuming that all three countries are participating in shallow integration, and then two of the countries choose to sign a bilateral narrow deep agreement. Therefore, to consider if countries have any incentive to form a deep bilateral agreement, we will start from the viable shallow agreements. We can summarize the strategic narrow deep and the myopic narrow deep strategies as follow:

(i) Starting from the shallow equilibrium $\left(\tau=\tau^{R}(\sigma), \sigma=\bar{\sigma}^{N}\right)$, the following narrow deep outcomes are possible: Given the border policies fixed at the shallow level policies $\bar{\tau}^{s h}<0$, the behind-the-border policies are either optimally determined as $\sigma_{i}=\sigma_{i}^{N D}$ 
or negotiated to zero, $\sigma_{i}=0$. However, the behind-the-border policies are either individually determined, $\sigma_{j}=\sigma_{j}^{R}\left(\tau, \sigma_{i}\right)$ or myopically set as shallow levels $\sigma_{j}=\bar{\sigma}^{s h}$, where $\bar{\sigma}^{s h}=\bar{\sigma}^{N}$. Therefore, the possible outcomes can be summarized as

- $\Gamma_{m}^{N D}\left(\tau=\bar{\tau}^{s h}, \sigma_{i}=\sigma_{i}^{N D}, \sigma_{j}=\bar{\sigma}^{s h}\right)$

- $\Gamma_{s}^{N D}\left(\tau=\bar{\tau}^{s h}, \sigma_{i}=\sigma_{i}^{N D}, \sigma_{j}=\sigma_{j}^{R}\left(\tau, \sigma_{i}\right)\right)$

- $\Gamma_{m}^{F}\left(\tau=\bar{\tau}^{s h}, \sigma_{i}=0, \sigma_{j}=\bar{\sigma}^{s h}\right)$

- $\Gamma_{s}^{F}\left(\tau=\bar{\tau}^{s h}, \sigma_{i}=0, \sigma_{j}=\sigma_{j}^{R}\left(\tau, \sigma_{i}\right)\right)$

(ii) Starting from the shallow agreement $\left(\tau=0, \sigma=\bar{\sigma}^{N}\right)$, the border policies remain zero as in the shallow. The behind-the-border policies among the member countries and the behind-the-border policy for the non-member country are determined through a similar procedure introduces in the previous case.

- $\Gamma_{m}^{N D}\left(\tau=0, \sigma_{i}=\sigma_{i}^{N D}, \sigma_{j}=\bar{\sigma}^{s h}\right)$

- $\Gamma_{s}^{N D}\left(\tau=0, \sigma_{i}=\sigma_{i}^{N D}, \sigma_{j}=\sigma_{j}^{R}\left(\tau, \sigma_{i}\right)\right)$

- $\Gamma_{m}^{F}\left(\tau=0, \sigma_{i}=0, \sigma_{j}=\bar{\sigma}^{s h}\right)$

- $\Gamma_{s}^{F}\left(\tau=0, \sigma_{i}=0, \sigma_{j}=\sigma_{j}^{R}\left(\tau, \sigma_{i}\right)\right)$

(iii) Following the shallow agreement $\left(\tau=t, \sigma=\bar{\sigma}^{N}\right)$, the following outcomes can be derived:

- $\Gamma_{m}^{N D}\left(\tau=\bar{t}^{s h}, \sigma_{i}=\sigma_{i}^{N D}, \sigma_{j}=\bar{\sigma}^{s h}\right)$

- $\Gamma_{s}^{N D}\left(\tau=\bar{t}^{s h}, \sigma_{i}=\sigma_{i}^{N D}, \sigma_{j}=\sigma_{j}^{R}\left(\tau, \sigma_{i}\right)\right)$

- $\Gamma_{m}^{F}\left(\tau=\bar{t}^{s h}, \sigma_{i}=0, \sigma_{j}=\bar{\sigma}^{s h}\right)$

- $\Gamma_{s}^{F}\left(\tau=\bar{t}^{s h}, \sigma_{i}=0, \sigma_{j}=\sigma_{j}^{R}\left(\tau, \sigma_{i}\right)\right)$ 
(iv) Following the shallow agreement $\left(\tau=\tau^{R}(\sigma), \sigma=\bar{\sigma}^{N}\right)$, the discriminatory narrow deep lead to a zero border and behind-the-border policy for the member countries, i.e. $\tau_{i}=0$ and $\sigma_{i}=0$. The border policies for the non-member countries remain the same as shallow, $\tau_{j}=\bar{\tau}^{s h}$ and the behind-the-border policies are chosen either strategically or myopically.

- $\Gamma_{m}^{D i s}\left(\tau_{i}=0, \sigma_{i}=0, \tau_{j}=\bar{\tau}^{s h}, \sigma_{j}=\bar{\sigma}^{s h}\right)$

- $\Gamma_{s}^{D i s}\left(\tau_{i}=0, \sigma_{i}=0, \tau_{j}=\bar{\tau}^{s h}, \sigma_{j}=\sigma_{j}^{R}\left(\tau_{i}, \tau_{j}, \sigma_{i}\right)\right)$

(v) Following the strategic shallow integration $\left(\tau=t, \sigma=\sigma^{N}\right)$, the narrow deep outcomes, similar to previous part, can be shown as

$$
\begin{aligned}
\text { - } \Gamma_{\bar{m}}^{D i s}\left(\tau_{i}=0, \sigma_{i}=0, \tau_{j}=\bar{t}, \sigma_{j}=\bar{\sigma}^{s h}\right) \\
\text { - } \Gamma_{\bar{s}}^{D i s}\left(\tau_{i}=0, \sigma_{i}=0, \tau_{j}=\bar{t}, \sigma_{j}=\sigma_{j}^{R}\left(\tau_{i}, \tau_{j}, \sigma_{i}\right)\right)
\end{aligned}
$$

In order to see whether countries $i$ and $h$ have an incentive to join to the narrow deep agreements, it is enough to compare the joint welfare for the member countries under this agreement with the one under shallow integration: that is $\left(W^{i h}\right)^{N D}>\left(W^{h}\right)^{s h}+$ $\left(W^{i}\right)^{s h}$. Since countries are the mirror image of each other, we only focus on a narrow deep agreement between a specific final-good producer and two intermediate good suppliers. However, the non-member country $j$ is not committed to any agreement regarding its behind-the-border policy and might have the incentive to deviate from the myopic shallow policies. This deviation could lead to lower joint welfare for the member countries, and subsequently, the narrow deep agreement under such circumstances is not viable. That is, knowing that the country $j$ would deviate from its shallow level behind-the-border policy, the member country will not engage in the narrow deep agreements. The details on the level of welfare for each narrow deep scenario is presented in the following lemma: 
Lemma 3.6.1. The following myopic outcome improves the joint welfare of the member countries:

(i) The non-discriminatory Myopic:

$\Gamma_{m}\left(\tau=\bar{t}, \sigma_{i}=\sigma^{N D}, \sigma_{j}=\bar{\sigma}^{s h}\right)$ and $\Gamma_{m}\left(\tau=0, \sigma_{i}=0, \sigma_{j}=\bar{\sigma}^{s h}\right)$

(ii) The discriminatory Myopic:

$\Gamma_{m}^{D i s}\left(\tau_{i}=0, \sigma_{i}=0, \tau_{j}=\bar{\tau}^{s h}, \sigma_{j}=\bar{\sigma}^{s h}\right)$ and $\Gamma_{m}^{D i s}\left(\tau_{i}=0, \sigma_{i}=0, \tau_{j}=\bar{t}^{s h}, \sigma_{j}=\bar{\sigma}^{s h}\right)$

Proof. See the appendix B.5

Proposition 3.6.1. Once the countries coordinate over a shallow agreement that lets them keep their behind-the-border policies at their non-cooperative Nash level, a narrow deep agreement that improves the welfare of member countries is possible.

Proof. See appendix B.6.

As it is noted in the above proposition, we can find narrow deep agreements under each possible shallow scenario. Therefore, countries $i$ and $j$ have an incentive to negotiate over the behind-the-border policy among each other, which leads to a level lower than the shallow (non-cooperative Nash) level. That is, this narrow deep agreement lets the government in the country $i$ reduce its consumption subsidy, which leads to an increase in the demand of country $h$. Although a lower consumption subsidy reduces the consumer and producer surplus in country $i$, the government earns higher revenue and consequently the total welfare in both countries will increase. Since the equilibrium shallow agreements are not from the first-best outcomes (the myopic outcomes), the possible narrow deep agreement is a second-best equilibrium. Therefore, if we restrict our model to the strategic outcome, the shallow integration is not going to be chosen over the Nash equilibrium from 
the first place; thus, the narrow deep agreements are not possible. Therefore, the question that might arise is whether countries engaged in deep integration under a multilateral setting?

Therefore, we need to check if the deep integration is viable under multilateral trade agreements. Following the results in section 3.3, we can conclude that the deep multilateral agreements can improve the welfare of all countries, and none of the countries have the incentive to deviate from those agreements.

Proposition 3.6.2. Although a deeper trade agreement under the preferential trade agreement improves the welfare of countries, countries are able to earn higher welfare with deeper multilateral trade agreement.

Proof. see the appendix B.7

As the above proposition suggests, the deep multilateral trade agreements are improving the welfare of all the three countries. Therefore, the narrow, deep integration is not necessarily the best possible deep agreement. Countries can improve their welfare by committing to a deep agreement under the multilateral trading system.

\subsection{Conclusion}

In this chapter, we further introduced the possibility of a hold-up problem when trade is in intermediate inputs. However, in contrast with the literature, we did not assume an imperfect contract setting between the buyers and sellers of the intermediate input. We considered that the production of the intermediate input requires some capacity installation for feasible production. Consequently, at the time that government in the final-good 
producers in one country and the input producers in another country decide on their border or behind-the-border policies, the intermediate input has been produced. Therefore, the final-good producers can hold intermediate input sellers by imposing border policies. Since the input production is fixed, the input producer countries try to alleviate the impact of the border policies by imposing behind-the-border policies.

Similar to chapter 2 , we analyzed the need for deeper trade agreements when trades are in intermediate goods. Our first set of results indicated that when trade is intermediate input, in the absence of deep integration, the volume of trade is inefficiently low. However, the deeper agreement not only increases the volume of trade, but it also increases the total welfare for each country.

We have further shown that under the shallow integration, given the fact that countries are allowed to keep their behind-the-border policies at non-cooperative Nash levels, the welfare of countries improves. We have also introduced, the possibility that two of the countries start a bilateral narrow deep agreement and negotiate over the level of behindthe-border policies and concluded that a deeper trade agreement is possible under the preferential trade agreement.

However, a deep trade agreement is not at its efficient level under the preferential trade agreements. That is, a deeper negotiation under the multilateral trade system is the most efficient equilibrium outcome for all of the countries.

We further focused on the need for input production before the determination of the policies to insert the hold-up possibility into our model. However, we plan to build a new model in the future to introduce stronger assumptions for the hold-up problem, since the need for capacity and the sunk cost associated with it is more distinguished in a dynamic setting game which allows renegotiation into the model. 


\section{Chapter 4}

\section{Trade Agreements and the Endogenous Structure of Multinational Firms}

\subsection{Introduction}

Trade in intermediate inputs has been increasing in recent decades. Using OECD inputoutput table, Miroudot and Lanz [2011] have shown that trade in intermediate inputs has been growing at an average of $6.2 \%$ for goods and 7\% for services between 1995 and 2006 . Similarly, Ramanarayanan [2007] has concluded that in the late 1990s, intermediate goods have comprised about $60 \%$ of total international merchandise trade for many of industrial economies. Although many papers study trade in intermediate goods, very little work has been done on the role of trade agreements when trade is also in intermediate inputs. Trade in intermediates takes two forms: outsourcing and foreign direct investment (FDI). The 
former occurs when a firm imports its required intermediate inputs from an independent supplier, and the latter happens when the firm obtains its intermediate inputs from a wholly-owned subsidiary. Based on data from the U.S. Census Bureau in 2009, 47\% of the U.S. imports are in intermediate goods. The share of intra-firm transactions (FDI) in U.S. imports of intermediate goods is $46 \%$, and the share of arm's-length trade (outsourcing) is around 52\% (Miroudot and Lanz [2011]). Given this, it is crucial to understand what makes firms choose one of the approaches mentioned above, their decision-making process, and the impact of a given decision on the enterprise.

Chisik and Davies [2004] have studied the impact of tax treaties on the size of the bilateral foreign direct investment (FDI) activity between two countries. While the authors have not considered the organizational choice of the firms, their study shows that the existence of different tax systems motivates countries to change the size of the FDI ownership.

The General Agreement on Tariffs and Trade (GATT) and World Trade Organization (WTO) were mainly designed to reduce tariffs among member governments, and they have been successful in reducing them through several rounds of negotiations. Other than import tariffs, there are several non-tariff trade barriers to trade flows. These barriers are categorized into two groups: border non-tariff measures (such as import quotas, import licensing, export taxes and subsidies), and behind-the-border non-tariff measures (such as domestic legislation on production, internal taxes, and domestic subsidies). Although the member countries do not negotiate over the level of non-tariff policies directly, the GATT/WTO contains several obligations to limit the use of various forms of this kind of policy. The GATT/WTO's lack of approach toward behind-the-border policies is called shallow integration. Hence, GATT/WTO members always choose the unilaterally optimal level of behind-the-border policies. However, trade in intermediate inputs does not always 
generate efficient policy choices by trading parties. The incomplete contract between buyers and sellers of intermediate inputs can impact the volume of trade in the intermediate goods and negotiation of trade measures other than the border policies or what is known as deep integration, which can induce the optimal level of inputs (Staiger [2012]). Therefore, given the rise in trade in intermediate inputs, it is reasonable to ask whether GATT/WTO treatment should move toward deep integration.

To answer this question, we adopt the following general framework. Let us consider a partial equilibrium environment with two small countries, home and foreign, who trade an intermediate input. All final-good producers are located in the home country, and production of the final-good requires imported inputs from the foreign country (input suppliers).

The intermediate inputs are specifically produced for the production of the final-good; this leads to a relationship-specific investment between the two parties. Final-good producers have two alternatives for obtaining the necessary amount of intermediate inputs. They can import intermediate goods from an independent supplier and engage in arm's-length trade, or they can import it from a wholly-owned subsidiary in the foreign country and engage in an intra-firm trade. When the final-good producers outsource their input, they have to pay a fixed cost (such as search cost) to find a suitable intermediate input supplier. Because of international transactions and different judicial systems, the contract between two parties is hard to enforce. As a result, the ex-ante contracts are not enforceable, and the international terms of trade between the buyers and sellers of the intermediate inputs are determined by bilateral negotiations and are not controlled by market-clearing conditions. On the other hand, with intra-firm trade, there is more control over the process of input investments, and the supply of intermediate goods exactly meets its demand. Therefore, the contract is perfect, and there is no chance of a hold-up problem, and consequently, no 
under-investment happens. However, production may be more costly due to a higher need for supervision. In addition to that, the associated fixed cost, composed of the expenses of searching for an appropriate input supplier, and the costs of setting up an organization, generates higher fixed cost compared to outsourcing it.

To overcome the under-investment problem, final-good producers and intermediate input suppliers sign trade agreements, determining the particular level of import subsidization; moreover, this gives an incentive to foreign suppliers to invest and provide the required level of intermediate inputs. Intuitively, the optimal trade policies under the trade agreement act as a tool to solve the under-investment problem that exists in outsourcing. Since there is no inefficiency when final-good producers choose FDI, trade policies do not affect the associated investment level.

Ornelas and Turner [2011] investigate the importance of import tariffs on intermediate goods on ownership choice, and they find that unilateral trade policies on inputs improve social welfare by mitigating the hold-up problem. Government intervention can lead to an inefficient organizational choice toward outsourcing.

Several authors have studied the optimal sourcing decisions and organizational form in an international context; most notably Helpman [2006], Grossman and Helpman [2003], and Ornelas and Turner [2008]. Chen et al. [2012] explore the choice between outsourcing and FDI by focusing on the nature of the capital required by the subsidiary. The authors differentiate between physical and knowledge-based capital and further conclude that firms that are more physical capital intensive tend to engage in outsourcing while firms that are more knowledge capital intensive tend to own a subsidiary.

In this chapter, we focus on two critical features of trade in intermediate inputs. First, introducing endogenous trade policies on intermediate inputs trade has an impact on the 
ownership trade-off of firms. The difference in governance costs and production costs provides some incentives for multinational firms to switch the ownership and gain higher profit. Therefore, trade taxes and policies, as a source of cost differences between the trading countries, have an impact on the firm's choice of ownership. We will further focus on the production cost differences as the main difference in firms' ownership and introduce trade tax differences to analyze the impact on ownership.

Second, the nature of trade in intermediate goods raises the question whether the rules and norms of the General Agreement on Tariffs and Trade (GATT) and its successor the World Trade Organization (WTO), which are mainly for final-goods, are still appropriate when so much trade is in intermediate goods. We show that trade between intermediate input suppliers and buyers involves opportunistic behavior that can lead to an inefficient trade volume of the intermediate inputs. To eliminate this inefficiency trade agreement should go beyond the expected GATT/WTO final-good international trade policies.

The results presented in this chapter follow the work of Antras and Staiger (2012). The authors studied trade agreements in the presence of offshoring. They further showed that trade agreements provide enough motivation for trading parties to overcome underinvestment in intermediate goods. Moreover, by comparing Nash policies with policies under trade agreements, they find that the role of the trade agreements is different from what the literature represents and further conclude that in the presence of offshoring the deep integration is needed.

There are two significant differences between the work that we present in this chapter and that of the Antràs and Staiger [2012]. First, we consider vertical foreign direct investment as alternative ownership for final-good producers in the home country. Particularly, the final-good producers import intermediate inputs within their boundaries and engage in intra-firm trade. Second, we assume that the contract between a parent firm and its 
foreign subsidiary is perfect. As a result of that, there is no under-investment on the level of intermediate inputs, and international terms of trade between two parties satisfy the market-clearing conditions. As a result, this has an impact on the requirements for deep integration.

The first result of this chapter shows that both the final-good producers' profit and welfare increases with trade agreements, motivating the final-good producers to choose outsourcing over FDI ownership. Regardless of organizational type, final-good producers find it optimal to impose behind-the-border policies to manipulate the price of the finalgood and, consequently, the profit of their trading parties. Intuitively, the need for deep integration is not limited to the case of outsourcing with imperfect contracts between buyers and sellers.

The second result of this chapter investigates an endogenous choice between outsourcing and FDI in the presence of deep trade agreements. We show trading in intermediate goods, and the interdependence of buyers and sellers in any organizational choice requires negotiations behind-the-border policies. Although the input investment under outsourcing is inefficiently low, the extra cost (fixed and production cost) associated with the FDI ownership makes some final-good producers choose outsourcing over FDI.

The remainder of this chapter is organized as follows: in section 4.2, we present the base model of organizational production choice where we introduce foreign direct investment into the framework of Antràs and Staiger [2012]. In section 4.3, we study the impact of deep trade agreements on the ownership choice. Section 4.4 describes the shallow trade policies where behind-the-border policies are determined unilaterally. In section 4.5, we study the Nash equilibrium trade policy options when governments maximize their national welfare. Finally, we discuss the motives and roles of trade agreements under each of the ownership category. Section 4.6 concludes the chapter. 


\subsection{Basic Structure}

Consider an economy with two small countries, home and foreign, and a large rest of the world. Consumers in the home and foreign country have identical preferences over a given final-good and a numeraire good, represented by:

$$
U^{j}=c_{0}^{j}+\nu\left(c_{1}^{j}\right) \quad \nu^{\prime}>0, \nu^{\prime \prime}<0
$$

where $c_{0}^{j}$ is the consumption of the numeraire good that is traded freely and enters linearly into the utility function. The production of one unit of the numeraire good requires one unit of labor, and the market for this good is perfectly competitive with the wages being normalized to one in both countries. The labor supply in both countries is sufficient so that there is positive numeraire production in both countries. The consumption of the finalgood, $c_{1}^{j}$, increases the utility at a diminishing rate, that is $v^{\prime}>0, v^{\prime \prime}<0$. The demand function for each good is given by $c_{1}^{j}=D\left(P_{1}^{H}\right)$ and $c_{0}^{j}=E-P_{1} D\left(P_{1}\right)$, respectively, where $D($.$) is the inverse of u^{\prime}() ;$.$E is the total income of a representative consumer and P_{1}$ represents the price of the final-good.

Production of the final-good requires intermediate inputs using the technology function $y(x)=\sqrt{x}$, which transform inputs to the final-goods. Suppose that the home country is allocated with a unit measure of the final-good producers, while the foreign country is allocated with a unit measure of intermediate inputs suppliers. The final-good producers in the home have no market power; that is, the price of the final-good is determined in the world market. The quantity of the final-good is set such that the world price of the final-good is equal to one.

The final-good producers in home obtain inputs from the foreign input suppliers, and they have two alternatives: they can either outsource the required inputs from independent 
foreign suppliers or import them from the wholly-owned subsidiaries in the foreign country. In the former, the home producers and foreign suppliers engage in an arm's-length trade, and the provided inputs are customized to the need of buyers and have no value to other producers. In the latter, two parties are involved in international intra-firm trade or FDI ownership.

The nature of the bilateral contract between buyers and sellers of intermediate goods is different under each of the alternatives. Under outsourcing, contracts are incomplete and not enforceable ex-ante, and intermediate inputs, suppliers can hold up the final-good producers. The cost of the input investment will be sunk at the time of the contract, and as a result of that, the foreign suppliers may increase the price of the input. The price of the input is not determined through the market, and contract parties bargain over the price and surplus. With FDI, however, ownership final-good producers and input suppliers are supervised under one entity and contracts between them are complete, and market-clearing conditions determine the price of the traded intermediate goods.

\subsection{Deep Trade Agreement}

\subsubsection{Deep Free Trade}

We start by analyzing what organizational type would a final-good producer choose when intermediate inputs and final-goods are traded at no cost. Due to incomplete contracts, the price at which the intermediate inputs are sold to buyers is determined ex-post; thus, input

suppliers under-invest on the intermediate goods. Outsourcing is leading to an inefficiently low volume of input trade that can be eliminated if the final-good producers choose FDI. The equilibrium ownership is characterized by sub-game perfect equilibrium based on the 
following stages:

Stage 1: Final-good producers decide on the ownership structure, and pay the fixed cost associated with each type.

Stage 2: The level of intermediate inputs is determined by (a) foreign suppliers in outsourcing; (b) home headquarters in FDI.

Stage 3: The share of surplus for each party is decided by (a) bargaining in outsourcing; (b) previous agreement in FDI.

Stage 4: The final-good producers import the input and produce the final-good and payments are paid as agreed upon in stage 3.

The timing in the model is slightly different based on the type of ownership. Under outsourcing, in the second stage, foreign input suppliers decide on the level of investment in intermediate inputs. In stage 3 , buyers and sellers bargain over the price of the intermediate inputs and the level of joint surplus. However, under FDI, in stage 2, each of the multinational firms decides on the input investment level. In stage 3 , the profit of the multinational firms will be divided between the parents and their subsidiaries.

In stage 4 , the final-good has been produced and sold at a home price $P_{1}$ (since there is no cost to trading $P_{1}^{H}=P_{1}^{F}=P_{1}$ ). Now consider that a final-good producer outsources intermediate inputs, and in stage 3, the final-good producer and input supplier bargain over the price of inputs and their surplus. The Nash bargaining problem, which is the solution to Rubinstein bargaining model, is as follows:

$$
\max _{p_{x}}\left(P_{1} y(x)-p_{x} x\right)^{\alpha}\left(p_{x} x\right)^{(1-\alpha)}
$$


Where $P_{1}$ is the price of the final-good, $p_{x}$ is the price of the input, and $\alpha$ and $(1-\alpha)$ are the bargaining powers for the final-good producer and the supplier of the intermediate inputs, respectively. The above problem is solved to find the bargaining price of input which is equal to:

$$
p_{x}=\frac{(1-\alpha) P_{1} y(x)}{x}
$$

The share of the final-good producer from the joint surplus will be equal to $\alpha P_{1}^{H} y(x)$, and the share of the foreign input supplier will be $(1-\alpha) P_{1}^{H} y(x)$. Moving back to the second stage, the foreign input supplier decides on the level of input investment by maximizing his profit:

$$
\max _{x}(1-\alpha)\left(P_{1} y(x)\right)-x
$$

The marginal cost of intermediate inputs is assumed to be one. The first-order condition of the above problem is then equal to $P_{1} y^{\prime}(x)=\frac{1}{1-\alpha}$. With $y(x)=\sqrt{x}$ and $P_{1}=1$, the input level provided by the foreign supplier under outsourcing will be equal to:

$$
x_{O}=\frac{(1-\alpha)^{2}}{4}
$$

The profit function for the home final-good producer, in equilibrium, is presented as:

$$
\pi_{H}^{O}=\alpha\left(P_{1}^{H} y(x)\right)-F_{O}=\alpha\left(\frac{1-\alpha}{2}\right)-F_{O}
$$

where $F_{O}$ is the fixed cost associated with the outsourcing, which is considered to be the cost of searching for an appropriate input supplier.

Under FDI, however, the total profit of the multinational firm distributed between parent and its foreign subsidiary with fractions $\beta$ and $1-\beta$, respectively. Going back to stage 2 , the level of input investment is determined by maximizing the total profit of the 
multinational firm as follow:

$$
\max _{x} \mathrm{P}_{1}^{H} y(x)-\lambda x-F_{F D I}
$$

Where $\lambda$ is the marginal cost of the input production in the foreign subsidiary; as a result of higher supervision in the FDI ownership, the input production has a higher marginal cost compared to the outsourcing. As the marginal cost of production under outsourcing is equal to one, to show the marginal cost under FDI is higher, we can set $\lambda>1 . F_{F D I}$ is the fixed cost involved with the setting up of a foreign subsidiary, and it is considered to be higher than $F_{O}$. The first-order condition of equation (4.5) gives $P_{1}^{H} y^{\prime}(x)=\lambda$, and with the production function represented as $y(x)=\sqrt{x}$, the equilibrium level of input will be equal to $x_{F D I}=\frac{1}{4 \lambda^{2}}$. The final-good producer in home earns a fraction of $\beta$ of the total profit, shown below:

$$
\pi_{H}^{F D I}=\beta\left(P_{1}^{H} y(x)-\lambda x-F_{F D I}\right)=\beta\left(\frac{1}{4 \lambda}-F_{F D I}\right)
$$

Finally, in the first stage, the final-good producer decides on the ownership structure. The final-good producer chooses outsourcing over FDI if the profit is higher when the required input is outsourced, $\pi_{H}^{O}>\pi_{H}^{F D I}$. This can be rewritten as:

$$
\alpha\left(\frac{1-\alpha}{2}\right)-F_{O}>\beta\left(\frac{1}{4 \lambda}-F_{F D I}\right)
$$

The final-good producer's profit and its organizational structure depending on the fixed cost, marginal cost, and share of the surplus. The result of the above equations is summarized in the following proposition.

Proposition 4.3.1. Under free trade, the final-good producers choose outsourcing over FDI iff $\frac{\beta}{2 \lambda}+2\left(F_{O}-\beta F_{F D I}\right) \leq \alpha(1-\alpha) \forall \alpha \in(0,1)$. 
Proof. See the appendix C.1

Intuitively, under free trade, FDI is chosen only when the share of fixed cost for the final-good producers is less than what they should pay as outsourcing (fixed) search cost. As $\beta$ increases, the share of the fixed cost under the FDI becomes larger compared to the outsourcing, and the final-good producers choose FDI if $F_{O}-\beta F_{F D I}<\frac{\beta}{2 \lambda}$. With $F_{F D I}>F_{O}$ this condition holds only for small FDI marginal cost, $\lambda \in(1,2)$.

World welfare that is the sum of the home and foreign social welfare is presented based on the organizational type of the final-good producers as:

$$
\begin{gathered}
W_{O}^{W}=C S^{H}\left(P_{1}^{H}\right)+C S^{F}\left(P_{1}^{F}\right)+\pi_{H}^{O}+\pi_{F}^{O}=C S^{H}\left(P_{1}^{H}\right)+C S^{F}\left(P_{1}^{F}\right)+\frac{1-\alpha}{2}-\frac{(1-\alpha)^{2}}{4}-F_{O} \\
W_{F D I}^{W}=C S^{H}\left(P_{1}^{H}\right)+C S^{F}\left(P_{1}^{F}\right)+\pi_{H}^{F D I}+\pi_{F}^{F D I}=C S^{H}\left(P_{1}^{H}\right)+C S^{F}\left(P_{1}^{F}\right)+\frac{1}{4 \lambda}-F_{F D I}
\end{gathered}
$$

Under the free trade and with a fixed price for final-goods, the consumers's surplus remains the same for each ownership type. Therefore, world welfare is higher under outsourcing if the producers' surplus is higher compared to FDI. That is $W_{O}^{W}>W_{F D I}^{W}$ if $\pi_{H}^{O}+\pi_{F}^{O}>\pi_{H}^{F D I}+\pi_{F}^{F D I}$

Proposition 4.3.2. Under free trade, world welfare is always higher if final-good producers choose to outsource.

Proof. See the appendix C.2

The above proposition indicates that although outsourcing the level of the investment on input is less than what firms can get under the FDI, the higher fixed cost and production cost associated with the FDI lead to a lower level of world welfare. 


\subsubsection{Deep Integration}

We can further study the impact of deep trade agreements on the ownership structure of final-good producers. We consider two sets of policy instruments: the border and behind-

the-border policies. Let $\tau_{x}^{H}$ and $\tau_{x}^{F}$ be the trade tax (border policy) on intermediate inputs imposed by the home and foreign country, respectively. Moreover, assume that the home country imposes a behind-the-border policy $\tau_{1}^{H}$ on the final-good. The timing of the model is then as follows:

Stage 1: Final-good producers decide on the ownership type, and pay the fixed cost associated with each type.

Stage 2: The social planner selects $\tau_{1}^{H}$ on the final-good, and $\tau_{x}^{H}$ on the home import of the intermediate inputs, and $\tau_{x}^{F}$ on the foreign export of the inputs.

Stage 3: The level of intermediate input is determined: (a) by the foreign supplier under outsourcing; (b) by home headquarter under FDI.

Stage 4: The share of surplus for each party is decided by (a) bargaining in outsourcing; (b) previous agreement in FDI.

Stage 5: The final-good producers import the input and produce the final-good, and payments are paid as agreed on in stage 4 .

The backward induction follows the same procedure as in the previous case. Suppose a final-good producer chooses outsourcing to produce the final-good and needs to buy intermediate inputs. Thus, after finding an appropriate input supplier, the two trading parties bargain over the price of input and the level of joint surplus. The Nash bargaining 
problem is then presented as:

$$
\max _{P_{x}}\left(\left[1+\tau_{1}^{H}\right] y(x)-p_{x} x-\tau_{x} x\right)^{\alpha}\left(p_{x} x\right)^{[1-\alpha]}
$$

where the price of the final-good is now equal to $1+\tau_{1}^{H}$ and $\tau_{x}=\tau_{x}^{H}+\tau_{x}^{F}$ is the trade cost of intermediate input. The main reason behind considering the sum of trade policies on intermediate goods is that in the world welfare, it is only the sum that matters. The resulting joint surplus would be equal to $\left(1+\tau_{1}^{H}\right) y(x)-\tau_{x} x$. Based on this surplus, the foreign input supplier decides on the level of input such that it maximizes his profit:

$$
\max _{x}\left((1-\alpha)\left(\left(1+\tau_{1}^{H}\right) y(x)-\tau_{x} x\right)-x\right)
$$

The first-order condition and the equilibrium level of input are equal to:

$$
\begin{gathered}
(1-\alpha)\left(1+\tau_{1}^{H}\right) y^{\prime}(x)=(1-\alpha) \tau_{x}+1 \\
x_{O}=\frac{\left((1-\alpha)\left(1+\tau_{1}^{H}\right)\right)^{2}}{4\left((1-\alpha) \tau_{x}+1\right)^{2}}
\end{gathered}
$$

The level of input under outsourcing ownership depends on trade taxes on intermediate inputs and the behind-the-border policy on the final-good. The final-good producer imports $x_{O}$ and produce the final-good and earn:

$$
\pi_{H}=\alpha\left(\left(1+\tau_{1}^{H}\right) y(x)-\tau_{x} x\right)-F_{O}
$$

However, when the final-good producer chooses to offshore input under the FDI ownership from a wholly-owned subsidiary, contracts are perfect, and the multinational firm earns $\left(1+\tau_{1}^{H}\right) y(x)$ by selling the final-good. The cost of production for each unit is the sum of marginal cost, $\lambda$, and the trade tax on input. Therefore, the total profit of the multinational firm becomes:

$$
\pi_{F D I}=\left(1+\tau_{1}^{H}\right) y(x)-\left(\tau_{x}+\lambda\right) x-F_{F D I}
$$


The multinational firm determines the level of input by maximizing the above total profit. Then first-order condition and the resulting input investment are:

$$
\begin{gathered}
\left(1+\tau_{1}^{H}\right) y^{\prime}(x)-\left(\tau_{x}+\lambda\right)=0 \\
x_{F D I}=\frac{\left(1+\tau_{1}^{H}\right)^{2}}{4\left(\tau_{x}+\lambda\right)^{2}}
\end{gathered}
$$

The profit is distributed between the final-good producer and its subsidiary by share of $\beta$ and $(1-\beta)$, respectively. Therefore, the parent firm in the home country and the foreign affiliate earn the following profits:

$$
\begin{gathered}
\pi_{H}^{F D I}=\beta\left(\left(1+\tau_{1}^{H}\right) y(x)-\left(\tau_{x}+\lambda\right) x-F_{F D I}\right) \\
\pi_{F}^{F D I}=(1-\beta)\left(\left(1+\tau_{1}^{H}\right) y(x)-\left(\tau_{x}+\lambda\right) x-F_{F D I}\right)
\end{gathered}
$$

In the second stage, the optimal trade policies are determined by maximizing the world trade welfare. The home and foreign welfare under outsourcing are given by:

$$
\begin{gathered}
W_{O}^{H}=C S^{H}\left(P_{1}^{H}\right)+\pi_{H}+\tau_{1}^{H}\left[D_{1}\left(P_{1}^{H}\right)-y(x)\right]+\tau_{x}^{H} x \\
W_{O}^{F}=C S^{H}\left(P_{1}^{H}\right)+\pi_{F}+\tau_{x}^{F} x
\end{gathered}
$$

The world welfare which is the sum of home and foreign social welfare is given by:

$$
W_{O}^{W}=W_{O}^{H}+W_{O}^{F}=C S^{H}\left(P_{1}^{H}\right)+C S^{F}\left(P_{1}^{F}\right)+y(x)+\tau_{1}^{H} D_{1}\left(P_{1}^{H}\right)-x-F_{O}
$$

The world welfare is a function of border and behind-the-border policies. The efficient level of polices, $\tau_{1}^{H}$ and $\tau_{x}$ are determined from the following first order conditions:

$$
\begin{gathered}
\frac{\partial W^{W}}{\partial \tau_{1}^{H}}: \frac{\partial x}{\partial \tau_{1}^{H}}\left(y^{\prime}(x)-1\right)+\tau_{1}^{H} \frac{\partial D 1\left(P_{1}^{H}\right)}{\partial P_{1}^{H}}=0 \\
\frac{\partial W^{W}}{\partial \tau_{x}}:\left(y^{\prime}(x)-1\right) \frac{\partial x}{\partial \tau_{x}}=0
\end{gathered}
$$


A simple analysis of the equations (4.9), (4.11) and (4.12) shows the optimal policies as:

$$
\begin{gathered}
\tau_{1}^{H}=0 \\
\tau_{x}=\frac{-\alpha}{1-\alpha}
\end{gathered}
$$

The world welfare under the FDI is given by:

$$
W_{F D I}^{W}=C S^{H}\left(P_{1}^{H}\right)+C S^{F}\left(P_{1}^{F}\right)+y(x)+\tau_{1}^{H} D\left(P_{1}^{H}\right)-\lambda x-F_{F D I}
$$

The efficient level of policies under the FDI is simply obtained through the following firstorder conditions:

$$
\begin{gathered}
\frac{\partial W^{W}}{\partial \tau_{1}^{H}}: \frac{\partial x}{\partial \tau_{1}^{H}}\left(y^{\prime}(x)-\lambda\right)+\tau_{1}^{H} \frac{\partial D_{1}\left(P_{1}^{H}\right)}{\partial P_{1}^{H}}=0 \\
\frac{\partial W^{W}}{\partial \tau_{x}}:\left(y^{\prime}(x)-\lambda\right) \frac{\partial x}{\partial \tau_{x}}=0
\end{gathered}
$$

Using equations (4.10), (4.15) and (4.16) the following optimal policies can be derived:

$$
\begin{gathered}
\tau_{1}^{H}=0 \\
\tau_{x}=0
\end{gathered}
$$

With the optimal level of policies, it is straight forward to get the foreign supplier's level of investment as: $x^{O}=\frac{1}{4}$ and $x^{F D I}=\frac{1}{4 \lambda^{2}}$ under the outsourcing and FDI, respectively. Following these investment levels, the final-good producer earns $\pi_{O}^{H}=\alpha \frac{2-\alpha}{4(1-\alpha)}-F_{O}$ by choosing outsourcing and $\pi_{F D I}^{H}=\beta\left(\frac{1}{4 \lambda}-F_{F D I}\right)$ by FDI.

Back to the first stage, the final-good producer decides on its type of ownership by comparing the profit under each case. That is, the final-good producer chooses the outsourcing over FDI if $\pi_{O}^{H}>\pi_{F D I}^{H}$. The condition for choosing outsourcing over FDI is then presented as:

$$
\frac{\alpha(2-\alpha)}{4(1-\alpha)}-F_{O}>\beta\left(\frac{1}{4 \lambda}-F_{F D I}\right)
$$


Proposition 4.3.3. Under the optimal negotiated trade policy (i) with $\beta F_{F D I}-F_{O}-$ $\frac{\beta}{4 \lambda}>0$ final-good producers are better off by choosing outsourcing over FDI $\forall \alpha$, (ii) with $\beta F_{F D I}-F_{O}-\frac{\beta}{4 \lambda}<0$, the final-good producers choose outsourcing only if their bargaining power $\alpha$ is large enough.

It is easy to show that there exists a threshold for the final-good producers' bargaining power, $\bar{\alpha}$, where the final-good producers with a larger bargaining power choose outsourcing over FDI. The question that may arise here is whether signing trade agreements have an impact on this threshold. Since trade policies under deep integration are the same as those under free trade for firms with FDI ownership, to answer this question, it is enough to compare the final-good producers' profit who choose to outsource under free trade and trade agreements. The following proposition summarizes the answer to this:

Proposition 4.3.4. Outsourcing is chosen over FDI for a wide range of parameter values under optimal deep integration.

Proof. See the appendix C.4

Introducing optimal constrained trade policies solves the under-investment problem of outsourcing. Consequently, in the presence of trade agreements some firms that did not involve in outsourcing before finding outsourcing more profitable and, thus, the bargaining power threshold will decrease.

Finally, we compare the world welfare under the two cases of outsourcing and FDI. The world welfare would be higher under the outsourcing ownership if $W_{O}^{W}>W_{F D I}^{W}$. The world welfare, considering the efficient level of policies, is represented as:

$$
W_{O}^{W}=C S^{H}\left(P_{1}^{H}\right)+C S^{F}\left(P_{1}^{F}\right)+\frac{1}{4}-F_{O}
$$




$$
W_{F D I}^{W}=C S^{H}\left(P_{1}^{H}\right)+C S^{F}\left(P_{1}^{F}\right)+\frac{1}{4 \lambda}-F_{F D I}
$$

Therefore, outsourcing leads to higher world welfare if:

$$
\frac{1-\lambda}{4 \lambda}<F_{F D I}-F_{O}
$$

Proposition 4.3.5. In the presence of negotiated trade policies, world welfare is always higher under outsourcing ownership.

Proof. See the appendix C.5

The world welfare for final-good producers who choose FDI remains unchanged under

the free trade and efficient trade policies. A comparison of $W_{O}^{W}$ between free trade and negotiated trade policies indicates a higher level of world welfare is linked to the latter case. Thus, signing trade agreement between trading parties leads to an increase in the outsourcing ownership and the level of the world welfare.

\subsection{The shallow Trade Agreement}

\subsubsection{Shallow Free Trade}

We can further analyze the ownership structure of firms under the shallow consideration; that is, final-good producers and intermediate inputs suppliers only negotiate over the border policies, and final-good producers can unilaterally decide on the behind-the-border policies. The comparison between shallow and deep type of policies can answer the questions about the application of shallow versus deep integration.

Following the conventions of section 4.3 we start with the free trade equilibrium. Under shallow free trade, the trade in intermediate inputs is free. However, the final-good 
producer decides on the level of policy on the final-good unilaterally. The timing of the model is similar to the case of deep free trade; the only difference is that after the first stage, the home country selects a behind-the-border policy, $\tau_{1}$, on the final-good. Using a similar approach, under outsourcing, the trading parties bargain over the price of intermediate goods and their joint surplus. The Nash bargaining problem and the associated joint surplus is as follow:

$$
\begin{gathered}
\max _{p_{x}}\left(\left(1+\tau_{1}^{\mathrm{H}}\right) \mathrm{P}_{1} \mathrm{y}(\mathrm{x})-\mathrm{p}_{\mathrm{x}} \mathrm{x}\right)^{\alpha}\left(\mathrm{p}_{\mathrm{x}} \mathrm{x}\right)^{(1-\alpha)} \\
\alpha\left(1+\tau_{1}^{H}\right) P_{1} y(x)
\end{gathered}
$$

Moving back one stage, the foreign input supplier decides on the level of input investment by maximizing its profit:

$$
\max _{x}(1-\alpha)\left(1+\tau_{1}^{\mathrm{H}}\right) \mathrm{P}_{1} \mathrm{y}(\mathrm{x})-\mathrm{x}
$$

The optimal level of input investment is derived as:

$$
x_{O}=\frac{(1-\alpha)^{2}\left(1+\tau_{1}^{H}\right)^{2}}{4}
$$

Similarly, the headquarter of the multinational firm, under FDI, decides on the level of intermediate inputs by maximizing the total profit:

$$
\begin{gathered}
\pi_{O}^{H}=\alpha\left(1+\tau_{1}^{H}\right) y(x)-F_{O}=\frac{\alpha(1-\alpha)\left(1-\tau_{1}^{H}\right)^{2}}{2}-F_{O} \\
\max _{x}\left(1+\tau_{1}^{\mathrm{H}}\right) \mathrm{P}_{1} \mathrm{y}(\mathrm{x})-\lambda \mathrm{x}-\mathrm{F}_{\mathrm{FDI}}
\end{gathered}
$$

The level of investment is further derived as:

$$
x_{F D I}=\frac{\left(1+\tau_{x}^{H}\right)^{2}}{4 \lambda^{2}}
$$


Under the shallow free trade, the level of intermediate good depends on the behind-theborder policy. The final-good producer imports the intermediate input and produces the final-good. The associated profit under outsourcing and FDI is shown as:

$$
\begin{gathered}
\pi_{O}^{H}=\alpha\left(1+\tau_{1}^{H}\right) y(x)-F_{O}=\frac{\alpha(1-\alpha)\left(1-\tau_{1}^{H}\right)^{2}}{2}-F_{O} \\
\pi_{F D I}^{H}=\beta\left(\left(1+\tau_{1}^{H}\right) y(x)-\lambda x-F_{F D I}\right)=\beta\left(\frac{\left(1+\tau_{1}^{H}\right)^{2}}{4 \lambda}-F_{F D I}\right)
\end{gathered}
$$

In the second stage, the home country sets $\tau_{1}^{H}$ unilaterally by maximizing the home welfare function. For simplicity, we consider the final-good is only produced and consumed in the home country. Thus, home welfare is presented as:

$$
W_{O}^{H}=C S^{H}\left(P_{1}\right)+\pi_{O}^{H}+\tau_{1}^{H} D_{1}\left(P_{1}\right)=C S^{H}+\alpha\left(1+\tau_{1}^{H}\right) y(x)-F_{O}+\tau_{1}^{H} D_{1}\left(P_{1}\right)
$$

By using the first-order condition of the latter equation, the unilateral behind-the-border policy can be shown as:

$$
\tau_{1}^{H}=-1+\frac{2}{\alpha(1-\alpha)+\alpha(1-\alpha)^{2}-2}<-1
$$

Similarly, the home welfare and the level of behind-the-border policy under the FDI become:

$$
\begin{gathered}
W_{F D I}^{H}=C S^{H}\left(P_{1}\right)+\beta \frac{\left(1+\tau_{1}^{H}\right)^{2}}{4 \lambda}-\beta F_{F D I}+\tau_{1}^{H} D_{1}\left(P_{1}\right) \\
\tau_{1}^{H}=-\frac{\beta}{2 \lambda-\beta}
\end{gathered}
$$

Regardless of the ownership, the sign of the behind-the-border policy is negative, which leads to a lower level of intermediate inputs and profit for final-good producer. Also, the final-good producer can manipulate the price of the final-good to extract bargaining surplus from foreign suppliers. As a result of that, under outsourcing, the final-good producer sets $\tau_{1}^{H}$ such that the price of the final-good becomes negative. That is, outsourcing is not 
possible with shallow free trade. A multinational firm (with prohibited behind-the-border policy) can choose shallow free trade when $\pi^{\text {shallow }}>\pi^{\text {deep }}$. A comparison of these two cases indicates that final-good producer earns a higher profit under deep free trade. The above results are summarized in the following proposition:

Proposition 4.4.1. (i) The only possible type of ownership under shallow free trade is FDI;

(ii) A multinational firm always prefers deep free trade.

Proof. See the appendix C.6

\subsubsection{Shallow Integration}

We can further analyze the firm's ownership structure under shallow integration. Particularly, home final-good producers and foreign input suppliers only negotiate over the border policies, while behind-the-border policies are determined unilaterally by the home country. The timing of the model will be as follows:

Stage 1: final-good producers decide on the ownership type and pay the fixed cost associated with each type.

Stage 2: Social planner selects $\tau_{x}^{H}$ on the home import of intermediate inputs, and $\tau_{x}^{F}$ on the foreign export of the inputs.

Stage 3: Home country observes $\tau_{x}^{H}$ and $\tau_{x}^{F}$ and then chooses $\tau_{1}^{H}$ on the final-good.

Stage 4: The share of surplus for each party is decided by: (a) bargaining in outsourcing; (b) previous agreement in FDI. 
Stage 5: The final-good producers import the input and produce the final-good and payments are paid as agreed on in stage 4 .

To characterize the equilibrium, we start by analyzing the case of outsourcing. Taking a similar approach, the joint surplus would be equal to $\left(1+\tau_{1}^{H}\right) y(x)-\tau_{x} x$. Based on this surplus, the foreign input supplier maximizes his profit; the level of input investment in this stage is equal to the one on the deep integration. Moving back to stage 3 , the home country decides on the level of $\tau_{1}^{H}$. Home welfare function is shown as:

$$
W_{H}=C S^{H}\left(P_{1}^{H}\right)+\alpha\left(\left(1+\tau_{1}^{H}\right) y(x)-\tau_{x} x\right)-F_{O}+\tau_{1}^{H} D_{1}\left(P_{1}^{H}\right)+\tau_{x}^{H}
$$

The following reaction function can be derived using the first-order condition of the above welfare function:

$$
\tau_{1}^{H}\left(\tau_{x}^{h}, \tau_{1}^{F}\right) \equiv \tau_{1}^{H}\left(\tau_{x}\right)=-\frac{\alpha y(x)}{\frac{\partial D}{\partial P_{1}}}>0
$$

Back to the second stage, social planner decides on the border policies by maximizing the world welfare:

$$
W^{W}=C S^{H}+C S^{F}+\left(1+\tau_{1}^{H}\left(\tau_{x}\right)\right) y(x)-x-F_{O}+\tau_{1}^{H}\left(\tau_{x}\right) D\left(P_{1}\right)
$$

Using the first order conditions from the equation (4.9) and (4.21) we can derive the following equilibrium policies:

$$
\begin{gathered}
\tau_{x}=-\frac{\alpha\left(\alpha^{2}-2 \alpha+3\right)}{2(1-\alpha)}<0 \\
\tau_{1}^{H}=\frac{\alpha(1-\alpha)}{2-\alpha\left(\alpha^{2}-2 \alpha+3\right)-\alpha(1-\alpha)}>0
\end{gathered}
$$

Similarly, following the same procedure for firms with FDI ownership we have:

$$
\tau_{1}^{H}=\frac{\beta}{2 \beta^{2}-2 \beta+\lambda}
$$




$$
\tau_{x}=\frac{\beta(2 \beta-1)}{2}
$$

It is easy to show that, final-good producers under outsourcing prefer deep integration;

that is, they earn higher profits. Under FDI, the home country always sets $\tau_{1}^{H}$ ¿0 to ensure gain for both the parent and its subsidiary. When the home share of total profit is large enough, however, the foreign country set taxes on intermediate input trade to decrease the earnings for the final-good producer, which can impact the profit of the finalgood producers. That is final-good producers with a small share of surplus prefer shallow integration. The above results are summarized in the following proposition:

Proposition 4.4.2. The credibility of deep versus shallow integration depends on the organizational structure of final-good producers.

The above proposition indicates that the multinational firms with a small share of surplus prefer to sign trade agreements on traded goods while being able to set the behindthe-border policies unilaterally. This shallow integration compensates for the lower share of profit and motivates the intra-firm trade.

\subsection{Non-cooperative Nash Policies}

In this section, we integrate the unilateral trade policy choices of the home and foreign governments and compare the resulting Nash equilibrium policies to those negotiated efficient policies. Comparing optimal Nash policies with the negotiated one reveals the role and importance of trade agreements. The timing of the model is similar to the one in section 4.4. The only difference here is that in stage two, the home government selects a behind-the-border policy $\tau_{1}^{H}$ on the final-good and trade tax $\tau_{x}^{H}$ on the imported input; 
simultaneously, the foreign government selects a trade $\operatorname{tax} \tau_{x}^{F}$ on the exported input. The home welfare under outsourcing is represented as:

$$
W_{O}^{H}=C S^{H}\left(P_{1}^{H}\right)+\alpha\left[\left(1+\tau_{1}^{H}\right) y(x)-\tau_{x} x\right]-F_{O}+\tau_{1}^{H}\left[D_{1}\left(P_{1}^{H}\right)-y(x)\right]+\tau_{x}^{H} x
$$

The home country unilaterally decides on its trade policies by maximizing the welfare function; then the first-order conditions are derived as:

$$
\begin{gathered}
\frac{\partial W^{H}}{\partial \tau_{1}^{H}}: \tau_{1}^{H} \frac{\partial D_{1}}{\partial P_{1}^{H}}-(1-\alpha) y(x)+\left[\left(\alpha\left(1+\tau_{1}^{H}\right)-\tau_{1}^{H}\right) y^{\prime}(x)-\alpha\left(\tau_{x}^{H}+\tau_{x}^{F}\right)+\tau_{x}^{H}\right] \frac{\partial x}{\partial \tau_{1}^{H}}=0 \\
\frac{\partial W^{H}}{\partial \tau_{x}^{H}}:(1-\alpha) x+\left[\left(\alpha-(1-\alpha) y^{\prime}(x)+(1-\alpha) \tau_{x}^{H}-\alpha \tau_{x}^{F}\right] \frac{\partial x}{\partial \tau_{x}^{H}}=0\right.
\end{gathered}
$$

Given the foreign country trade policy, the best response policy functions in the home country are given by :

$$
\begin{gathered}
\left(\tau_{1}^{H}\right)^{B R}=-\frac{(1-\alpha) x\left[\frac{y(x)}{x}-y^{\prime}(x)\right]}{\left|\frac{\partial D\left(P_{1}^{H}\right)}{\partial P_{1}^{H}}\right|} \\
\left(\tau_{x}^{H}\right)^{B R}=-\frac{\alpha-(1-\alpha) \tau_{1}^{H} y^{\prime}(x)}{1-\alpha}-\frac{x}{\frac{\partial x}{\partial \tau_{x}^{H}}}+\frac{\alpha \tau_{x}^{F}}{1-\alpha} \\
\left(\tau x^{F}\right)^{B R}=-\frac{\alpha x}{\frac{\partial x}{\partial \tau_{x}^{F}}}
\end{gathered}
$$

Given $y(x)=\sqrt{x}$ and $x_{O}=\frac{(1-\alpha)^{2}\left(1+\tau_{1}^{H}\right)^{2}}{4\left((1-\alpha) \tau_{x}+1\right)^{2}}$, the best response functions can be written as:

$$
\begin{gathered}
\left(\tau_{1}^{H}\right)^{B R}=\frac{-\frac{1}{4}(1-\alpha)^{2}}{1+(1-\alpha) \tau_{x}+\frac{1}{4}(1-\alpha)^{2}} \\
\left(\tau_{x}^{F}\right)^{B R}=\frac{\alpha}{(1-\alpha)(2-\alpha)}+\frac{\alpha}{2-\alpha} \tau_{x}^{H} \\
\left(\tau_{x}^{H}\right)^{B R}=\frac{-2 \alpha}{1-\alpha^{2}}+\frac{1}{2}+\frac{1-\alpha}{1+\alpha} \tau_{x}^{F}
\end{gathered}
$$




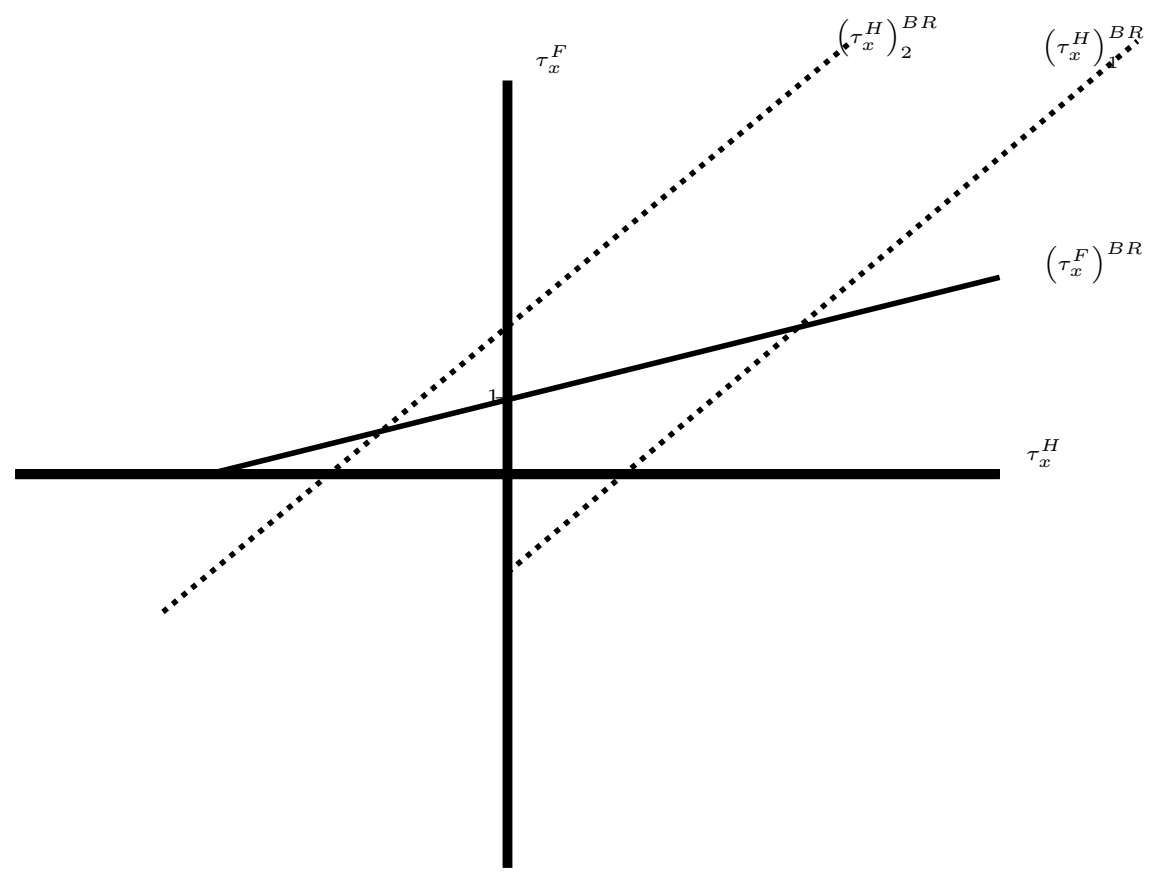

Figure 4.1: Best response function of trade policies under outsourcing.

The above equations indicate that the optimal level of behind-the-border policy on the final-good depends on the sum of the home and foreign country taxes on input and the bargaining power. Therefore to find out the sign of $\tau_{1}^{H}$, it is necessary first to determine the sign of $\tau_{x}$. The Nash input trade tax $\tau_{x}$ is, therefore, is determined using the $\left(\tau_{x}^{F}\right)^{B R}$ and $\left(\tau_{x}^{H}\right)^{B R}$.

It can be seen from figure 4.5 that the foreign export policy is always positive, but the home import trade policy on intermediate goods can be positive or negative. The intercept of the home's best response function depends on $\alpha$. That is, the Nash trade policy on input is positive with small enough bargaining power and negative otherwise ( with $\alpha<0.41$, $\tau_{x}>0$ and with $\left.\alpha>0.41, \tau_{x}<0\right)$. Thus, the sum of these policies, $\tau_{x}$, can be either 
positive or negative, depending on the bargaining power. However, we can easily show that the sign of the behind-the-border policy on the final-good is always negative.

The same procedure can be followed for the case of FDI ownership. The home welfare function is presented as: Intuitively, the level of trade tax on intermediate goods depends on the bargaining power of the final-good producers. Under outsourcing, a final-good producer seeks to obtain an appropriate amount of intermediate inputs and earns profit from selling the final product. Therefore, the unilateral trade policies are imposed to motivate the intermediate suppliers to invest efficiently. However, the fact that the surplus is shared between the two trading parties, and the surplus depends on the price of the final-good, motivates the home country to impose some production subsidies to reduce the price of the final-good.

$$
W_{F D I}^{H}=C S^{H}\left(P_{1}^{H}\right)+\beta\left[\left(1+\tau_{1}^{H}\right) y(x)-\left(\tau_{x}+\lambda\right) x-F_{F} D I\right]+\tau_{1}^{H}\left[D_{1}\left(P_{1}^{H}\right)-y(x)\right]+\tau_{x}^{H} x
$$

Then the Nash policies are derived form the following first order conditions:

$$
\begin{gathered}
\frac{\partial W^{H}}{\partial \tau_{1}^{H}}: \tau_{1}^{H} \frac{\partial D_{1}\left(P_{1}^{H}\right)}{\partial P_{1}^{H}}-(1-\beta) y(x)+\left[\left(\beta-(1-\beta) \tau_{1}^{H}\right) y^{\prime}(x)+(1-\beta) \tau_{x}^{H}-\lambda \beta-\beta \tau_{x}^{F}\right] \frac{\partial x}{\partial \tau_{1}^{H}}=0 \\
\frac{\partial W^{H}}{\partial \tau_{x}^{H}}:(1-\beta) x+\left[\left(\beta-(1-\beta) \tau_{1}^{H}\right) y^{\prime}(x)+(1-\beta) \tau_{x}^{H}-\beta \lambda-\beta \tau_{x}^{F}\right] \frac{\partial x}{\partial \tau_{x}^{H}}=0
\end{gathered}
$$

For a given value of foreign trade policy the best response functions are given as:

$$
\begin{gathered}
\left(\tau_{1}^{H}\right)^{B R}=-\frac{(1-\beta) x\left(\frac{y(x)}{x}-y^{\prime}(x)\right)}{\left|\frac{\mid \partial D_{1}}{\partial P_{1}^{H}}\right|} \\
\left(\tau_{x}^{H}\right)^{B R}=-\frac{\left(\beta-(1-\beta) \tau_{1}^{H}\right) y^{\prime}(x)}{1-\beta}-\frac{x}{\frac{\partial x}{\partial \tau_{x}^{H}}}+\frac{\beta \lambda}{1-\beta}+\frac{\beta \tau_{x}^{F}}{1-\beta}
\end{gathered}
$$

Simultaneously, a foreign country unilaterally set its trade policy by maximizing its welfare, and as a result, the following is derived as:

$$
\left(\tau_{x}^{F}\right)^{B R}=-\frac{\beta x}{\frac{\partial x}{\partial \tau_{x}^{F}}}
$$




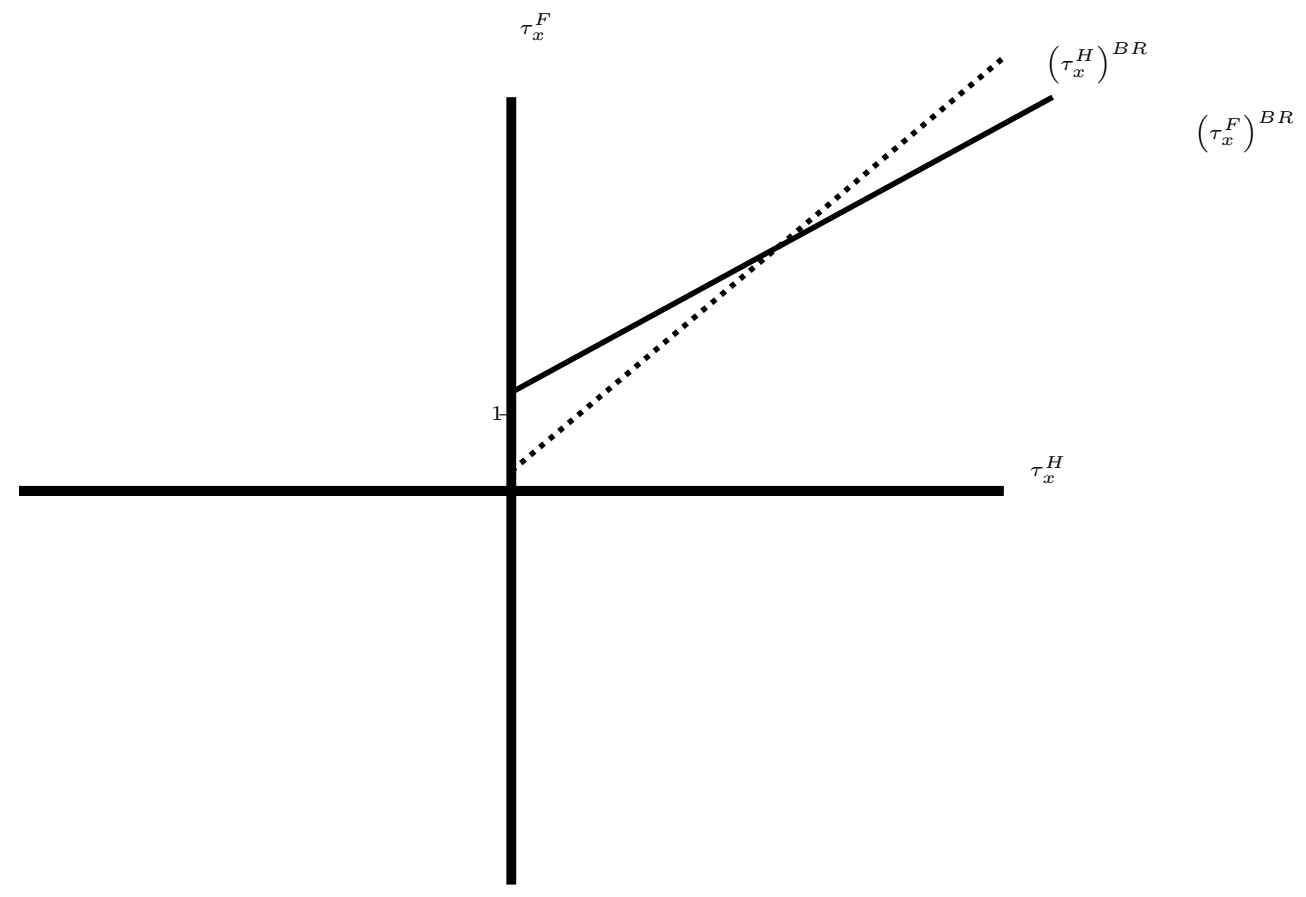

Figure 4.2: Best response function of trade policies under FDI.

Given $y(x)=\sqrt{(x)}$ and $x_{F D I}=\frac{1}{4}\left(\frac{1+\tau_{1}^{H}}{\tau_{x}+\lambda}\right)^{2}$, the above best response functions can be written as:

$$
\begin{gathered}
\left(\tau_{1}^{H}\right)^{B R}=\frac{-\frac{1}{4}(1-\beta)}{\tau_{x}+\lambda+\frac{1}{4}(1-\beta)} \\
\left(\tau_{x}^{F}\right)^{B R}=\frac{\beta}{2-\beta} \tau_{x}^{H}+\frac{\beta}{2-\beta} \lambda \\
\left(\tau_{x}^{H}\right)^{B R}=\frac{-(1-\beta)}{2(1+\beta)}+\frac{\beta(1-\beta)}{(1+\beta)(2-\beta)} \lambda+\frac{\beta(1-\beta)}{(1+\beta)(2-\beta)} \tau_{x}^{F}
\end{gathered}
$$

The Nash input trade tax $\tau_{x}$ is determined using the $\left(\tau_{x}^{F}\right)^{B R}$ and $\left(\tau_{x}^{H}\right)^{B R}$. The figure below shows the Nash policy: 
As can be seen in the above figure, the sign of the unilateral Nash trade taxes imposed by the home and foreign governments is positive. In particular, with perfect contracts between parent firms and their foreign subsidiaries and no under-investment on input, trading parties in the home and foreign country seek for some revenue by imposing import tariff and export tax, respectively.

Finally, the sign of the behind-the-border policy remains negative, as in the case of outsourcing. Although the parent firms and their subsidiaries are under one entity, the fact that they have to share their profit gives an incentive to the final-good producers to extract marginal profits from their foreign affiliates.

Therefore, regarding the ownership structure, the Nash behind-the-border policies make the price of the final product inadequately low; moreover, the trade taxes on input under FDI would be higher than optimal levels. Thus, comparing the results with the one from the previous section indicates the role that trade agreements play on fixing the inefficiencies associated with unilateral trade policies. The above results are summarized as follows:

Proposition 4.5.1. The Nash unilateral policies can be categorized in two groups:

(i) Border Nash policies that depend on the organizational type. (a) Under the outsourcing, the home country imposes import tariff if its bargaining power is less than a threshold, $\alpha<\alpha$, and imposes import subsidy otherwise. Simultaneously, the foreign country imposes an export tax on the intermediate inputs. (b) Under the FDI, the home country imposes an import tariff on input, while simultaneously, the foreign country imposes an export tax.

(ii) Behind-the-border Nash policies. Regarding the ownership of final-good producers, the home county sets production subsides on the final-good. 
Proposition 4.5.1 indicates the existence of the under-investment associated with outsourcing will invoke import subsidization when the bargaining power is large enough and will set import tariffs with small enough bargaining to gain some revenue. Moreover, the trade taxes on input under FDI would be higher than optimal levels. However, regardless of the ownership structure, the Nash behind-the-border policies make the price of the final product inadequately low.

The trade agreements liberalize the behind-the-border policies under both types of ownership and direct the border policies toward the optimal levels. Therefore, it is reasonable to conclude that trade agreements under GATT/WTO should move toward deep integration. The reasons behind the need for deep integration are the nature of intermediate goods and how the two trading parties are attached. However, as proposition 4.3.5 states, WTO shallow integration can still be applicable for firms with FDI ownership and with a small share of the surplus. This can be referred to as FDI in developing countries.

\subsection{Conclusion}

In this chapter, we studied the impacts of endogenous trade policies on the organizational structure of firms. If the required input is ideally provided with FDI ownership, then the final-good producers can avoid hold-up problems associated with outsourcing and choose the FDI. However, our results show that the extra cost linked to intra-firm trade leads to outsourcing and remains as an alternative for the final-good producers. Furthermore, the introduction of the trade agreements solves the under-investment problem associated with outsourcing. Therefore, all other factors remain the same, the final-good producers choose to outsource the inputs.

Our work is also related to the recent literature on the consideration of deep integration 
by the GATT/WTO (Antràs and Staiger [2012], Blanchard [2010] and Blanchard [2015]). Although our findings are consistent with those in literature, our main result indicates that deep integration is needed no matter what organizational type a firm chooses. The deep integration is not limited to the case of imperfect contracts, and the nature of trade in intermediate goods requires the need for the behind-the-border intervention.

We further focus mainly on the general form of the vertical FDI and how this alternative is affected by trade agreements. However, the fact that FDI has been increasing in recent years invites the question of whether distinguishing between greenfield and mergers and acquisition types of FDI impacts the decision of the final-good producers, and what would be the role of trade agreements in this new environment? 


\section{References}

Robert D Anderson, Anna Caroline Müller, and Philippe Pelletier. Regional trade agreements \& procurement rules: Facilitators or hindrances? Robert Schuman Centre for Advanced Studies Research Paper No. RSCAS, 81, 2015.

Pol Antràs and Robert W Staiger. Offshoring and the role of trade agreements. American Economic Review, 102(7):3140-83, 2012.

Kyle Bagwell, Chad P Bown, and Robert W Staiger. Is the wto passé? Journal of Economic Literature, 54(4):1125-1231, 2016.

Richard Baldwin. Wto 2.0: Governance of 21st century trade. The Review of International Organizations, 9(2):261-283, 2014.

Emily J Blanchard. Reevaluating the role of trade agreements: Does investment globalization make the wto obsolete? Journal of International Economics, 82(1):63-72, 2010.

Emily J Blanchard. A shifting mandate: international ownership, global fragmentation, and a case for deeper integration under the wto. World Trade Review, 14(1):87-99, 2015.

Theresa Tracey Helen Carpenter and Andreas Lendle. How preferential is world trade? Technical report, Graduate Institute of International and Development Studies, Centre for ..., 2010. 
Yongmin Chen, Ignatius J Horstmann, and James R Markusen. Physical capital, knowledge capital, and the choice between fdi and outsourcing. Canadian Journal of Economics/Revue canadienne d'économique, 45(1):1-15, 2012.

Richard Chisik and Ronald B Davies. Asymmetric fdi and tax-treaty bargaining: theory and evidence. Journal of Public Economics, 88(6):1119-1148, 2004.

Tai-Yeong Chung. Incomplete contracts, specific investments, and risk sharing. The Review of Economic Studies, 58(5):1031-1042, 1991.

Yose Rizal Damuri. How preferential are preferential trade agreements? Technical report, Graduate Institute of International and Development Studies, 2012.

Federico J Díez. The asymmetric effects of tariffs on intra-firm trade and offshoring decisions. Journal of International Economics, 93(1):76-91, 2014.

Gene M Grossman and Elhanan Helpman. Outsourcing versus fdi in industry equilibrium. Journal of the European Economic Association, 1(2-3):317-327, 2003.

Oliver Hart and John Moore. Incomplete contracts and renegotiation. Econometrica: Journal of the Econometric Society, pages 755-785, 1988.

Elhanan Helpman. Trade, fdi, and the organization of firms. Journal of economic literature, 44(3):589-630, 2006.

Craig L Jackson. Social policy hamonization and worker rights in the european union: A model for north america. NCJ Int'l L. \& Com. Reg., 21:1, 1995.

Robert C Johnson and Guillermo Noguera. A portrait of trade in value-added over four decades. Review of Economics and Statistics, 99(5):896-911, 2017. 
Robert Z Lawrence. Regionalism, multilateralism, and deeper integration. Brookings Institution Press, 2000.

James R Markusen. The boundaries of multinational enterprises and the theory of international trade. Journal of Economic perspectives, 9(2):169-189, 1995.

S Miroudot and R Lanz. Intra-firm trade: Patterns, determinants and policy implications. Technical report, OECD Trade Policy Working Papers, 2011.

Sébastien Miroudot, Rainer Lanz, and Alexandros Ragoussis. Trade in intermediate goods and services. 2009.

Alen Mulabdic, Alberto Osnago, and Michele Ruta. Deep integration and UK-EU trade relations. The World Bank, 2017.

Emanuel Ornelas and John L Turner. Trade liberalization, outsourcing, and the hold-up problem. Journal of International Economics, 74(1):225-241, 2008.

Emanuel Ornelas and John L Turner. Protection and international sourcing. The Economic Journal, 122(559):26-63, 2011.

Emanuel Ornelas, John L Turner, and Grant Bickwit. Preferential trade agreements and global sourcing. Available at SSRN 3270993, 2018.

Ananth Ramanarayanan. Imported inputs and international trade dynamics. Technical report, Citeseer, 2007.

William P Rogerson. Contractual solutions to the hold-up problem. The Review of Economic Studies, 59(4):777-793, 1992. 
Kamal Saggi, Woan Foong Wong, and Halis Murat Yildiz. Should the wto require free trade agreements to eliminate internal tariffs? Journal of International Economics, 118: 316-330, 2019.

WTO Secretariat. World trade report 2011: The wto and preferential trade agreements: From co-existence to coherence. Geneva: World Trade Organization, 2011.

Robert W Staiger. Non-tariff measures and the wto. Economic Research and Statistics Division Working Paper, (2012-01), 2012.

Robert W Staiger and Alan O Sykes. International trade, national treatment, and domestic regulation. The Journal of Legal Studies, 40(1):149-203, 2011. 


\section{Appendix A}

\section{Proof of Lemmas in Chapter 2}

\section{A.1 Welfare Derivations and Analysis}

Using equations (2.9), (2.10), and (2.11) we are able to derive the welfare function from equation (2.12) as a function of border and behind-the-border policies $\left(\tau_{i}, \tau_{j}, \sigma_{i}, \sigma_{j}\right)$ as follow:

$$
\begin{aligned}
W_{i}\left(\sigma_{i}, p_{i}\left(\sigma_{i}, \sigma_{j} \tau_{i}, \tau_{j}\right)\right) & =\int_{p_{i}^{i}}^{\phi} D\left(p_{i}^{i}\right)+\int_{c}^{p_{i}} x\left(p_{i}\right)-\sigma_{i} D\left(p_{i}^{i}\right) \\
W_{j}\left(\sigma_{j}, p_{j}\left(\sigma_{i}, \sigma_{j}, \tau_{i}, \tau_{j}\right)\right) & =\int_{p_{j}^{j}}^{\phi} D\left(p_{j}^{j}\right)+\int_{c}^{p_{j}} x\left(p_{j}\right)-\sigma_{j} D\left(p_{j}^{j}\right) \\
W_{h}\left(\tau_{i}, \tau_{j}, p_{X}\left(\sigma_{i}, \sigma_{j}, \tau_{i}, \tau_{j}\right)\right) & =\int_{p_{X}}^{\alpha} D\left(p_{X}\right)+\tau_{i} D\left(p_{X}\right)+\tau_{j} D\left(p_{X}\right)
\end{aligned}
$$


where

$$
\begin{aligned}
C S_{i}\left(\tau_{i}, \tau_{j}, \sigma_{i}, \sigma_{j}\right) & =\int_{p_{i}^{i}}^{\phi} D\left(p_{i}^{i}\right)=\frac{1}{2}\left(\frac{36 \theta+14 \sigma_{i}+3 \sigma_{j}+6 \tau_{i}+6 \tau_{j}}{24}\right)^{2} \\
C S_{X}\left(\tau_{i}, \tau_{j}, \sigma_{i}, \sigma_{j}\right) & =\int_{p_{X}}^{\alpha} D\left(p_{X}\right)=\frac{1}{2}\left(\frac{12 \theta-6 \sigma_{i}-6 \sigma_{j}-12 \tau_{i}-12 \tau_{j}}{24}\right)^{2} \\
P S_{i}\left(\tau_{i}, \tau_{j}, \sigma_{i}, \sigma_{j}\right) & =\int_{c}^{p_{i}} x\left(p_{i}\right)=\frac{1}{2}\left(\frac{6 \theta+3 \sigma_{i}-\sigma_{j}-2 \tau_{i}-2 \tau_{j}}{8}\right)^{2} \\
\operatorname{Tr}_{i}\left(\tau_{i}, \tau_{j}, \sigma_{i}, \sigma_{j}\right) & =\tau_{i} D\left(p_{X}\right)=\frac{\tau_{i}\left(12 \theta-6 \sigma_{i}-6 \sigma_{j}-12 \tau_{i}-12 \tau_{j}\right)}{24} \\
R_{h}\left(\tau_{i}, \tau_{j}, \sigma_{i}, \sigma_{j}\right) & =\sigma_{i} D\left(p_{i}^{i}\right)=\frac{\sigma_{i}\left(36 \theta+14 \sigma_{i}+3 \sigma_{j}+6 \tau_{i}+6 \tau_{j}\right)}{24}
\end{aligned}
$$

\section{A.2 Proof of lemma 2.6.1}

Using the above welfare function and the optimal non-cooperative Nash equilibrium, the welfare and the input production levels for each country can be shown in table A.2.

\begin{tabular}{|c|c|c|c|c|c|}
\hline Type & $x$ & $W^{h}$ & $W^{i}$ & $W^{j}$ & $W^{T}$ \\
\hline Feetrade $: \tau^{F T}=0, \sigma^{F T}=0$ & $0.75 \theta$ & $0.125 \theta^{2}$ & $0.312 \theta^{2}$ & $0.312 \theta^{2}$ & $0.749 \theta^{2}$ \\
\hline Nash $: \tau^{N}=5 \theta / 36, \sigma^{N}=\theta / 6$ & $13 \theta / 18$ & $0.115 \theta^{2}$ & $0.285 \theta^{2}$ & $0.285 \theta^{2}$ & $0.686 \theta^{2}$ \\
\hline
\end{tabular}

Table A.1: Summary of welfare and intermediate input levels under free trade and Nash equilibrium

It is straight forward from the results in the table to show:

$$
\begin{aligned}
W_{T}^{F T}>W_{T}^{N H}>W_{\nu}^{F T}>W_{\nu}^{N}>W_{h}^{F T}>W_{h}^{N} \\
x^{F T}>x^{N}
\end{aligned}
$$




\section{A.3 Proof of lemma 2.7.1}

Using the above welfare functions, to form $W_{W}=W_{h}+W_{i}+W_{j}$, and equation (2.18), it is straight forward to derive the optimal shallow border policies. Furthermore, the behindthe-border policies are either fixed at the original non-cooperative levels or optimally determined from equation (2.16). Then, it is easy to derive the welfare of each country under different shallow integration scenarios. The welfare and the input production levels for each country can be shown in table A.3.

\begin{tabular}{|c|c|c|c|c|c|}
\hline Type & $x^{s h}$ & $W^{h}$ & $W^{i}$ & $W^{j}$ & $W^{T}$ \\
\hline$\Gamma_{m}^{s h}(-\theta / 12, \theta / 6)$ & $5 \theta / 6$ & $0.041 \theta^{2}$ & $0.347 \theta^{2}$ & $0.347 \theta^{2}$ & $0.736 \theta^{2}$ \\
\hline$\Gamma_{m}^{F}(0, \theta / 6)$ & $19 \theta / 24$ & $0.086 \theta^{2}$ & $0.321 \theta^{2}$ & $0.321 \theta^{2}$ & $0.729 \theta^{2}$ \\
\hline$\Gamma_{s}^{F}(0,3 \theta / 13)$ & $21 \theta / 26$ & $0.073 \theta^{2}$ & $0.318 \theta^{2}$ & $0.318 \theta^{2}$ & $0.710 \theta^{2}$ \\
\hline$\Gamma_{s}^{s h}(-3 \theta / 20,3 \theta / 10)$ & $9 \theta / 10$ & $-0.025 \theta^{2}$ & $0.365 \theta^{2}$ & $0.365 \theta^{2}$ & $0.705 \theta^{2}$ \\
\hline$\Gamma_{m}(\theta / 12, \theta / 6)$ & $3 \theta / 4$ & $0.111 \theta^{2}$ & $0.298 \theta^{2}$ & $0.298 \theta^{2}$ & $0.707 \theta^{2}$ \\
\hline$\Gamma_{s}(\theta / 12,5 \theta / 26)$ & $59 \theta / 78$ & $0.104 \theta^{2}$ & $0.297 \theta^{2}$ & $0.297 \theta^{2}$ & $0.698 \theta^{2}$ \\
\hline
\end{tabular}

Table A.2: Summary of welfare and intermediate input levels under shallow integration

It is straight forward to see the following ranking for the welfare and input production levels from the above table:

- $W_{T}\left(\Gamma_{m}^{s h}\right)>W_{T}\left(\Gamma_{m}^{F}\right)>W_{T}\left(\Gamma_{s}^{F}\right)>W_{T}\left(\Gamma_{m}\right)>W_{T}\left(\Gamma_{s}^{s h}\right)>W_{T}\left(\Gamma_{s}\right)>W_{T}(r)$

- $W_{h}\left(\Gamma_{m}\right)>W_{h}\left(\Gamma_{s}\right)>W_{h}\left(\Gamma_{m}^{F}\right)>W\left(\Gamma_{s}^{F}\right)>W_{h}\left(\Gamma_{m}^{s h}\right)>W_{h}\left(\Gamma_{s}^{s h}\right)<W_{h}(r)$

- $W_{i}\left(\Gamma_{s}^{s h}\right)>W_{i}\left(\Gamma_{m}^{s h}\right)>W_{i}\left(\Gamma_{m}^{F}\right)>W_{i}\left(\Gamma_{s}^{F}\right)>W_{i}\left(\Gamma_{m}\right)>W_{i}\left(\Gamma_{s}\right)>W_{i}(r)$

- $x\left(\Gamma_{s}^{s h}\right)>x\left(\Gamma_{m}^{s h}\right)>x\left(\Gamma_{s}^{F}\right)>x\left(\Gamma_{m}^{F}\right)>x\left(\Gamma_{s}\right)>x\left(\Gamma_{m}\right)>x(r)$ 
It is clear from A.2 and A.3 that $\Delta \omega_{T}^{s h}>0, \Delta x^{d}>0, \Delta x>0$ for all the shallow trade agreements.

\section{A.4 Proof of lemma 2.7.2}

Following equation 2.14, we are able to find the behind-the-border policies of the deviating country, $i$. Therefore, using the above welfare, and the optimal policies, we are able to summarize the results on the production and welfare in the following table:

\begin{tabular}{|c|c|c|c|c|c|}
\hline Type & $x_{i}^{d}$ & $x_{j}$ & $W_{h}$ & $W_{i}^{d}$ & $W_{j}$ \\
\hline$\Gamma_{m^{d}}^{s h}(-\theta / 12,13 \theta / 46, \theta / 6)$ & $121 \theta / 138$ & $113 \theta / 138$ & $0.0324 \theta^{2}$ & $0.352 \theta^{2}$ & $0.337 \theta^{2}$ \\
\hline$\Gamma_{m^{d}}^{F}(0,11 \theta / 46, \theta / 6)$ & $113 \theta / 138$ & $108 \theta / 138$ & $0.079 \theta^{2}$ & $0.227 \theta^{2}$ & $0.249 \theta^{2}$ \\
\hline$\Gamma_{s^{d}}^{F}(0,3 \theta / 13,3 \theta / 13)$ & $21 \theta / 26$ & $21 \theta / 26$ & $0.073 \theta^{2}$ & $0.318 \theta^{2}$ & $0.318 \theta^{2}$ \\
\hline$\Gamma_{s^{d}}^{s h}(-3 \theta / 20,3 \theta / 10,3 \theta / 10)$ & $9 \theta / 10$ & $9 \theta / 10$ & $-0.025 \theta^{2}$ & $0.365 \theta^{2}$ & $0.365 \theta^{2}$ \\
\hline$\Gamma_{m^{d}}(\theta / 12,9 \theta / 46, \theta / 6)$ & $105 \theta / 138$ & $103 \theta / 138$ & $0.107 \theta^{2}$ & $0.2989 \theta^{2}$ & $0.296 \theta^{2}$ \\
\hline$\Gamma_{s^{d}}(\theta / 12,5 \theta / 26,5 \theta / 26)$ & $59 \theta / 78$ & $59 \theta / 78$ & $0.104 \theta^{2}$ & $0.297 \theta^{2}$ & $0.297 \theta^{2}$ \\
\hline
\end{tabular}

Table A.3: Summary of the input production and welfare when country $i$ deviates

where $\Gamma_{m^{d}}^{s h}\left(\tau^{s h}, \sigma_{i}^{d}, \sigma_{j}\right), \Gamma_{m^{d}}^{F}\left(\tau^{F}, \sigma_{i}^{d}, \sigma_{j}\right), \Gamma_{m^{d}}\left(\bar{\tau}, \sigma_{i}^{d}, \sigma_{j}\right), \Gamma_{s^{d}}^{s h}\left(\tau^{s} h, \sigma_{i}^{d}, \sigma_{j}\right), \Gamma_{s^{d}}^{F}\left(\tau^{F}, \sigma_{i}^{d}, \sigma_{j}\right)$ and $\Gamma_{s^{d}}\left(\bar{\tau}, \sigma_{i}^{d}, \sigma_{j}\right)$ are the myopic and strategic policy vectors when country $i$ deviates. Let's define $\Delta W\left(\Gamma^{d}\right)=W_{i}\left(\Gamma^{d}\right)-W_{i}(\Gamma)$. It is straight forward from results presented in table A.3 and table A.4 to see that $\Delta W\left(\Gamma_{m^{d}}^{s h}\right)>0$ and $\Delta W\left(\Gamma_{m^{d}}\right)>0$. 


\section{A.5 Proof of lemma 2.7.3}

From equation 2.16 and the optimal shallow border policies, we are able to derive the welfare of each country when the countries $i$ and $j$ deviates from their myopic non cooperative policies.

\begin{tabular}{|c|c|c|c|c|c|}
\hline Type & $x^{d}$ & $x_{j}$ & $W_{h}$ & $W_{i}^{d}$ & $W_{j}$ \\
\hline$\Gamma_{m^{d}}^{s h}(-\theta / 12,7 \theta / 26)$ & $67 \theta / 78$ & $0.025 \theta^{2}$ & $0.342 \theta^{2}$ & $0.342 \theta^{2}$ & $0.709 \theta^{2}$ \\
\hline$\Gamma_{m^{d}}^{F}(0,3 \theta / 13)$ & $21 \theta / 26$ & $0.073 \theta^{2}$ & $0.318 \theta^{2}$ & $0.318 \theta^{2}$ & $0.710 \theta^{2}$ \\
\hline$\Gamma_{m^{d}}(\theta / 12,5 \theta / 26,5 \theta / 26)$ & $59 \theta / 78$ & $59 \theta / 78$ & $0.104 \theta^{2}$ & $0.297 \theta^{2}$ & $0.297 \theta^{2}$ \\
\hline
\end{tabular}

Table A.4: Summary of the input production and welfare when countries $i$ and $j$ deviate

It is clear from the above table that $\Delta W_{j(i)}\left(\Gamma_{m^{d}}^{s h}\right)<0, \Delta W_{j(i)}\left(\Gamma_{m^{d}}^{F}\right)<0$ and $W_{j(i)}\left(\Gamma_{m^{d}}\right)<0$. Therefore, there is no incentive for the joint deviation from any of the myopic shallow outcome.

\section{A.6 Proof of lemma 2.8.1}

Following equation (2.19) and the optimal shallow border policies, we are able to summarize the welfare of each country when the countries $i$ and $h$ sign a narrow deep bilateral agreement.

It is clear from the table A.6 and A.3 to see the narrow deep outcomes that improve the joint welfare of member countries as follow: 


\begin{tabular}{|c|c|c|c|c|c|c|}
\hline Type & $x_{i}$ & $x_{j}$ & $W_{h}$ & $W_{i}$ & $W_{j}$ & $W^{i h}$ \\
\hline$\Gamma_{m}^{N D}(0,11 \theta / 24, \theta / 6)$ & $96 \theta / 126$ & $101 \theta / 126$ & $0.095 \theta^{2}$ & $0.314 \theta^{2}$ & $0.327 \theta^{2}$ & $0.409 \theta^{2}$ \\
\hline$\Gamma_{s}^{N D}(0, \theta / 12,3 \theta / 12)$ & $9 \theta / 12$ & $10 \theta / 12$ & $0.086 \theta^{2}$ & $0.309 \theta^{2}$ & $0.329 \theta^{2}$ & $0.395 \theta^{2}$ \\
\hline$\Gamma_{s}^{F}(0,0,6 \theta / 23)$ & $33 \theta / 46$ & $39 \theta / 46$ & $0.094 \theta^{2}$ & $0.297 \theta^{2}$ & $0.336 \theta^{2}$ & $0.391 \theta^{2}$ \\
\hline$\Gamma_{m}^{F}(0,0, \theta / 6)$ & $35 \theta / 48$ & $39 \theta / 48$ & $0.105 \theta^{2}$ & $0.302 \theta^{2}$ & $0.333 \theta^{2}$ & $0.407 \theta^{2}$ \\
\hline$\Gamma_{m}^{N D}(-3 \theta / 20,47 \theta / 20,3 \theta / 10)$ & $183 \theta / 210$ & $191 \theta / 210$ & $-0.021 \theta^{2}$ & $0.362 \theta^{2}$ & $0.372 \theta^{2}$ & $0.341 \theta^{2}$ \\
\hline$\Gamma_{s}^{N D}(-3 \theta / 20,53 \theta / 240,87 \theta / 240)$ & $224 / 240$ & $207 \theta / 240$ & $-0.024 \theta^{2}$ & $0.357 \theta^{2}$ & $0.397 \theta^{2}$ & $0.333 \theta^{2}$ \\
\hline$\Gamma_{m}^{F}(-3 \theta / 20,0,3 \theta / 10)$ & $63 \theta / 80$ & $75 \theta / 80$ & $-0.007 \theta^{2}$ & $0.332 \theta^{2}$ & $0.396 \theta^{2}$ & $0.325 \theta^{2}$ \\
\hline$\Gamma_{s}^{F}(-3 \theta / 20,0,39 \theta / 115)$ & $180 / 230$ & $219 \theta / 230$ & $-0.0098 \theta^{2}$ & $0.329 \theta^{2}$ & $0.396 \theta^{2}$ & $0.320 \theta^{2}$ \\
\hline$\Gamma_{m}^{N D}(\theta / 12,11 \theta / 1638,5 \theta / 26)$ & $125 \theta / 182$ & $1277 \theta / 1638$ & $-0.003 \theta^{2}$ & $0.294 \theta^{2}$ & $-0.483 \theta^{2}$ & $0.291 \theta^{2}$ \\
\hline$\Gamma_{s}^{N D}(\theta / 12, \theta / 180,39 \theta / 180)$ & $246 \theta / 360$ & $284 \theta / 360$ & $0.125 \theta^{2}$ & $0.283 \theta^{2}$ & $0.309 \theta^{2}$ & $0.409 \theta^{2}$ \\
\hline$\Gamma_{m}^{F}(\theta / 12,0,5 \theta / 26)$ & $427 \theta / 624$ & $87 \theta / 624$ & $0.129 \theta^{2}$ & $0.283 \theta^{2}$ & $0.310 \theta^{2}$ & 0.413 \\
\hline$\Gamma_{s}^{F}(\theta / 12,0,5 \theta / 23)$ & $94 \theta / 138$ & $109 \theta / 138$ & $0.126 \theta^{2}$ & $0.282^{2}$ & $0.310 \theta^{2}$ & $0.408 \theta^{2}$ \\
\hline$\Gamma_{m}^{D i s}(0,0,-3 \theta / 20,3 \theta / 10)$ & $63 \theta / 80$ & $75 \theta / 80$ & $0.079 \theta^{2}$ & $0.332 \theta^{2}$ & $0.396 \theta^{2}$ & $0.411 \theta^{2}$ \\
\hline$\Gamma_{s}^{D i s}(0,0,-3 \theta / 20,27 \theta / 92)$ & $1347 \theta / 1840$ & $1617 \theta / 1840$ & $0.046 \theta^{2}$ & $0.297 \theta^{2}$ & $0.403 \theta^{2}$ & $0.340 \theta^{2}$ \\
\hline$\Gamma_{m}^{D i s}(0,0, \theta / 12,5 \theta / 26)$ & $55 \theta / 78$ & $125 \theta / 156$ & $0.049 \theta^{2}$ & $0.292 \theta^{2}$ & $0.326 \theta^{2}$ & $0.342 \theta^{2}$ \\
\hline$\Gamma_{s}^{D i s}(0,0, \theta / 12,67 \theta / 276)$ & $261 \theta / 368$ & $179 \theta / 276$ & $0.031 \theta^{2}$ & $0.318 \theta^{2}$ & -0.073 & $0.340 \theta^{2}$ \\
\hline
\end{tabular}

Table A.5: Summary of the input production and welfare levels under Narrow deep agreements

$$
\begin{aligned}
W\left(\Gamma_{m}^{N D}(0,11 \theta / 126, \theta / 6)\right) & >W\left(\Gamma_{m}^{s h}(0, \theta / 6)\right) \\
W\left(\Gamma_{s}^{F}(0,0, \theta / 6)\right) & >W\left(\Gamma_{m}^{s h}(0, \theta / 6)\right) \\
W\left(\Gamma_{m}^{N D}(-3 \theta / 20,47 / 210,3 \theta / 10)\right. & >W\left(\Gamma_{m}^{s h}(-3 \theta / 20,3 \theta / 10)\right) \\
W\left(\Gamma_{s}^{N D}(\theta / 12, \theta / 180,39 \theta / 180)\right) & >W\left(\Gamma_{s}^{s h}(\theta / 12,5 \theta / 26)\right) \\
W\left(\Gamma_{m}^{F}(\theta / 12,0,5 \theta / 26)\right) & >W\left(\Gamma_{s}^{s h}(\theta / 12,5 \theta / 26)\right) \\
W\left(\Gamma_{s}^{F}(\theta / 12, o, 5 \theta / 23)\right) & >W\left(\Gamma_{s}^{s h}(\theta / 12,5 \theta / 26)\right) \\
W\left(\Gamma_{\bar{m}}^{D i s}(0,0,-3 \theta / 20,3 \theta / 10)\right) & >W\left(\Gamma_{m}^{s h}(-3 \theta / 20,3 \theta / 10)\right)
\end{aligned}
$$

\section{A.7 Proof of lemma 2.8.2}

From the results in table $A .6$, it is straight forward to the following results:

Starting from the first narrow deep outcome $\left(\tau=0, \sigma_{i}=\sigma_{i}^{N D}, \sigma_{j}=\sigma^{\bar{s} h}\right)$, the non mem- 
ber country earn a higher welfare by deviating from the fixed shallow level behind the border policies, i.e. response optimally to the other policies: $W_{j}^{d}\left(\tau=0, \sigma_{i}=\sigma_{i}^{N D}, \sigma_{j}^{d}=\right.$ $\left.\sigma^{R}\left(\tau, \sigma_{i}\right)\right)>W_{j}\left(\tau=0, \sigma_{i}=\sigma_{i}^{N D}, \sigma_{j}=\bar{\sigma}^{s h}\right)$. However, this deviation lead to a lower joint welfare for the member countries. Therefore, the myopic outcome is not equilibrium. Similarly, starting from narrow deep agreement $\left(\tau=\bar{\tau}^{s h}, \sigma_{i}=\sigma_{i}^{N D}, \sigma_{j}=\bar{\sigma}^{s h}\right)$, the non member country $j$ has incentive to deviate form the fixed shallow level behind-the-border policy and respond optimally to the border and member countries' behind the border policy, $W_{j}^{d}\left(\tau=\bar{\tau}^{s h}, \sigma_{i}=\sigma_{i}^{N D}, \sigma_{j}^{d}=\sigma^{R}\left(\tau, \sigma_{i}\right)\right)>W_{j}\left(\tau=\bar{\tau}^{s h}, \sigma_{i}, \sigma_{j}\right)$. However, the joint welfare of the member country will decrease and the member countries wont choose this agreement,i.e the myopic outcome is not equilibrium. Finally, similar to the previous cases, under the discriminatory myopic outcome, the non member country earn higher welfare by deviating from the fixed shallow level behind-the-border policies. Therefore, non of the myopic outcomes are equilibrium.

\section{A.8 Proof of proposition 2.8.1}

The proof of this proposition is immediate from the results on lemma 2.8.1. 


\section{Appendix B}

\section{Proof of Lemmas in Chapter 3}

\section{B.1 Proof of lemma 3.4.1}

Using the above welfare function and the optimal non-cooperative Nash equilibrium, the welfare and the input production levels for each country can be shown in table A.2. It is

\begin{tabular}{|c|c|c|c|c|c|}
\hline Type & $x$ & $W^{h}$ & $W^{i}$ & $W^{j}$ & $W^{T}$ \\
\hline Freetrade $: \tau^{F T}=0, \sigma^{F T}=0$ & $0.75 \theta$ & $0.125 \theta^{2}$ & $0.312 \theta^{2}$ & $0.312 \theta^{2}$ & $0.749 \theta^{2}$ \\
\hline Nash $: \tau^{N}=\theta / 6, \sigma^{N}=\theta / 3$ & $0.75 \theta$ & $0.060 \theta^{2}$ & $0.256 \theta^{2}$ & $0.256 \theta^{2}$ & $0.583 \theta^{2}$ \\
\hline
\end{tabular}

Table B.1: Summary of welfare and intermediate input levels under free trade and Nash equilibrium

straight forward form the results in the table to show:

$$
\begin{gathered}
W_{T}^{F T}>W_{T}^{N}>W_{\nu}^{F T}>W_{\nu}^{N}>W_{h}^{F T}>W_{h}^{N} \\
x^{F T}=x^{N}
\end{gathered}
$$




\section{B.2 Proof of lemma 3.5.1}

Using the above welfare functions, to form $W_{W}=W_{h}+W_{i}+W_{j}$, and equation (3.6), it is straight forward to derive the optimal shallow border policies. Furthermore, the behind-the-border policies are either fixed at the original non cooperative levels or optimally determined from equation (3.4). Then, it is easy to derive the welfare of each country under different shallow integration scenarios. The welfare and the input production levels for each country is summarized in table (B.2).

\begin{tabular}{|c|c|c|c|c|c|}
\hline Type & $x$ & $W^{h}$ & $W^{i}$ & $W^{j}$ & $W^{T}$ \\
\hline$\Gamma_{s}^{s h}(-\sigma, \sigma)$ & $\infty$ & $\infty$ & $\infty$ & $\infty$ & $\infty$ \\
\hline$\Gamma_{m}^{s h}(-\theta / 3, \theta / 3)$ & $\theta$ & $-0.222 \theta^{2}$ & $0.444 \theta^{2}$ & $0.444 \theta^{2}$ & $0.666 \theta^{2}$ \\
\hline$\Gamma_{s}^{F}(0, \theta / 2)$ & $7 \theta / 8$ & $0.031 \theta^{2}$ & $0.265 \theta^{2}$ & $0.265 \theta^{2}$ & $0.561 \theta^{2}$ \\
\hline$\Gamma_{m}^{F}(0, \theta / 3)$ & $5 \theta / 6$ & $0.055 \theta^{2}$ & $0.305 \theta^{2}$ & $0.305 \theta^{2}$ & $0.666 \theta^{2}$ \\
\hline$\Gamma_{m}(\theta / 12, \theta / 3)$ & $19 \theta / 24$ & $0.072 \theta^{2}$ & $0.279 \theta^{2}$ & $0.279 \theta^{2}$ & $0.631 \theta^{2}$ \\
\hline$\Gamma_{s}(\theta / 12,5 \theta / 12)$ & $13 \theta 16$ & $0.052 \theta^{2}$ & $0.260 \theta^{2}$ & $0.260 \theta^{2}$ & $0.572 \theta^{2}$ \\
\hline
\end{tabular}

Table B.2: Summary of welfare and input levels under shallow integration

It is straight forward to see the following ranking for the welfare and input production levels from the above table:

- $W_{T}\left(\Gamma_{m}^{s h}\right)=W_{T}\left(\Gamma_{m}^{F}\right)>W_{T}\left(\Gamma_{m}\right)>W(r)>W_{T}\left(\Gamma_{s}\right)>W_{T}\left(\Gamma_{s}^{F}\right)>W_{T}\left(\Gamma_{s}^{s h}\right)$

- $W_{h}\left(\Gamma_{m}\right)>W_{h}(r)>W_{h}\left(\Gamma_{m}^{F}\right)>W_{h}\left(\Gamma_{s}\right)>W_{h}\left(\Gamma_{s}^{F}\right)>W_{h}\left(\Gamma_{m}^{s h}\right)>W_{h}\left(\Gamma_{s}^{s h}\right)$

- $W_{i}\left(\Gamma_{m} s h\right)>W_{i}\left(\Gamma_{m}^{F}\right)>W_{i}\left(\Gamma_{m}\right)>W_{i}(r)=W_{i}\left(\Gamma_{s}^{F}\right)>W_{i}\left(\Gamma_{s}\right)$ 
- $x\left(\Gamma_{m}^{s h}\right)>x\left(\Gamma_{m}^{F}\right)>x\left(\Gamma_{s}\right)>x\left(\Gamma_{m}\right)$

It is clear from table (B.1) and (B.2) that $\Delta \omega_{T}^{s h}>0$ only for the myopic shallow policies. When the border policies are negotiated optimally, the strategic outcome is not possible and the behind-the-border policy cannot fully re-optimized. Therefore, $\sigma \rightarrow \infty, \tau \rightarrow \infty$ and $x \rightarrow \infty$.

\section{B.3 Proof of lemma 3.5.2}

Following equation (3.2), we are able to find the behind-the-border policies of deviating country, $i$. Therefore, using above welfare, and the optimal policies, we are able to summarize the results on the production and welfare as follow:

\begin{tabular}{|c|c|c|c|c|c|c|}
\hline Type & $x_{i}^{s h}$ & $x_{j}^{s h}$ & $W^{h}$ & $\left(W^{i}\right)^{d}$ & $W^{j}$ & $\left(W^{i}\right)^{s h}$ \\
\hline$\Gamma_{m^{d}}^{s h}(-\theta / 3, \theta, \theta / 3)$ & $15 \theta / 12$ & $15 \theta / 12$ & $-0.208 \theta^{2}$ & $0.312 \theta^{2}$ & $0.368 \theta^{2}$ & $0.444 \theta^{2}$ \\
\hline$\Gamma_{m}^{F}(0,5 \theta / 9, \theta / 3)$ & $33 \theta / 36$ & $29 \theta / 36$ & $0.038 \theta^{2}$ & $0.269 \theta^{2}$ & $0.287 \theta^{2}$ & $0.305 \theta^{2}$ \\
\hline$\Gamma_{m}(\theta / 12,4 \theta / 9, \theta / 3)$ & $5 \theta / 6$ & $7 \theta / 9$ & $0.061 \theta^{2}$ & $-0.06 \theta^{2}$ & $0.009 \theta^{2}$ & $0.279 \theta^{2}$ \\
\hline
\end{tabular}

Table B.3: Summary of welfare and input levels when country i deviates

where $\Gamma_{m^{d}}^{s h}\left(\tau^{s h}, \sigma_{i}^{d}, \sigma_{j}\right), \Gamma_{m^{d}}^{F}\left(\tau^{F}, \sigma_{i}^{d}, \sigma_{j}\right)$ and $\Gamma_{m^{d}}\left(\bar{\tau}, \sigma_{i}^{d}, \sigma_{j}\right)$ are the myopic policy vectors when country $i$ deviates. Let's define $\Delta W\left(\Gamma^{d}\right)=W_{i}\left(\Gamma^{d}\right)-W_{i}(\Gamma)$. It is straight forward from results on tables B.2 and B.3 to find $\Delta W\left(\Gamma^{d}\right)<0$.

Using equation (3.4) and the above welfare, we are able to determine the input production and welfare levels when countries $i$ and $j$ jointly deviate from their non cooperative 
Nash levels.

\begin{tabular}{|c|c|c|c|c|c|}
\hline Type & $x^{d}$ & $W^{h}$ & $W^{i}$ & $W^{j}$ & $W^{T}$ \\
\hline$\tau^{s h}=-\theta / 3, \sigma^{s h}=5 \theta / 6$ & $9 \theta / 8$ & $-0.190 \theta^{2}$ & $0.293 \theta^{2}$ & $0.293 \theta^{2}$ & $0.396 \theta^{2}$ \\
\hline
\end{tabular}

Table B.4: Joint deviation

It is straight forward to see from the results in tables B.3 and B.3 that once a unilateral deviation of country $i(j)$ from shallow outcome lead to a lower welfare level for the deviating country:

$$
\begin{aligned}
W_{j}\left(\Gamma_{m}^{s h}(-3 \theta / 3, \theta / 3, \theta)\right. & <W_{j}\left(\Gamma_{m}^{s h}(-3 \theta / 3,3 \theta / 3)\right) \\
W_{j}\left(\Gamma_{m}^{F}(0, \theta / 3,5 \theta / 9)\right. & <W_{j}\left(\Gamma_{m}^{s h}(-3 \theta / 3,3 \theta / 3)\right) \\
W_{j}\left(\Gamma_{\bar{m}}(\theta / 12, \theta / 3,5 \theta / 12)\right) & <W_{j}\left(\Gamma_{m}^{s h}(\theta / 12,3 \theta / 3)\right) \\
W_{j(i)}\left(\Gamma_{m}^{s h}(-3 \theta / 3,5 \theta / 6)\right. & <W_{j}\left(\Gamma_{m}^{s h}(-3 \theta / 3,3 \theta / 3)\right)
\end{aligned}
$$

\section{B.4 Proof of proposition 3.5.1}

The proof is immediate from the results on lemma 3.4.1, 3.5.1 and 3.5.2

\section{B.5 Proof of lemma 3.6.1}

From the above table it is straight forward to derive the following results:

A narrow deep outcome is possible if

$$
W_{i h}^{s h}(\tau, \sigma)>W_{i h}^{N D}(\tau, \sigma)
$$




\begin{tabular}{|c|c|c|c|c|c|c|}
\hline Type & $x_{i}^{N D}$ & $x_{j}^{N D}$ & $W^{h}$ & $W^{i}$ & $W^{j}$ & $W_{i h}$ \\
\hline$\Gamma_{m}^{N D}(-\theta / 3,17 \theta / 15, \theta / 3)$ & $13 \theta / 10$ & $9 \theta / 10$ & $-0.202 \theta^{2}$ & $0.248 \theta^{2}$ & $0.354 \theta^{2}$ & $0.045 \theta^{2}$ \\
\hline$\Gamma_{s}^{N D}(-\theta / 3,22 \theta / 21,16 \theta / 21)$ & $17 \theta / 14$ & $15 \theta / 14$ & $-0.181 \theta^{2}$ & $0.211 \theta^{2}$ & $0.286 \theta^{2}$ & $0.03 \theta^{2}$ \\
\hline$\Gamma_{s^{\prime}}^{N D}(3 / 17 \theta,-2 \theta / 17,3 \theta / 17)$ & $19 \theta / 34$ & $29 \theta / 34$ & $0.110 \theta^{2}$ & $0.246 \theta^{2}$ & $0.260 \theta^{2}$ & $0.357 \theta^{2}$ \\
\hline$\Gamma_{m}^{F}(-\theta / 3,0, \theta / 3)$ & $7 \theta / 8$ & $25 \theta / 24$ & $-0.218 \theta^{2}$ & $0.39 \theta^{2}$ & $0.49 \theta^{2}$ & $0.171 \theta^{2}$ \\
\hline$\Gamma_{s}^{F}(-\theta / 3,0,10 \theta / 9)$ & $7 \theta / 9$ & $4 \theta / 3$ & $-0.216 \theta^{2}$ & $0.327 \theta^{2}$ & $0.327 \theta^{2}$ & $0.111 \theta^{2}$ \\
\hline$\Gamma_{s \tau, \sigma}^{N D}(\theta / 5,0,2 \theta / 5)$ & $3 \theta / 5$ & $4 \theta / 5$ & $0.100 \theta^{2}$ & $0.260 \theta^{2}$ & $0.260 \theta^{2}$ & $0.360 \theta^{2}$ \\
\hline$\Gamma_{s}^{N D}(5 \theta / 33,-\theta / 33, \theta / 3)$ & $41 \theta / 66$ & $53 \theta / 66$ & $0.119 \theta^{2}$ & $0.264 \theta^{2}$ & $0.290 \theta^{2}$ & $0.384 \theta^{2}$ \\
\hline$\Gamma_{m}^{N D}(0, t h e t a / 3$, theta/3) & $5 \theta / 6$ & $5 \theta / 6$ & $0.055 \theta^{2}$ & $0.305 \theta^{2}$ & $0.305 \theta^{2}$ & $0.360 \theta^{2}$ \\
\hline$\Gamma_{s}^{N D}(0,2 \theta / 7,4 \theta / 7)$ & $11 \theta / 14$ & $13 \theta / 14$ & $0.040 \theta^{2}$ & $0.290 \theta^{2}$ & $0.270 \theta^{2}$ & $0.331 \theta^{2}$ \\
\hline$\Gamma_{m}^{F}(0,0, \theta / 3)$ & $17 \theta / 24$ & $7 \theta / 8$ & $0.086 \theta^{2}$ & $0.293 \theta^{2}$ & $0.340 \theta^{2}$ & $0.380 \theta^{2}$ \\
\hline$\Gamma_{s}^{F}(0,0,2 \theta / 3)$ & $2 \theta / 3$ & $\theta$ & $0.055 \theta^{2}$ & $0.278 \theta^{2}$ & $0.280 \theta^{2}$ & $0.333 \theta^{2}$ \\
\hline$\Gamma_{m}(\theta / 12,2 \theta / 15, \theta / 3)$ & $43 \theta / 40$ & $49 \theta / 60$ & $0.095 \theta^{2}$ & $0.288 \theta^{2}$ & $0.290 \theta^{2}$ & $0.383 \theta^{2}$ \\
\hline$\Gamma_{s}(\theta / 12,2 \theta / 21,11 \theta / 21)$ & $19 \theta / 28$ & $25 \theta / 28$ & $0.078 \theta^{2}$ & $0.277 \theta^{2}$ & $0.267 \theta^{2}$ & $0.355 \theta^{2}$ \\
\hline$\Gamma_{m}(\theta / 12,0, \theta / 3)$ & $2 \theta / 3$ & $5 \theta / 6$ & $0.111 \theta^{2}$ & $0.277 \theta^{2}$ & $0.306 \theta^{2}$ & $0.388 \theta^{2}$ \\
\hline$\Gamma_{s}(\theta / 12,0,5 \theta / 9)$ & $23 \theta / 36$ & $11 \theta / 12$ & $0.084 \theta^{2}$ & $0.269 \theta^{2}$ & $0.269 \theta^{2}$ & $0.254 \theta^{2}$ \\
\hline$\Gamma_{m}^{D i s}(0,0,-\theta / 3$, theta/3) & $19 \theta / 24$ & $23 \theta / 24$ & $-0.243 \theta^{2}$ & $0.335 \theta^{2}$ & $0.405 \theta^{2}$ & $0.310 \theta^{2}$ \\
\hline$\Gamma_{s}^{D i s}(0,0,-\theta / 3,8 \theta / 9)$ & $13 \theta / 18$ & $7 \theta / 6$ & $-0.049 \theta^{2}$ & $0.299 \theta^{2}$ & $0.299 \theta^{2}$ & $0.250 \theta^{2}$ \\
\hline$\Gamma_{s i s}^{D i s}(0,0, \theta / 4$, theta/2) & $5 \theta / 8$ & $7 \theta / 8$ & $0.093 \theta^{2}$ & $0.265 \theta^{2}$ & $0.266 \theta^{2}$ & $0.359 \theta^{2}$ \\
\hline$\Gamma_{m}^{D i s}(0,0, \theta / 12, \theta / 3)$ & $11 \theta / 16$ & $41 \theta / 48$ & $0.101 \theta^{2}$ & $0.285 \theta^{2}$ & $0.32 \theta^{2}$ & $0.386 \theta^{2}$ \\
\hline$\Gamma_{s}^{D i s}(0,0, \theta / 12,11 \theta / 18)$ & $74 \theta / 72$ & $23 \theta / 24$ & $0.072 \theta^{2}$ & $0.273 \theta^{2}$ & $0.273 \theta^{2}$ & $0.345 \theta^{2}$ \\
\hline
\end{tabular}

Table B.5: Summary of welfare and input levels under narrow deep integration

Starting from a shallow integration with policy set $(\tau, \sigma)=(-\theta / 3, \theta / 3)$ a narrow deep outcome is possible if the non member country set its behind-the-border policy fixed at the non cooperative Nash and country $i$ re optimize it's shallow border policies accordingly, $\left(\tau, \sigma_{i}, \sigma_{j}\right)=(5 \theta / 33,-\theta / 33, \theta / 3)$. In addition, if we allow discrimination, a narrow deep outcome with $\left(\tau_{i}, \sigma_{i}, \tau_{j}, \sigma_{j}\right)=(0,0,-\theta / 3, \theta / 3)$ is possible. Following the results in table B.5, these two outcomes are equilibrium and there is no incentive for countries to deviate from these two outcomes. Similarly, starting from shallow integration with policy set $(\tau, \sigma)=(0, \theta / 3)$ a following narrow deep outcome is equilibrium: $\left(\tau, \sigma_{i}, \sigma_{j}\right)=(0,0, \theta / 3)$. Finally, starting from the shallow integration with policy set $(\tau, \sigma)=(\theta / 12, \theta / 3)$ the fol- 
lowing outcomes are equilibrium:

$$
\begin{aligned}
\left(\tau, \sigma_{i}, \sigma_{j}\right) & =(\theta / 12,2 \theta / 15, \theta / 3) \\
\left(\tau, \sigma_{,} \sigma_{j}\right) & =(\theta / 12,0, \theta / 3) \\
\left(\tau_{i}, \sigma_{i}, \tau_{j}, \sigma_{j}\right) & =(0,0, \theta / 12, \theta / 3)
\end{aligned}
$$

It is worthwhile to note that, in all the outcomes that we let the optimal response for both the border policy and the non member behind the border policy, the level of the border policy turns to be higher than non cooperative Nash, which made the narrow deep outcome unattainable. Also, we consider a narrow deep discriminatory outcome with non zero border policies. However, the best response function for the negotiated border and behind the border policies among member countries are linearly dependent. To obtain a result, we consider the following approaches: first, we consider $\sigma_{i}=0$ and find $\tau_{i}=\tau^{R}\left(\tau_{j}, \sigma_{i}, \sigma_{j}\right)$; second, we consider $\left(\tau_{i}=0\right)$ and find $\sigma_{i}=\sigma^{R}\left(\tau_{i}, \tau_{j}, \sigma_{i}, \sigma_{j}\right)$. The first approach leads to a border policy greater than the non cooperative Nash, and consequently, the outcome is not available.

\section{B.6 Proof of proposition 3.6.1}

Following the results in table B.5, it is straight forward to see that there is no incentive for deviation of the non member countries when they choose theirs behind the border policies at Nash levels. Therefore, the narrow deep outcome under such a setting is equilibrium. 


\section{B.7 Proof of proposition 3.6.2}

Following the results in table B.1, it straight forward to show that deviation of country $i(j)$ from the-behind-the border policy, or country $h$ from the border policy lead to the non-cooperative Nash levels with lower welfare. Therefore, there is no credible deviation from the deep multilateral outcome. Also, by comparing the result from table B.1 with the one from B.5, we conclude that there is no incentive for countries $i$ and $h$ to deviate from the deep multilateral trade agreements to form narrow deep bilateral trade agreement. 


\section{Appendix C}

\section{Proof of Lemmas in Chapter 4}

\section{C.1 Proof of proposition 4.3.1}

Final-good producers choose outsourcing over FDI when $\pi_{H}^{O}>\pi_{F D I}^{H} \Rightarrow \alpha(1-\alpha)-\frac{\beta}{2 \lambda}-$ $2\left(F_{O}-\beta F_{F D I}\right)>0, \forall \alpha \in(0,1)$.

With $\frac{\beta}{2 \lambda}+2\left(F_{O}-\beta F_{F D I}\right)<0$ the sign of the above equation is always positive and with $\frac{\beta}{2 \lambda}+2\left(F_{O}-\beta F_{F D I}\right)>0$ be large enough the sign turns negative.

\section{C.2 Proof of proposition 4.3.1}

World welfare is higher under outsourcing if $\frac{1-\alpha^{2}}{4}-F_{O}>\frac{1}{4 \lambda}-F_{F D I}$. With $\alpha \in(0,1)$, and $\lambda>1$ and $F_{F D I}>F_{O}$ it can be shown that the above inequality always holds. Thus, the world welfare is always higher under outsourcing. 


\section{C.3 Proof of proposition 4.3.2}

The proof is immediate from the argument in the text.

\section{C.4 Proof of proposition 4.3.2}

Final-good producers earn higher profit if $\frac{\alpha(2-\alpha)}{4(1-\alpha)}-F_{O}>\frac{\alpha(1-\alpha)}{2}-F_{O}$. This equation holds for any bargaining power, $\alpha \in(0,1)$. That is, $\left(\pi_{O}^{H}\right)^{C E}>\left(\pi_{O}^{H}\right)^{F T} \Rightarrow \frac{2-\alpha}{2(1-\alpha)^{2}}>1$.

\section{C.5 Proof of proposition 4.3.5}

$W_{O}^{W}=C S^{H}+C S^{F}+\frac{1}{4}-F_{O}$ and $W_{F D I}^{W}=C S^{H}+C S^{F}+\frac{1}{4 \lambda}-F_{F D I}$. The consumer surplus in both countries is the same under the outsourcing and FDI ownership and with $\lambda>1$ and $F_{O}<F_{F D I}$; therefore, it is obvious that the world welfare is higher under outsourcing.

\section{C.6 Proof of proposition 4.4.1}

(i) Since $p_{1}=1+\tau_{1}^{H}$, thus $\tau_{1}^{H} \geq-1$. Under outsourcing is is easy to show that $\tau_{1}^{H}$ is less than -1 since $\alpha(1-\alpha)+\alpha(1-\alpha)^{2}-2<0$. Under FDI, however, $\tau_{1}^{H}$ is always higher than -1. Therefore, shallow free trade is only possible under FDI.

(ii) $\left(\pi_{F D I}^{H}\right)^{\text {shallow }}>\left(\pi_{F D I}^{H}\right)^{\text {deep }} \rightarrow \frac{\lambda-\beta}{2 \lambda-\beta}>\frac{1}{2}$ which does not hold. Thus, firms do not choose shallow free trade. 


\section{C.7 Proof of lemma 4.4.2}

The proof is immediate from the argument in the text.

\section{C.8 Proof of proposition 4.5.1}

The proof is immediate from the argument in the text. 